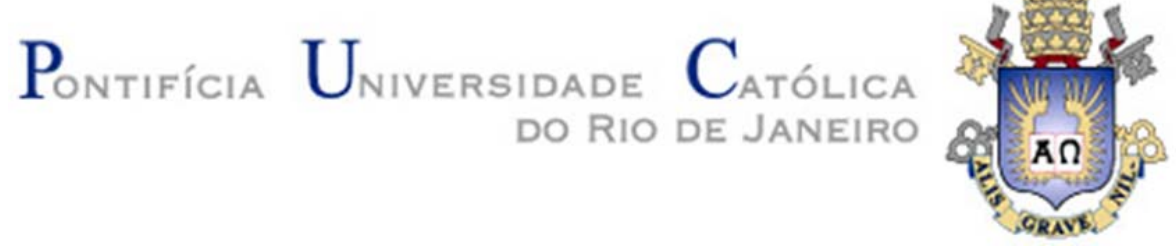

Tharcisio Alexandrino Caldeira

\title{
Prontidão e Aceitação de Tecnologias em Serviços: \\ Mobile Payments
}

Tese de Doutorado

Tese apresentada ao Programa de Pós-Graduação em Administração de Empresas da PUC-Rio como requisito parcial para obtenção do título de Doutor em Administração de Empresas.

Orientador: Prof. Jorge Brantes Ferreira

Rio de Janeiro

Julho de 2016 


\title{
Tharcisio Alexandrino Caldeira
}

\section{Prontidão e Aceitação de Tecnologias em Serviços: Mobile}

Payments

\begin{abstract}
Tese apresentada como requisito parcial para obtenção do grau de Doutor pelo Programa de Pós-graduação em Administração de Empresas da PUC-Rio. Aprovada pela Comissão Examinadora abaixo assinada.
\end{abstract}

Prof. Jorge Brantes Ferreira

Orientador

Departamento de Administração - PUC-Rio

Prof. Jorge Ferreira da Silva Departamento de Administração - PUC-Rio

Profa. Angela Maria Cavalcanti da Rocha Departamento de Administração - PUC-Rio

Prof. Angilberto Sabino de Freitas Universidade do Grande Rio

Prof. Fernando Bins Luce

UFRGS

Profa. Mônica Herz

Vice-Decana de Pós-Graduação do CCS

Rio de Janeiro, 5 de julho de 2016 
Todos os direitos reservados. É proibida a reprodução total ou parcial do trabalho sem autorização da universidade, do autor e do orientador.

\section{Tharcisio Alexandrino Caldeira}

Bacharel em Ciências Econômicas pela Universidade Federal de Viçosa (2007). Mestre em Economia Aplicada pela Universidade Federal de Viçosa (2009). Atualmente é Professor do Departamento Acadêmico de Ciências Gerenciais (DACG) do Instituto Federal de Educação, Ciência e Tecnologia do Sudeste de Minas Gerais campus Rio Pomba

Ficha Catalográfica

Caldeira, Tharcisio Alexandrino

Prontidão e aceitação de tecnologias em serviços : mobile payments / Tharcisio Alexandrino Caldeira ; orientador: Jorge Brantes Ferreira. - 2016.

145 f. : il. color. ; $30 \mathrm{~cm}$

Tese (doutorado)-Pontifícia Universidade Católica do Rio de Janeiro, Departamento de Administração, 2016.

Inclui bibliografia

1. Administração - Teses. 2. Prontidão e aceitação de tecnologias. 3. Serviços financeiros. 4. M-payments. I. Ferreira, Jorge Brantes. II. Pontifícia Universidade Católica do Rio de Janeiro. Departamento de Administração. III. Título. 
"No silêncio e na obscuridade da proscrição social, muitas vezes logramos a felicidade de conhecer-nos". - André Luiz

“As palavras só devem ser usadas quando não houver mais espaço para o silêncio". - Autoria desconhecida 


\section{Agradecimentos}

À Deus, por me conceder a oportunidade de aprender mais a cada dia;

Aos meus pais, por me darem as asas sem as quais não poderia alçar voos tão significativos nesta vida;

À minha esposa, parceira e melhor amiga, Andréia. Sem você, eu jamais chegaria tão longe. Você é a alegria, a calma e a sabedoria que servem de suporte a todo esforço meu. Me espelho em seus atos para tentar ser uma pessoa e um educador melhor. Este trabalho é tão seu quanto meu;

À PUC-Rio e ao IF Sudeste de Minas Gerais, pela parceria estabelecida que permitiu minha capacitação e pelo suporte oferecido durante a mesma;

Ao meu orientador, Prof. Jorge Brantes Ferreira, pelos preciosos ensinamentos, pela paciência e pela maneira simples de lidar com problemas complexos;

Ao professor Paulo Cesar de Mendonça Motta, por compartilhar um pouco de seu imenso conhecimento comigo e por me fazer compreender que nunca podemos deixar de servir com alma. Brinco com meus colegas que "quando eu crescer" quero ser um professor como ele;

À professora Alessandra de Sá Mello da Costa, que é o exemplo vivo de "servir com alma" mencionado anteriormente;

Aos demais professores do IAG. Vocês não têm ideia do impacto que exercem na vida pessoal e profissional de cada doutorando que passa pelo IAG;

Aos professores membros da banca examinadora (defesa de projeto e de tese), pelas contribuições colocadas de forma singela - sem diminuir o trabalho apresentado - e que engrandeceram significativamente o resultado final desta pesquisa;

Aos funcionários do IAG, por estarem sempre à disposição para ajudar no que for preciso. Vocês simplificam e muito a vida dos estudantes;

Aos demais parentes, colegas e amigos que me acompanharam nessa jornada, pela compreensão em função do "sumiço social" decorrente do doutoramento. 


\section{Resumo}

Caldeira, Tharcisio Alexandrino; Ferreira, Jorge Brantes. Prontidão e Aceitação de Tecnologias em Serviços: Mobile Payments. Rio de Janeiro, 2015. 145p. Tese de Doutorado - Departamento de Administração, Pontifícia Universidade Católica do Rio de Janeiro.

Esta pesquisa teve como objetivo investigar os principais fatores que influenciam a adoção e uso de tecnologias no setor de serviços, mais especificadamente no setor de serviços financeiros. O arcabouço teórico permitiu a definição de construtos cognitivos e afetivos para a elaboração do modelo conceitual. Além disso, este modelo incluiu construtos de elevada importância para o consumo de serviços financeiros, como Confiança e Risco Percebido. Por fim, o construto de Prontidão para a Tecnologia, desenvolvido por Parasuraman e Colby (2014) foi adicionado ao modelo, a fim de analisar a influência da predisposição individual em relação às tecnologias em geral, enquanto antecedente dos demais construtos. Os dados da pesquisa foram obtidos por meio de uma survey online, que foi respondida por 402 estudantes ou recém-formados de cursos de graduação e pós-graduação. O modelo final da pesquisa, denominado Modelo de Prontidão e Aceitação de Mobile Payments, indicou que a Prontidão para a Tecnologia exerce maior influência sobre os aspectos cognitivos do que sobre os afetivos, indicando que a prontidão auxilia significativamente o processo racional de avaliação da tecnologia. Além disso, os resultados indicaram que o construto de Utilidades e Vantagens Percebidas exerceu a maior influência sobre a Atitude, seguido pela Confiança e pela Apreciação da Qualidade Percebida, confirmando que os aspectos cognitivos são predominantes no processo de decisão quanto ao uso de serviços financeiros. Por fim, o Risco Percebido apresentou uma influência negativa, mas de pequena magnitude, sobre a Intenção de Uso. O Modelo de Prontidão e Aceitação de Mobile Payments foi capaz de explicar cerca de $76 \%$ da Atitude e $68 \%$ da Intenção em relação ao uso de tecnologias, mostrando-se um modelo com boa capacidade preditiva e de contribuição relevante para a literatura de aceitação de tecnologias.

\section{Palvavras-chave}

Prontidão e Aceitação de Tecnologias; Serviços Financeiros; M-payments. 


\section{Abstract}

Caldeira, Tharcisio Alexandrino; Ferreira, Jorge Brantes (Advisor). Readiness and Acceptance in Services: Mobile Payments. Rio de Janeiro, 2015. 145p. Doctoral Thesis - Departamento de Administração, Pontifícia Universidade Católica do Rio de Janeiro.

This research aimed to investigate what factors influence the adoption and use of technologies in services, more specifically in the financial services sector. The theoretical framework allowed the definition of cognitive and affective constructs for the preparation of the conceptual model. Furthermore, this model also includes constructs with high relevance for consumption of financial services, like Trust and Perceived Risk. Finally, the Technology Readiness construct, developed by Parasuraman and Colby (2014), was added to the model in order to analyze the influence of individual predisposition in relation to technology in general, as an antecedent of the other constructs. Data was collected via an online survey, which was answered by 402 students or recent graduated of graduate and post-graduate courses. The final model, named Model of Readiness and Acceptance of Mobile Payments, indicated that the Readiness Technology has stronger effects on cognitive aspects than on the affective aspects, indicating that readiness significantly assists the rational evaluation process about the use of technologies. Furthermore, the results indicated that the Perceived Usefulness and Advantage construct has the strongest effect over Attitude, followed by Trust and by Enjoyment of Perceived Quality, confirming that the cognitive aspects are predominant in decision-making regarding the use of financial services. Finally, Perceived Risk had a negative but very little effect over Intention. The Model of Readiness and Acceptance of Mobile Payments was able to explain about $76 \%$ of Attitude and $68 \%$ of Intention, showing itself a model with good predictive capability and presenting significant contribution to the literature of acceptance of technologies.

\section{Keywords}

Technology Readiness; Innovations’ Adoption; Mobile Payments. 


\section{Sumário}

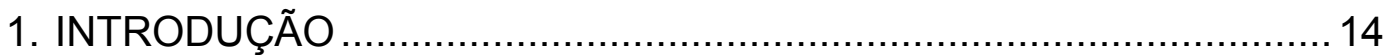

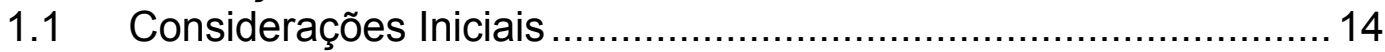

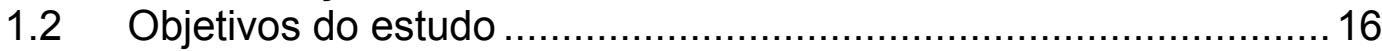

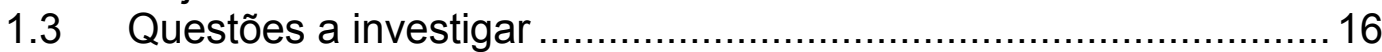

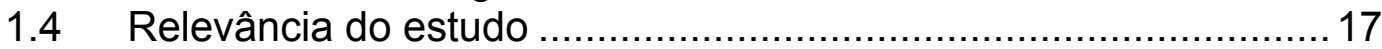

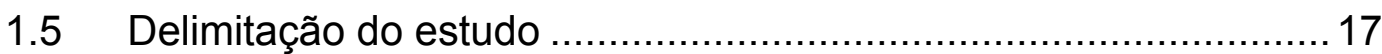

1.6 Organização do estudo......................................................... 18

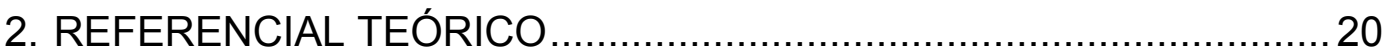

2.1 Teoria da Difusão de Inovações - IDT .......................................2 20

2.1.1 O processo de decisão quanto à inovação ...................................21

2.1.2 Atributos das inovações...................................................... 22

2.2 Principais modelos de prontidão e aceitação de tecnologias..........23

2.2.1 Teoria da Ação Racionalizada - TRA ........................................ 24

2.2.2 Teoria do Comportamento Planejado - TPB ….......................... 25

2.2.3 Modelo de Aceitação de Tecnologias - TAM..............................26

2.2.4 Teoria Unificada de Aceitação e Uso da Tecnologia - UTAUT .......28

2.2.5 Modelo de Aceitação de Tecnologias pelo Consumidor - CAT ......30

2.2.6 Prontidão para a Tecnologia - TRI ............................................. 32

2.2.7 Prontidão e Aceitação de Tecnologias pelo Consumidor - CART.. 34

2.3 Serviços e tecnologia ..................................................................... 35

2.3.1 Aceitação de tecnologias no setor de serviços .............................. 37

2.3.1.1. Confiança e aceitação de tecnologias no setor de serviços ........ 42

2.3.1.2. Risco e aceitação de tecnologias no setor de serviços ................ 45

2.3.1.3. A prontidão para a tecnologia no setor de serviços ...................... 46

2.3.1.4. A percepção de qualidade e a aceitação de tecnologias no

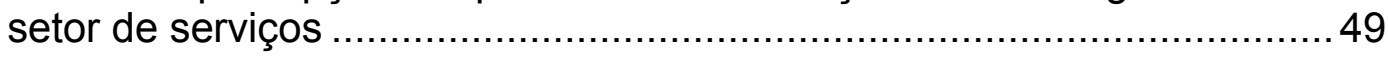

2.3.1.5. Influência combinada de risco, confiança e/ou prontidão para a tecnologia sobre outros construtos ligados à aceitação de tecnologias ...51 2.3.1.6. Síntese da literatura investigada sobre aceitação de tecnologias no setor de serviços .......................................................... 55

2.4 Formulação do modelo conceitual e hipóteses de pesquisa...........69

2.4.1 Prontidão para a Tecnologia - TRI ........................................... 70

2.4.2 Facilidade de Uso Percebida - PEU ........................................ 74

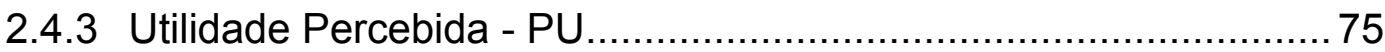

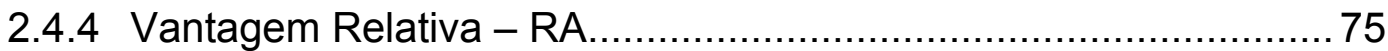

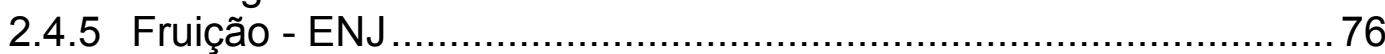

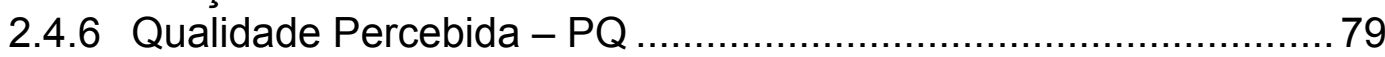

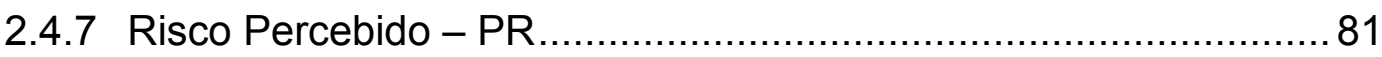

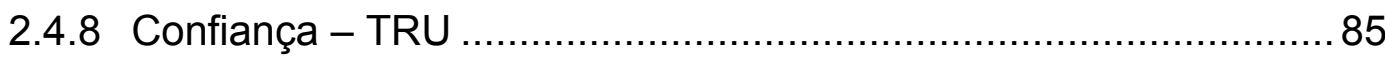

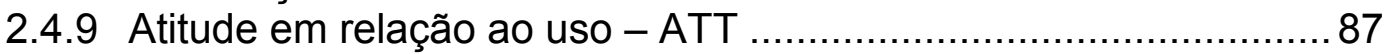

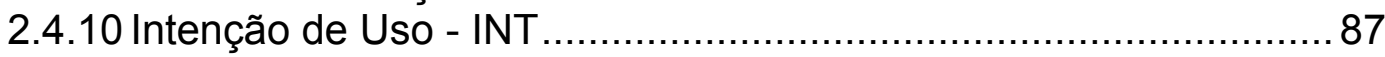

2.4.11 Síntese do modelo utilizado na pesquisa ................................... 88 


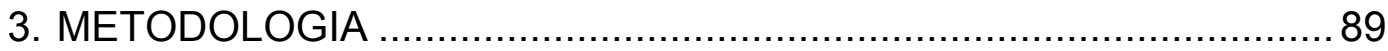

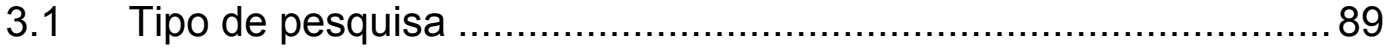

3.2 Operacionalização das variáveis …………….......................... 89

3.3 População e amostragem ........................................................ 91

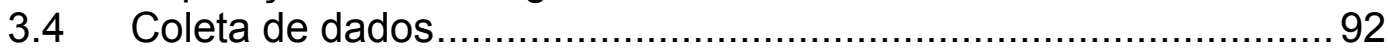

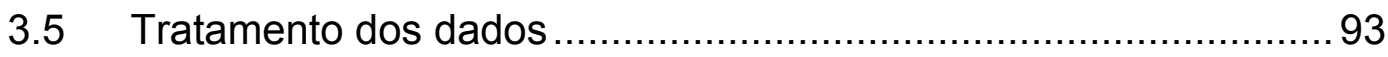

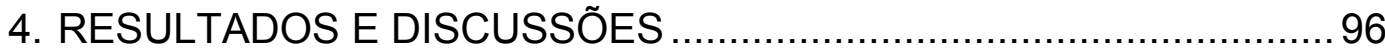

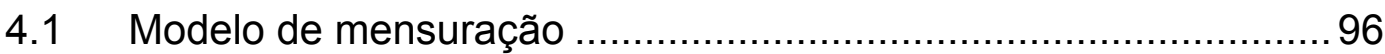

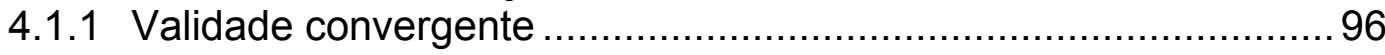

4.1.2 Validade discriminante...................................................... 100

4.1.3 Validade da face e validade nomológica .................................. 103

4.1.4 Ajuste geral do modelo de mensuração .................................... 104

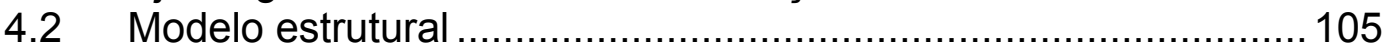

4.2.1 Normalidade dos dados da pesquisa...................................... 106

4.2.2 Ajuste geral do modelo estrutural .......................................... 107

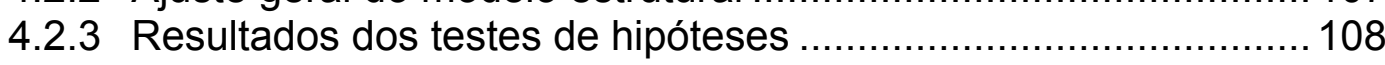

4.2.4 Análise de modelos alternativos .............................................. 111

4.3 Discussão dos resultados ....................................................... 115

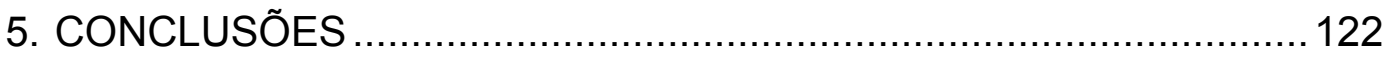

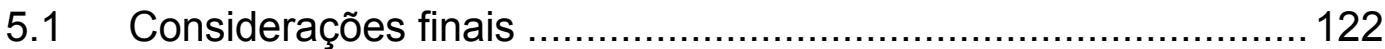

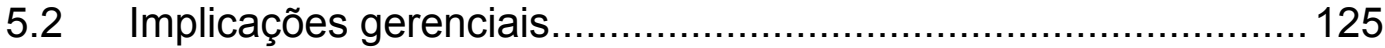

5.3 Limitações da pesquisa ....................................................126

5.4 Sugestões para pesquisas futuras ........................................ 127

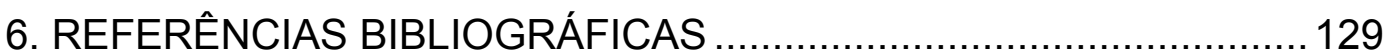

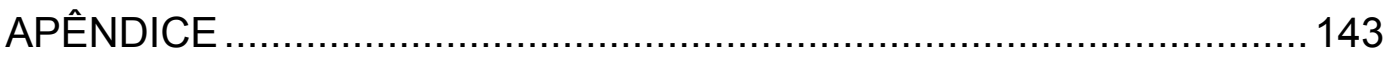




\section{Lista de figuras}

Figura 1: Estágios do processo de tomada de decisão acerca de

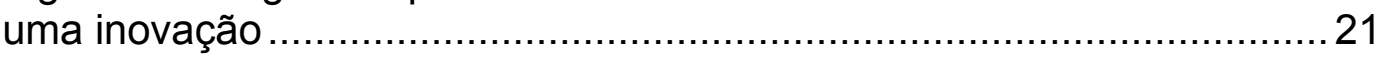

Figura 2: Teoria da Ação Racionalizada - TRA …………………......... 24

Figura 3: Teoria do Comportamento Planejado - TPB............................ 25

Figura 4: Modelo de Aceitação de Tecnologias - TAM ............................. 27

Figura 5: Teoria Unificada de Aceitação e Uso de Tecnologias

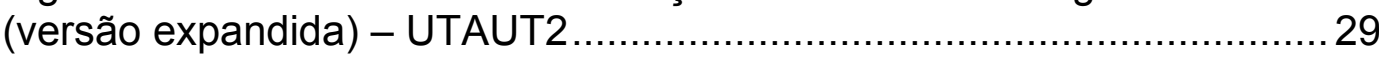

Figura 6: Modelo de Aceitação de Tecnologias pelo Consumidor - CAT . 31

Figura 7: Conjuntura Teórica do Índice de Prontidão à Tecnologia - TRI. 33

Figura 8: Modelo de Prontidão e Aceitação de Tecnologias pelo

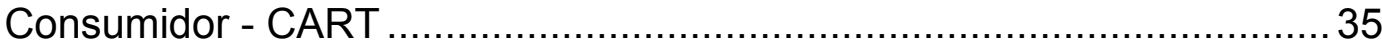

Figura 9: Influência do modelo TAM e da confiança sobre a aceitação

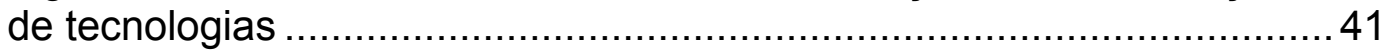

Figura 10: Influência da confiança e da familiaridade sobre a intenção

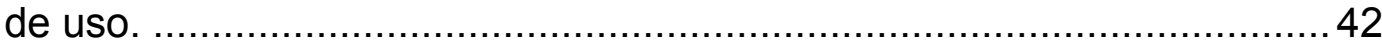

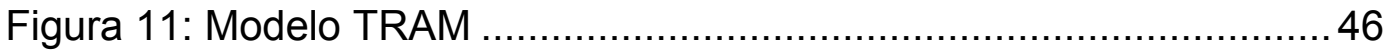

Figura 12: Modelo de Aceitação pelo Consumidor de Lojas Virtuais .......48

Figura 13: Fatores que influenciam a adoção de serviços de comércio

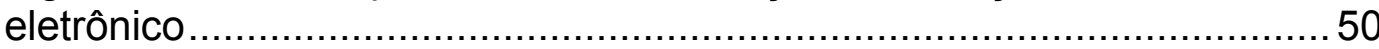

Figura 14: Influência da qualidade percebida, da confiança e da motivação hedônica na aceitação de tecnologias

Figura 15: Influência da credibilidade do prestador de serviço sobre o risco e a intenção de uso.

Figura 16: Modelo de Prontidão e Aceitação de Mobile Payments. ......... 69

Figura 17: Formas de Percepção de Risco .......................................... 84

Figura 18: Cenas extraídas do vídeo introdutório do questionário de

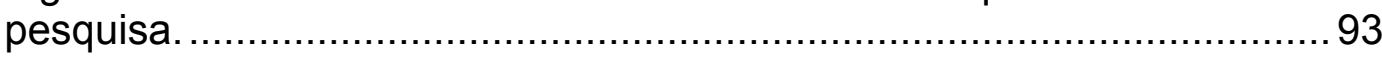

Figura 19: Modelo conceitual e hipóteses de pesquisa, após ajustes.... 105

Figura 20: Modelo estrutural e coeficientes das relações verificadas. ... 109

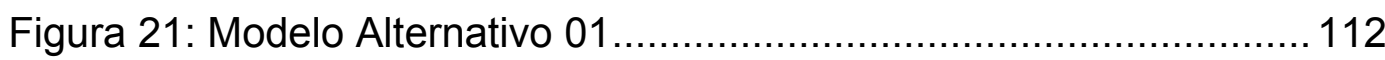

Figura 22: Modelo Alternativo 02................................................... 113

Figura 23: Modelo de Prontidão e Aceitação de Mobile Payments Versão Final 


\section{Lista de quadros}

Quadro 1: Características discriminantes dos serviços, em relação a produtos.

Quadro 2: Síntese da literatura analisada sobre aceitação de tecnologias no setor de serviços. 56

Quadro 3: As quatro dimensões da Prontidão para a Tecnologia.............70

Quadro 4: Potenciais dimensões da qualidade de um serviço...................79

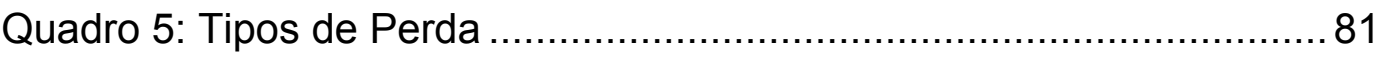

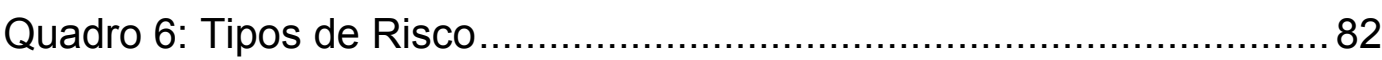

Quadro 7: Síntese das hipóteses propostas pela pesquisa. .................... 88

Quadro 8: Escalas utilizadas na definição dos construtos do modelo

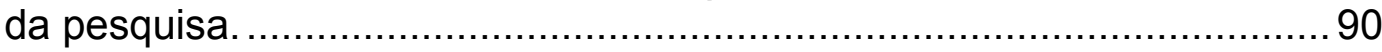

Quadro 9: Estágios do processo de modelagem de equações

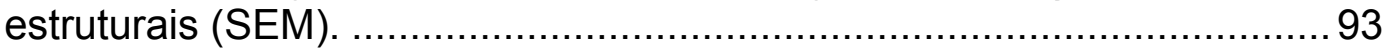

Quadro 10: Matriz da análise de validade discriminante ....................... 100

Quadro 11: Matriz de validade discriminante após ajustes. ................... 102

Quadro 12: Matriz de correlações entre os construtos.......................... 103 


\section{Lista de tabelas}

Tabela 1: Cargas fatoriais padronizadas......................................... 97

Tabela 2: Análise de Confiabilidade, Confiabilidade Composta e Variância Média Extraída (AVE).................................................... 99

Tabela 3: Indicadores de ajuste geral do modelo de mensuração........ 104

Tabela 4: Análise de normalidade dos da pesquisa............................ 106

Tabela 5: Indicadores de ajuste geral do modelo estrutural.................. 107

Tabela 6: Análise de significância das hipóteses do modelo

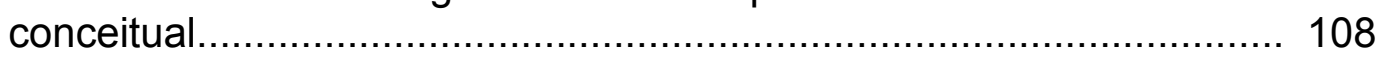

Tabela 7: Comparação entre os modelos analisados, de acordo com । indicadores de ajuste geral.............................................................. 114

@ Tabela 8: Verificação das hipóteses propostas após ajustes do modelo...... 


\section{Siglas e Abreviações}
ATT Attitude - Atitude
CART Consumer Acceptance and Readiness of Technology - Prontidão e Aceitação de Tecnologias pelo Consumidor.
CAT Consumer Acceptance of Technology - Aceitação de Tecnologias pelo Consumidor
ENJ Enjoyment - Fruição
EPQ Enjoyment of Perceived Quality - Apreciação da Qualidade Percebida
IDT Innovations Diffusion Theory - Teoria da Difusão de Inovações
INT Intention - Intenção
PEU Perceived Ease of Use - Facilidade Percebida de Uso
PQ Perceived Quality - Qualidade Percebida
PR Perceived Risk - Risco Percebido
PU Perceived Usefulness - Utilidade Percebida
PUA Perceived Usefulness and Advantages - Utilidade e Vantagens Percebidas
RA Relative Advantage - Vantagem Relativa
SEM Structural Equation Modelling - Modelagem de Equações Estruturais
TAM Technology Acceptance Model - Modelo de Aceitação de Tecnologias
TPB Theory of Planned Behavior - Teoria do Comportamento Planejado
TR Technology Readiness - Prontidão para a Tecnologia
TRA Theory of Reasoned Action - Teoria da Ação Racionalizada
TRAM Technology Readiness and Acceptance Model - Modelo de Prontidão e Aceitação de Tecnologias
TRI Technology Readiness Index - Índice de Prontidão para a Tecnologia
TRU Trust - Confiança
TTF Technology-Task Fit - Ajuste Tecnologia-Tarefa
UTAUT Unified Theory of Acceptance and Use of Technology - Teoria Unificada de Aceitação e Uso de Tecnologia 


\section{1. Introdução}

\section{1}

\section{Considerações iniciais}

Inovações tecnológicas, de maneira geral, permitem a inserção de novos produtos ou de melhoramentos de produtos em um sistema econômico, gerando um novo mercado e modificando o sistema econômico de forma a ampliá-lo, caracterizando a definição de Schumpeter (1997) de desenvolvimento econômico. Dentro deste contexto é possível afirmar, portanto, que a tecnologia desempenha papel crucial no desenvolvimento de uma economia (ROGERS, 1976). Além disso, a continuidade de uma empresa em um ambiente competitivo está relacionada à sua capacidade de criação de inovações tecnológicas ou de rápida adaptação diante de inovações que afetem seu setor como um todo.

No entanto, o sucesso de uma inovação depende essencialmente de sua aceitação pela sociedade. A adoção de inovações, por meio de novas ideias, produtos e serviços, é um fenômeno que, apesar de estudado há tempos, ainda gera diversas questões tanto para empresas quanto para pesquisadores de Marketing (BAE; CHANG, 2012; KIM; FORSYTHE, 2010). Neste contexto, diversos modelos e teorias foram elaboradas com o intuito de tentar explicar o comportamento do consumidor em relação à aceitação de novas tecnologias (VENKATESH et al., 2003).

Além disso, no caso do setor de serviços financeiros, Staykova e Damsgaard (2015) indicam que poucas inovações geraram vantagens competitivas de forma efetiva, posto que foram rapidamente copiadas pelos concorrentes. Vários são os exemplos indicados pelos autores que ilustram como determinados bancos falharam em obter vantagens duradouras, uma vez que os concorrentes passariam a apresentar serviços similares pouco tempo depois do lançamento da inovação, iniciando uma corrida por novos processos inovadores. 
A mais recente revolução nos serviços financeiros envolve a rápida disseminação e adoção dos smartphones, que incorporaram inúmeros tipos de aplicativos, incluindo aplicativos ligados à serviços de pagamentos móveis (STAYKOVA; DAMSGAARD, 2015). Estes serviços, denominados m-payments, podem ser definidos como uma forma de pagamento na qual tanto instruções quanto os próprios dados referentes ao pagamento são conduzidos por meio de aparelhos móveis (XIN; TECHATASSANASOONTORN; TAN, 2015). Cruz et al. (2010) indicam que os m-payments distinguem-se do mobile banking pelo fato de não envolverem diretamente um banco na operacionalização dos pagamentos envolvidos.

Os m-payments surgiram na Finlândia em 1997, quando a CocaCola passou a testar máquinas que aceitavam pagamentos por SMS (DAHLBERG; GUO; ONDRUS, 2015). Atualmente, pode-se considerar que, em função de seu crescimento significativo, os m-payments se tornarão o principal alicerce do comércio eletrônico (GARRETT et al., 2014; SLADE; WILLIAMS; DWIVEDI, 2013; YANG et al., 2015; ZHOU, 2013, 2014)

Os m-payments apresentam características significativamente diferentes de inovações anteriores ligadas aos serviços financeiros, pois a digitalização destes serviços proporciona reduzidos custos marginais, proporcionando economias de escala (STAYKOVA; DAMSGAARD, 2015). Diante disto, os autores indicam que a competição se intensificou entre os prestadores de m-payments, e o desafio deste setor agora envolve a captação e manutenção de uma base cada vez maior de usuários, a fim de reduzir o custo fixo médio decorrente do desenvolvimento dos aplicativos envolvidos.

Diante da intensa concorrência entre os prestadores de serviços de m-payments, é de se esperar que essa busca por uma base cada vez maior de usuários também ocorra no Brasil, onde é iminente o início das atividades das empresas prestadoras deste tipo de serviço. Diante disto, torna-se fundamental para estas empresas compreender os fatores que podem levar o consumidor a utilizar ou não um serviço de m-payment. 


\section{2}

\section{Objetivos do estudo}

Diante do contexto apresentado, o presente estudo pretendeu desenvolver e testar um modelo de prontidão e aceitação de mobile payments, buscando considerar fatores cognitivos, afetivos e também características importantes ligadas a serviços financeiros que possam influenciar a adoção de serviços de m-payments por consumidores.

\section{3 \\ Questões a investigar}

A revisão de literatura, a ser apresentada no próximo capítulo, indicou que a adoção de inovações pode ser influenciada tanto por fatores cognitivos quanto emocionais, além da influência da prontidão para a tecnologia (DAVIS; BAGOZZI; WARSHAW, 1989; KULVIWAT et al., 2007; PARASURAMAN; COLBY, 2014; VENKATESH; L. THONG; XU, 2012). No entanto, posto que o objeto de análise é um serviço financeiro (no caso, o serviço de m-payment), alguns aspectos adicionais devem ser observados, como a percepção de qualidade, de confiança e de risco envolvido nas transações financeiras, posto que estas representam um assunto sensível para consumidores (CHEN; CHEN; CHEN, 2009; KÖSTER; MATT; HESS, 2016; MOROSAN; DEFRANCO, 2016; YANG et al., 2012). Diante disto, esta pesquisa busca responder as seguintes questões:

- Como a prontidão para a tecnologia afeta a percepção de qualidade e a percepção de risco envolvido na adoção de um serviço de m-payment?

- Como a percepção de risco acerca de um serviço de m-payment afeta a intenção de adoção do mesmo?

- Como a confiança em relação a um serviço de m-payment afeta a intenção de adoção do mesmo?

- Como a percepção de qualidade afeta a intenção de adoção de um serviço de m-payment? 


\section{4}

\section{Relevância do estudo}

Em termos acadêmicos, o presente estudo se mostrou relevante por ampliar as discussões acerca da difusão e aceitação de tecnologias, apresentando um modelo mais direcionado à adoção de m-payments. Tal direcionamento se deu por meio da fusão de modelos de prontidão e aceitação de tecnologias com construtos que refletissem a influência de características observadas predominantemente no setor de serviços financeiros.

Apesar da quantidade significativa de pesquisas na área de difusão e aceitação de inovações aplicadas ao setor de serviços, não foi encontrado um modelo que analisasse, simultaneamente, as relações entre prontidão para a tecnologia, aceitação de tecnologias e determinadas características predominantes no setor de serviços financeiros, como confiança e percepção de risco. A relevância do presente trabalho se dá em função deste apresentar um novo modelo de aceitação de tecnologias, que busca examinar as relações entre os conceitos supracitados.

Em termos de aplicações gerenciais, esta pesquisa apresenta elementos que permitem um melhor direcionamento das estratégias de marketing, posto que estas podem ser orientadas em função dos principais fatores que levam o consumidor a decidir pela adoção dos serviços de m-payments.

\section{5}

\section{Delimitação do estudo}

Em relação ao arcabouço teórico utilizado no estudo, o mesmo foi delimitado pela Teoria de Difusão de Inovações - IDT, do inglês Innovations Diffusion Theory - de Rogers (2003). A IDT descreve como ocorre o processo de decisão de adoção ou rejeição de uma inovação, bem como indica os principais atributos que uma inovação deve apresentar. A delimitação teórica, contudo, não se limitou somente à análise da IDT, mas também por diversos modelos e teorias que tinham como objetivo explicar o comportamento do consumidor acerca da aceitação de inovações tecnológicas. 
No que tange à delimitação referente ao objeto de estudo, o modelo fruto da presente pesquisa foi testado somente no contexto dos sistemas de pagamentos móveis - mobile payments ou m-payments. No Brasil, o surgimento dos sistemas de m-payments ainda é recente e, portanto, pouco difundido. Sistemas como o Apple Pay, Samsung Pay, Goggle Payments e o AliPay ainda não chegaram ao Brasil que, por possuir mais de 280 milhões de linhas de telefonia móvel ativas, segundo a Associação Nacional de Telecomunicações - ANATEL (2015), apresenta-se como um mercado promissor para tal serviço.

\section{6}

\section{Organização do estudo}

O presente estudo, além desta introdução, apresenta em seu segundo capítulo o referencial teórico que norteia as questões de pesquisa. Esta revisão aborda, inicialmente, a literatura referente à difusão e aceitação de inovações. Em um segundo momento, são abordados os principais modelos de aceitação de tecnologias e os principais modelos aplicados no setor de serviços, a fim de justificar, com base em pesquisas anteriores, a necessidade de formulação de um modelo específico de adoção de serviços financeiros. Por fim, o referido capítulo apresenta as principais questões a serem investigadas na pesquisa, bem como o modelo conceitual a ser testado e as hipóteses de pesquisa oriundas deste modelo.

O terceiro capítulo apresenta a metodologia utilizada nesta pesquisa, no que diz respeito à população analisada, critérios de amostragem e forma de coleta de dados. Além disso, o referido capítulo aborda os métodos empregados no tratamento dos dados - no caso, a Modelagem de Equações Estruturais - e os processos utilizados para a obtenção dos resultados da pesquisa. 
Tais resultados são apresentados no quarto capítulo, iniciando com os testes do modelo de mensuração, seguido do teste do modelo estrutural. Além disso, são testados modelos estruturais alternativos, a fim de obter a melhor relação possível entre qualidade de ajuste a nível de parcimônia utilizado na composição do modelo. Por fim, os resultados são discutidos à luz da literatura investigada no referencial teórico.

Por fim, o quinto capítulo apresenta as considerações finais, retomando as questões de pesquisa e comparando-as aos resultados obtidos. Também são apresentadas as principais contribuições da pesquisa, em termos acadêmicos e gerenciais. Por fim, o referido capítulo indica as limitações da pesquisa e as sugestões para pesquisas futuras, no intuito de ampliar ainda mais o conhecimento disponível sobre a prontidão e aceitação de inovações tecnológicas. 


\section{2. \\ Referencial teórico}

O referencial teórico que norteia esta pesquisa abordou a literatura pertinente à adoção de tecnologias. Neste sentido, são apresentadas as principais teorias e modelos desenvolvidos com o intuito de identificar fatores que podem influenciar a aceitação de inovações.

Além disso, são apresentadas algumas características específicas do setor de serviços financeiros, a fim de evidenciar a necessidade da inclusão de alguns destes elementos no modelo conceitual de pesquisa que encerra este capítulo. Por fim, são apresentadas as hipóteses a serem atestadas no referido modelo.

\section{1}

\section{Teoria da Difusão de Inovações - IDT}

Rogers (2003), autor da Teoria de Difusão de Inovações - IDT define tecnologia como um projeto de ação experimental, a fim de reduzir a incerteza das relações de causa e efeito na busca por um resultado desejado. No escopo dos estudos de marketing, fica evidente, diante do exposto, a importância dos estudos sobre a aceitação do consumidor em relação a novas tecnologias. Neste sentido, a aceitação de tecnologias pode ser definida como a vontade de aceitar e utilizar novas tecnologias disponíveis (DAVIS, 1989).

A difusão é, portanto, um processo que envolve criação e compartilhamento de informações a respeito de uma inovação, de forma a reduzir a incerteza em relação à esta, conduzindo à adoção ou rejeição da inovação (ROGERS, 2003). 


\subsection{1}

\section{O processo de decisão quanto à inovação}

Segundo a IDT, o processo de decisão quanto à inovação é o processo pelo qual um indivíduo parte do conhecimento inicial da inovação, formando uma atitude a respeito desta (a respeito de adotá-la ou rejeitá-la), para implementá-la e, por fim, confirmar sua decisão (ROGERS, 2003). O comportamento durante tal processo consiste basicamente na percepção da novidade envolvida na inovação e em como lidar com a incerteza associada a esta novidade. Além disso, cabe ressaltar que, apesar da comprovação da existência destes estágios, a linha que os separa torna-se cada vez mais tênue à medida em que se avança no processo de decisão quanto à inovação (ROGERS, 2003). Um modelo que ilustra este processo pode ser visto a seguir na Figura 1.

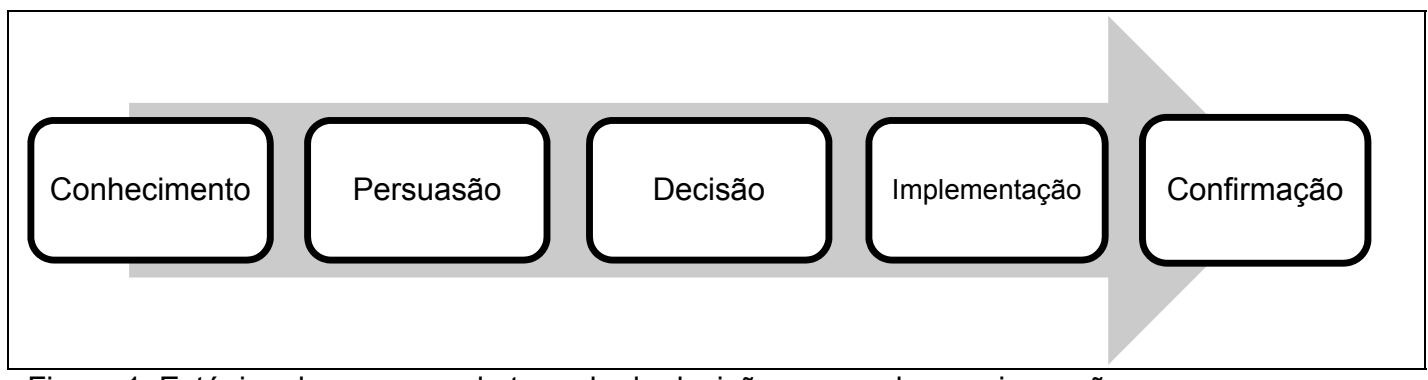

Figura 1: Estágios do processo de tomada de decisão acerca de uma inovação Fonte: adaptado de Rogers (2003).

De acordo com Rogers (2003), o estágio do conhecimento caracteriza-se pela apresentação inicial do indivíduo à inovação, de forma a adquirir a compreensão inicial sobre esta. Já o estágio da persuasão ocorre quando o indivíduo define uma atitude - favorável ou desfavorável - em relação à inovação. O estágio seguinte - decisão - se caracteriza pelo engajamento em atividades que levarão à escolha de adotar ou rejeitar a inovação.

Em caso de adoção, o estágio de implementação ocorre com a utilização efetiva da inovação. Por fim - no estágio de confirmação - o indivíduo busca reforçar a decisão já tomada. No entanto, nesse estágio as informações obtidas podem levar tanto à confirmação quanto à reversão da decisão anteriormente tomada, caracterizando a descontinuidade da inovação (ROGERS, 2003). 


\subsection{2}

\section{Atributos das inovações}

Rogers (2003) indica que a taxa de adoção de uma inovação é a velocidade relativa com a qual esta é adotada pelos membros de um determinado sistema social. Uma vez que diferentes inovações apresentam diferentes taxas de adoção, a Teoria de Difusão de Inovações buscou investigar como os atributos percebidos das inovações afetam sua taxa de adoção.

De acordo com a IDT, a taxa de adoção de uma inovação é afetada, em grande parte, por variações de cinco atributos percebidos: vantagem relativa, compatibilidade, complexidade, possibilidade de teste prévio e observabilidade (ROGERS, 2003).

Vantagem Relativa, segundo Rogers (2003), é o nível no qual uma inovação é percebida como superior à ideia a ser substituída. Tal superioridade pode ser definida, por exemplo, em termos de fatores econômicos ou status social, de acordo com a natureza da inovação. De acordo com a IDT, quanto maior a percepção de vantagens em relação à adoção de uma inovação, maior será a taxa de adoção da mesma.

Compatibilidade é o nível no qual uma inovação é percebida como consistente com os valores existentes, as experiências anteriores e as necessidades dos potenciais adotantes. De acordo com este conceito, uma nova ideia que é mais compatível apresenta menor nível de incerteza e se encaixa melhor na situação do adotante, ampliando sua taxa de adoção. Em geral a compatibilidade é avaliada em termos de valores e crenças socioculturais, ideias prévias ou mesmo as necessidades do cliente em relação à inovação (ROGERS, 2003).

Complexidade, segundo Rogers (2003), é o nível no qual uma inovação é percebida como relativamente difícil de compreender e/ou usar. Neste sentido, qualquer nova ideia pode ser classificada dentro de um continiuum entre complexidade e simplicidade. Segundo a IDT, quanto maior a complexidade percebida, menor a taxa de adoção da inovação. 
A Possibilidade de Teste Prévio diz respeito à possibilidade de um potencial adotante experimentar previamente uma inovação, antes de seu uso (ROGERS, 2003). Tal possibilidade pode influenciar positivamente a taxa de adoção da inovação, pois tende a reduzir a incerteza a respeito desta.

Observabilidade é o atributo que indica o nível no qual os resultados de uma inovação estão visíveis aos outros, ou seja, o nível pelo qual os resultados de uma inovação são percebidos e comunicados a outras pessoas (ROGERS, 2003). Neste sentido, a IDT indica que, quanto maior a observabilidade de uma inovação, maior será sua taxa de adoção. Softwares inovadores, por exemplo, tendem a apresentar uma menor taxa de adoção, quando comparados a componentes de hardwares, pois nem sempre a inovação propriamente dita é passível de observação.

\section{2}

\section{Principais modelos de prontidão e aceitação de tecnologias}

Ao pesquisar os paradoxos da tecnologia, Mick e Fournier (1998) acabam por desconstruir a visão excessivamente otimista que a Teoria da Difusão de Inovações traz em seu conteúdo, posto que os paradoxos indicam que a tecnologia não necessariamente será benéfica. Além disso, os mesmos paradoxos advindos da tecnologia despertam diferentes emoções que acabam por fazer com que a adoção de inovações seja realizada em tempos diferentes por diferentes indivíduos.

Bagozzi e Lee (1999) vão além e indicam que a avaliação do consumidor em relação à adoção gera determinadas emoções - positivas e/ou negativas - e a resposta a tais emoções leva o consumidor a testar, adotar ou resistir à inovação, sendo também possível que o consumidor resolva adiar a decisão de adoção.

Desta forma, é possível perceber que a Teoria de Difusão de Inovações não explica o que leva o consumidor a adotar ou não uma inovação - na verdade, trata-se de uma teoria muito ampla, não direcionada apenas para a investigação de fatores que possam influenciar a adoção ou não de novos produtos ou serviços. Isto se evidencia por 
meio dos diversos modelos que surgiram após a IDT, na tentativa de ampliar tal explicação.

\subsection{1}

Teoria da Ação Racionalizada - TRA

A Teoria da Ação Racionalizada - Theory of Reasoned Action, ou TRA - é uma teoria baseada principalmente na obra de Fishbein e Ajzen (1975), cujo objetivo era iniciar uma discussão teórica sobre as relações entre crenças, atitudes, intenções e comportamentos.

De acordo com Fishbein e Ajzen (1975), o comportamento de determinado indivíduo está intimamente ligado às suas intenções acerca de desempenhar tal comportamento. Tais intenções, por sua vez, são funções de determinadas crenças: por um lado, as crenças referentes às consequências do comportamento em questão determinam as atitudes em relação ao comportamento; por outro lado, crenças ligadas a normas subjetivas - pressão subjetiva exercida por pessoas de referência para exercer ou não o comportamento em questão - também influenciam significativamente a intenção de desempenhar ou não determinado comportamento. Desta forma, a TRA pode ser esquematizada de forma simplificada pela Figura 2.

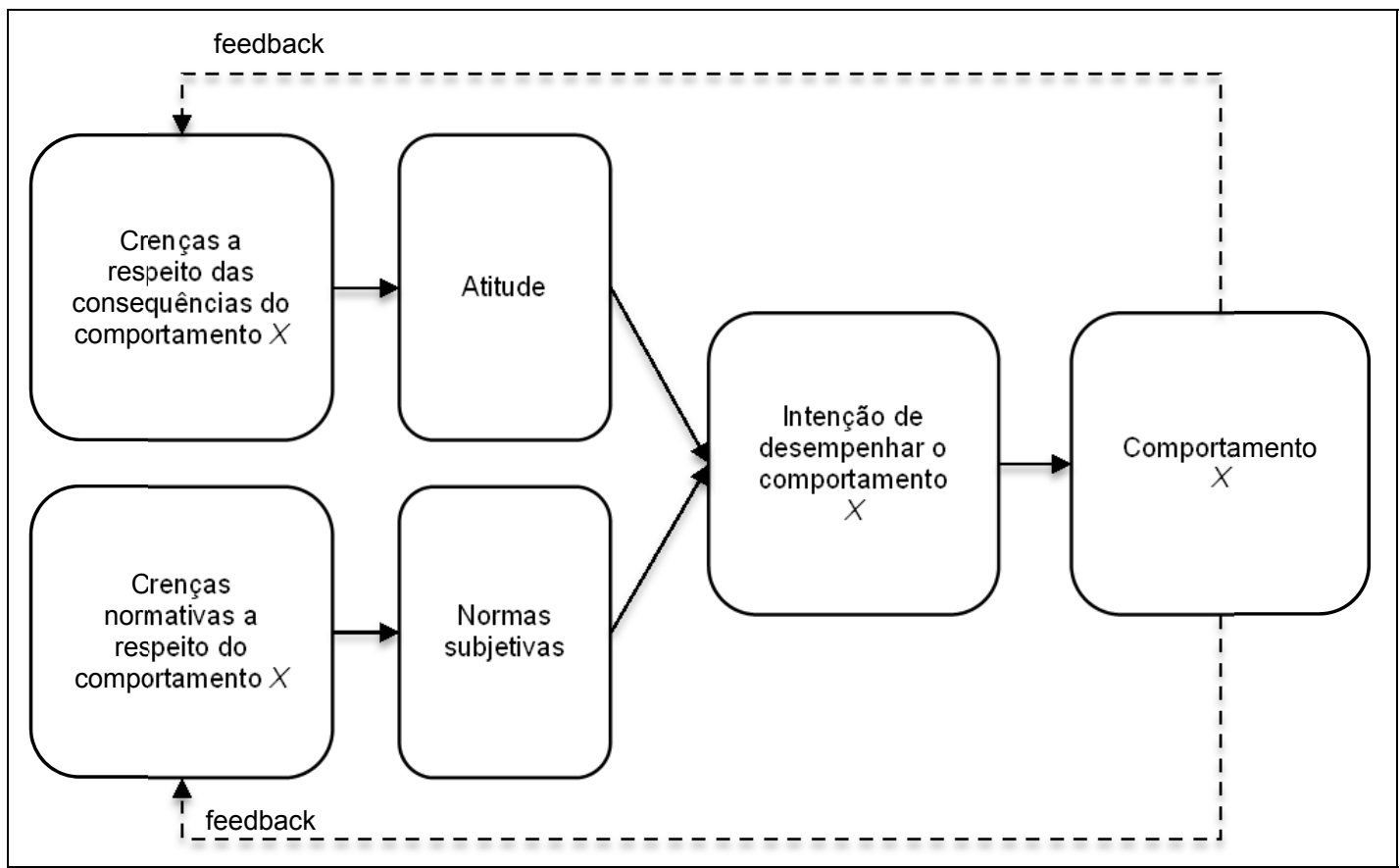

Figura 2: Teoria da Ação Racionalizada - TRA Fonte: adaptado de Fishbein e Ajzen (1975) 
A TRA pode ser utilizada para explicar o processo cognitivo envolvido na tomada de decisão de um indivíduo, ao assumir que este utiliza racionalmente todas as informações disponíveis para definir sua intenção de adotar ou não determinado comportamento (PAUL; MODI; PATEL, 2016).

\subsection{2}

\section{Teoria do Comportamento Planejado - TPB}

De acordo com Ajzen (1985), a TRA ilustra um cenário onde o indivíduo pode facilmente desempenhar determinado comportamento, se assim o desejar. Desta forma, o autor indica que a TRA originalmente se destina a cenários onde o indivíduo possui elevado controle da própria vontade.

No entanto, fatores internos e externos podem influenciar o controle da própria vontade, limitando-a. Ajzen (1985) utiliza como exemplo um cenário onde fumantes apresentam intenção inicial de largar o vício, mas suas intenções se alteram com o tempo ou eles falham ao tentar alterar o comportamento.

Assim, Ajzen (1985) modificou a TRA, de forma a tentar prever comportamentos em cenários onde o controle sobre a própria vontade é limitado, dando origem à Teoria do Comportamento Planejado - TPB, do inglês Theory of Planned Behavior, que pode ser representada na Figura 3.

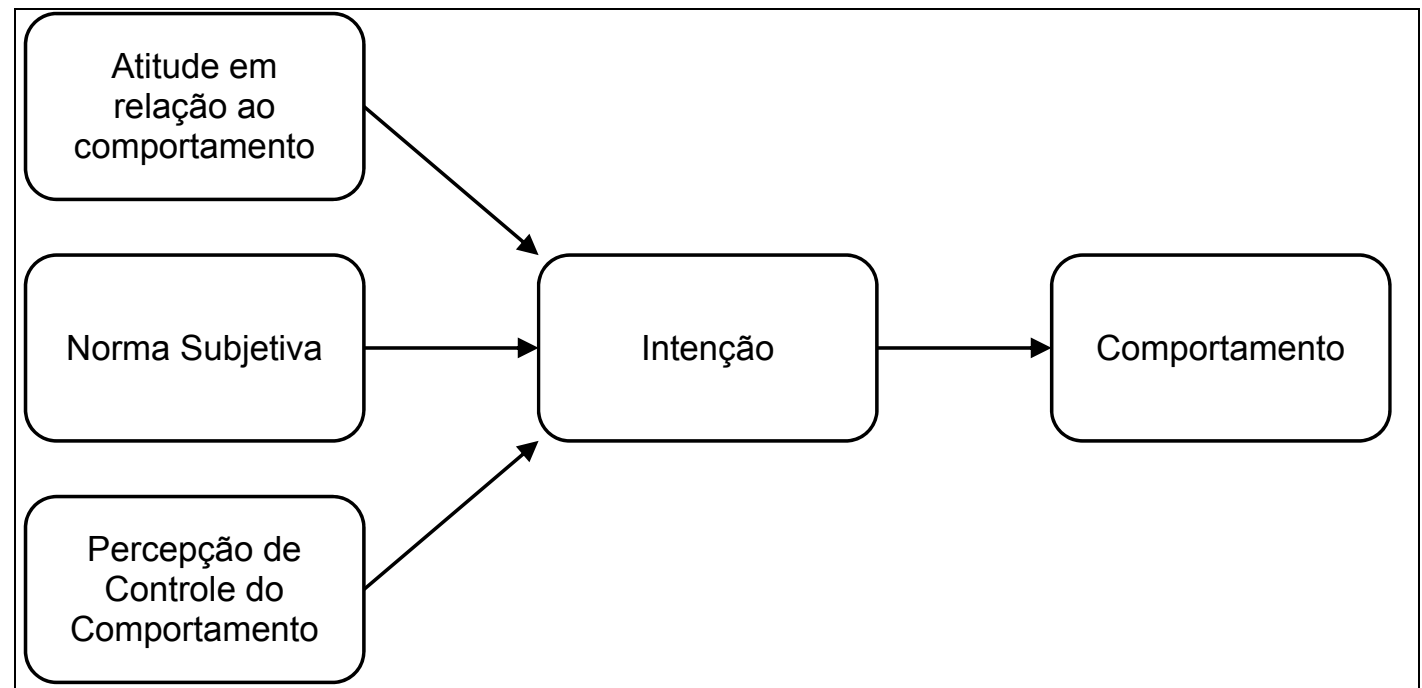

Figura 3: Teoria do Comportamento Planejado - TPB.

Fonte: adaptado de Ajzen (1985). 
Segundo Ajzen (1985), todo comportamento pode ser descrito como uma meta que envolve um nível maior ou menor de planejamento (intenção) que, por sua vez, está sujeita a determinado nível de incerteza (ausência de controle). Tal incerteza, ainda segundo o autor, pode ser provocada tanto por fatores internos - nível de informação, habilidades ou comportamentos emotivos intensos, por exemplo - quanto por fatores externos, como disponibilidade de tempo e oportunidade, por exemplo.

Tanto a TRA quanto a TPB mostraram-se teorias de alta relevância, posto que suas explicações sobre o comportamento humano passaram a compor a base da literatura sobre adoção de tecnologias, de forma que diversos modelos, gerados posteriormente, foram baseados nos construtos apresentados nas referidas teorias.

\subsection{3}

\section{Modelo de Aceitação de Tecnologias - TAM}

O Modelo de Aceitação de Tecnologias - TAM, do inglês Technology Acceptance Model - é considerado um dos principais modelos de aceitação de tecnologias, e foi elaborado por Davis (1986), sendo posteriormente refinado por Davis (1989) e Davis, Bagozzi e Warshall (1989), a fim de melhor compreender a adoção de sistemas de informações.

O modelo TAM utiliza como base a TRA de Fishbein e Ajzen (1975) para explicar o comportamento de um indivíduo por meio de sua intenção. De acordo com Davis et al. (1989, p. 985), um dos principais objetivos do modelo TAM é "fornecer uma base para mensurar o impacto de fatores externos sobre crenças internas, atitudes e intenções".

Neste sentido, o TAM propõe que duas avaliações cognitivas em particular - utilidade percebida e facilidade percebida de uso - são de elevada relevância para o comportamento de aceitação de tecnologias. A utilidade percebida é definida por Davis (1989) como o nível no qual a pessoa acredita que o uso de uma nova tecnologia aprimorará seu desempenho nas atividades desenvolvidas. Já a facilidade percebida de uso pode ser definida como sendo o nível de esforço adicional envolvido no uso de uma nova tecnologia (DAVIS, 1989). As normas subjetivas, por 
sua vez, não foram incluídas no modelo TAM, em função de suas incertezas teóricas e da complexidade de sua mensuração adequada ${ }^{1}$ (DAVIS; BAGOZZI; WARSHAW, 1989).

Segundo Davis et al. (1989), tanto a utilidade percebida quanto a facilidade percebida de uso são influenciadas por variáveis externas ao modelo, como características específicas do sistema e/ou do usuário. Tal concepção de variáveis externas foi baseada na TRA, posto que Fishbein e Ajzen (1975, p. 307) indicam que "variáveis externas ao modelo podem influenciar as intenções somente de forma indireta", atuando sobre seus componentes.

Davis et al. (1989) indicam que a estrutura parcimoniosa do modelo TAM com maior potencial explicativo do comportamento de uso é composta por apenas três construtos: Intenção de Comportamento, Utilidade Percebida e Facilidade Percebida de Uso (não incluindo o construto Atitude ${ }^{2}$ ). A Figura 4 mostra o diagrama conceitual do modelo TAM.

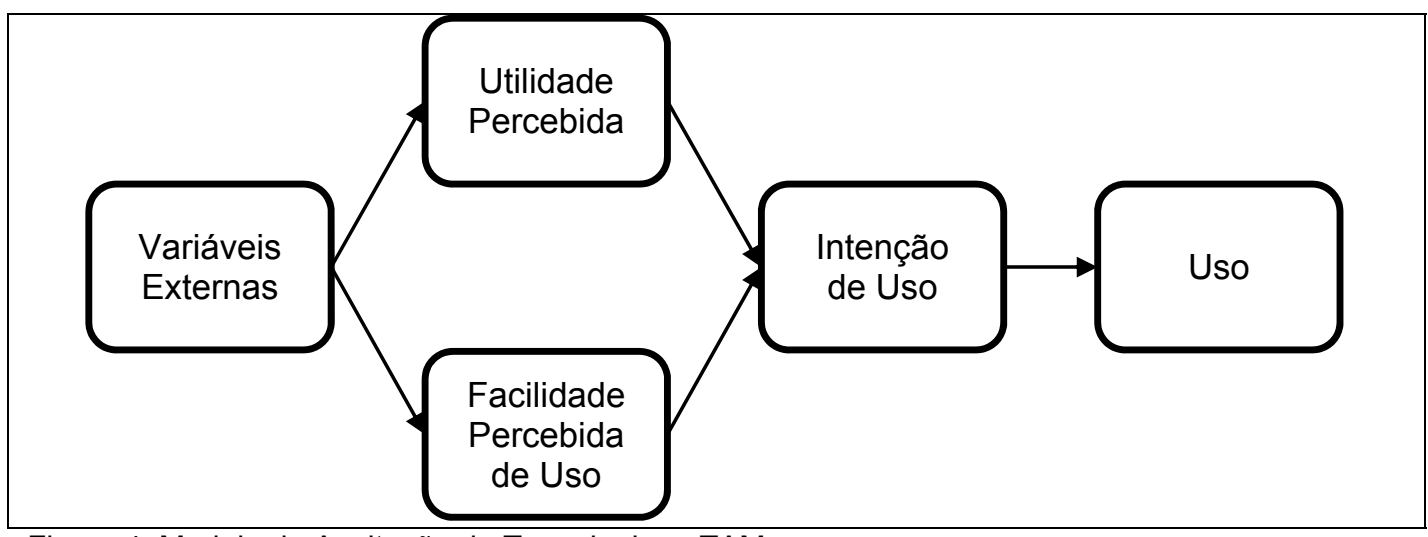

Figura 4: Modelo de Aceitação de Tecnologias - TAM

Fonte: adaptado de Davis et al. (1989).

Apesar de originalmente elaborado para explicar a aceitação de sistemas de informação inovadores, também foi amplamente utilizado na explicação de adoção de inovações por consumidores finais.

\footnotetext{
${ }^{1}$ As normas subjetivas (SN) exerce efeito direto sobre o comportamento de intenção (BI), mas também pode exercer efeitos indiretos, por meio de efeitos de SN sobre a atitude (A). Além disso, A pode afetar SN, gerando efeitos indiretos de A sobre BI.

${ }^{2} \mathrm{O}$ construto atitude foi suprimido do modelo final por não apresentar melhorias significativas na explicação do comportamento de adoção (DAVIS; BAGOZZI; WARSHAW, 1989).
} 
Desta forma, o modelo se tornou um dos mais testados e analisados nas pesquisas sobre difusão e aceitação de tecnologias. Segundo Yousafzai et al. (2007), a popularidade deste modelo se deve a três grandes fatores: design parcimonioso, base teórica forte e forte poder de generalização.

No entanto, diversos autores procuraram aprimorar o potencial explicativo do modelo TAM, a partir da investigação de outros construtos - inicialmente indicados como "variáveis externas" - que pudessem ser capazes de explicar determinados fenômenos relacionados ao comportamento de adoção de tecnologias. Em função da multiplicidade de modelos que se desdobraram a partir da Teoria de Difusão de Inovações e do modelo TAM, Venkatesh et al. (2003) elaboraram a Teoria Unificada de Aceitação e Uso da Tecnologia - UTAUT, que será abordada a seguir.

\subsection{4}

\section{Teoria Unificada de Aceitação e Uso da Tecnologia - UTAUT}

Venkatesh et al. (2003) buscaram rever e sintetizar todos os modelos existentes em torno de um único ponto de vista que pudesse explicar de forma convincente a aceitação de tecnologias. Desta forma, os autores elaboraram uma Teoria Unificada de Aceitação e Uso de Tecnologia - UTAUT, do inglês Unified Theory of Acceptance and Use of Technology - que incluiu, entre outros, os construtos componentes da TRA, TPB, da IDT e do modelo TAM.

A UTAUT postula que a intenção de uso é determinada por expectativas de desempenho, expectativas de efeito (nível de facilidade esperada), condições de facilitação e influência social. Por sua vez, tal intenção de uso influencia, juntamente com as condições de facilitação, o comportamento de uso (VENKATESH et al., 2003). Posteriormente, Venkatesh et al. (2012) expandiram a UTAUT, incluindo os construtos de motivação hedônica (definida como apreciação percebida), valor do preço (interpretação do consumidor sobre a relação entre custos financeiros e benefícios da tecnologia) e hábito (tendência de adotar um comportamento automaticamente após um período de aprendizagem). A 
Figura 5 apresenta a UTAUT2 expandida apresentada por Venkatesh et al. (2012).

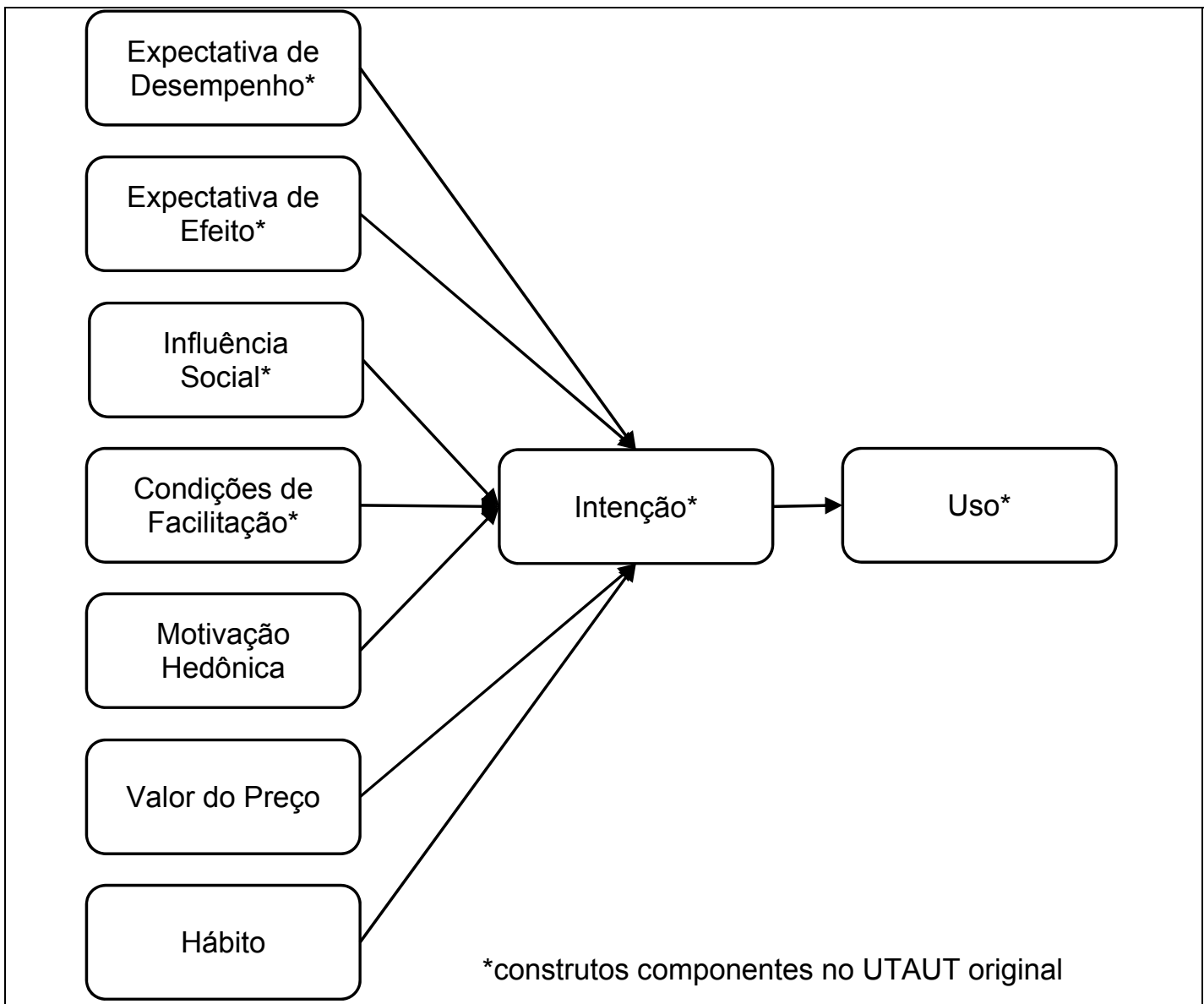

Figura 5: Teoria Unificada de Aceitação e Uso de Tecnologias (versão expandida) - UTAUT2 Fonte: Venkatesh et al. (2012).

No que diz respeito aos construtos formadores da intenção de uso, a expectativa de desempenho indica o nível no qual um indivíduo acredita que utilizar a tecnologia em questão "ajudará ele ou ela a obter ganhos de desempenho no trabalho" (VENKATESH et al., 2003). Já a expectativa de efeito, segundo os mesmos autores, indica o nível de facilidade associada ao uso da tecnologia.

A influência social busca mensurar o nível de percepção de um indivíduo em relação à opinião de pessoas importantes acerca do fato dele utilizar ou não a tecnologia em questão. Por sua vez, as condições de facilitação revelam o nível pelo qual um indivíduo acredita na existência de uma estrutura técnica e organizacional a fim de oferecer suporte à utilização da tecnologia em questão (VENKATESH et al., 2003). 
No que diz respeito aos construtos inseridos no UTAUT2, a motivação hedônica pode ser definida como sendo a diversão ou prazer derivados do uso da tecnologia (VENKATESH; L. THONG; XU, 2012). Os mesmos autores definem o valor do preço como sendo a percepção cognitiva dos consumidores acerca do tradeoff entre os benefícios percebidos oriundos do uso da tecnologia e os custos monetários envolvidos em tal utilização. Por fim, Venkatesh et al. (2012) definem o hábito como sendo a intensidade pela qual um indivíduo tende a desempenhar comportamentos automaticamente em função de seu processo de aprendizagem.

Os resultados obtidos por Venkatesh et al. (2003) e Venkatesh et al. (2012) revelaram que os modelos UTAUT e UTAUT2 são capazes de explicar aproximadamente $56 \%$ e $74 \%$ da intenção acerca do uso de tecnologias ${ }^{3}$. Estes resultados são superiores são superiores quando comparados ao modelo TAM, que explicou cerca de $38 \%$ da referida intenção, quando utilizados os mesmos dados (VENKATESH et al., 2003).

\subsection{5}

\section{Modelo de Aceitação de Tecnologias pelo Consumidor - CAT}

Buscando explicações especificamente para a adoção de tecnologias por consumidores, Kulviwat et al. (2007) desenvolveram um modelo dotado não só de fatores cognitivos, mas também de fatores afetivos ligados à decisão de adotar ou não uma tecnologia. Assim, os autores propuseram o Modelo de Aceitação de Tecnologia pelo Consumidor - CAT, do inglês Consumer Acceptance of Technology - que pode ser visto na Figura 6.

\footnotetext{
${ }^{3}$ Estes resultados foram obtidos após os construtos formadores da intenção sofrerem influência moderadora de variáveis ligadas à idade, gênero e experiência com a tecnologia (VENKATESH; L. THONG; XU, 2012)
} 


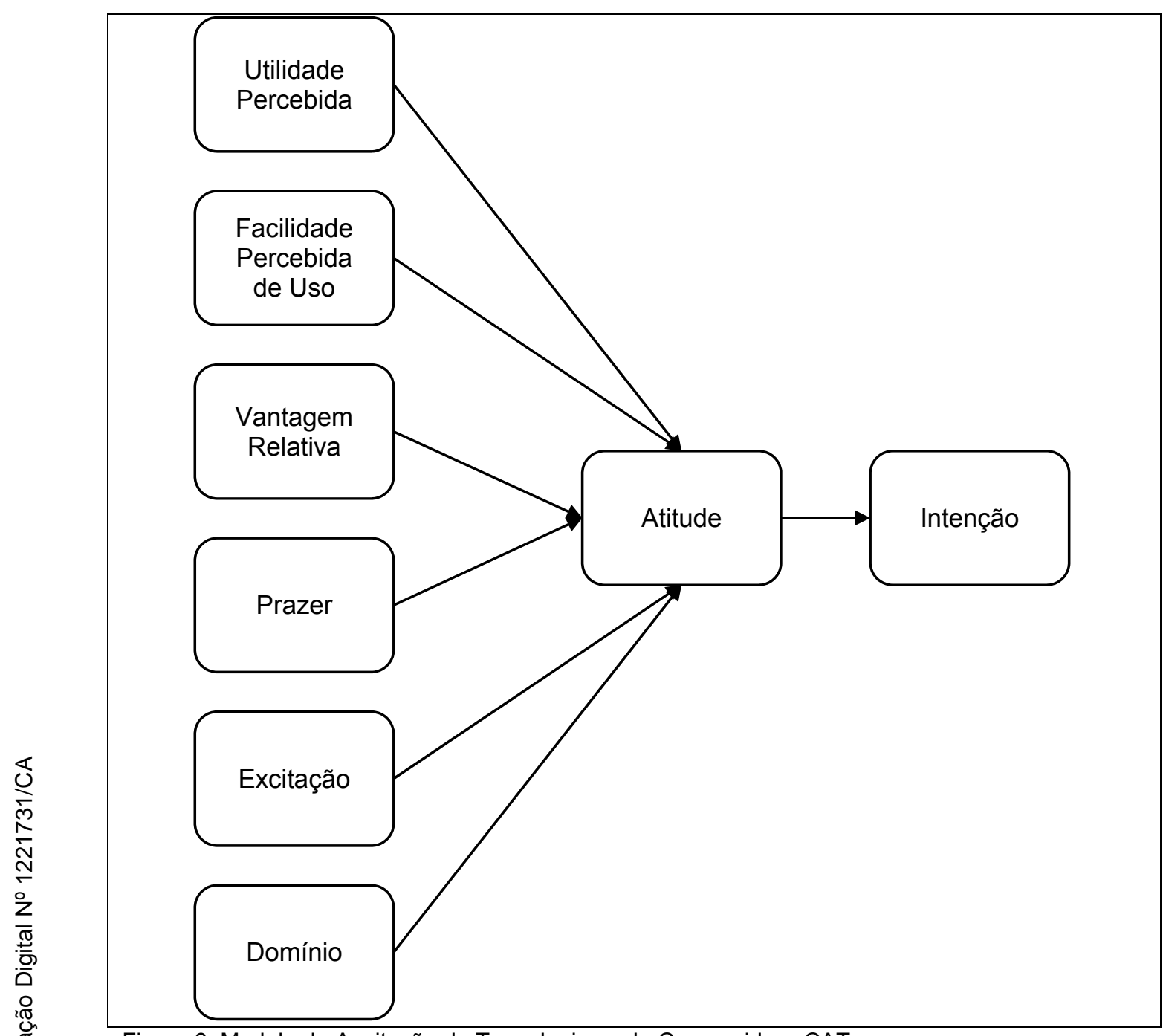

Figura 6: Modelo de Aceitação de Tecnologias pelo Consumidor - CAT

Fonte: adaptado de Kulviwat et al. (2007).

Os aspectos cognitivos do modelo CAT foram concebidos tendo como base o construto de vantagem relativa de Rogers (2003) e os construtos de utilidade percebida e facilidade percebida de uso, do modelo TAM de Davis et al. (1989), que já foram apresentados em seções anteriores.

Os aspectos afetivos do modelo CAT, por sua vez, foram baseados no modelo Prazer, Excitação e Domínio - PAD - de Mehrabian e Russel (1974). De acordo com estes autores, para todas situações de estímulo às quais um indivíduo pode estar sujeito existe um conjunto limitado de respostas emocionais. Este conjunto pode ser descrito de forma parcimoniosa como sendo formado por combinações de diferentes intensidades de prazer, excitação e domínio. 
Neste sentido, entende-se como prazer a resposta emocional diante de um estímulo - situada no continuum entre o agradável e o desagradável. Da mesma forma, respostas emocionais situadas entre o tédio e o frenesi definem a dimensão da excitação. Por fim, o sentimento de domínio define o nível no qual o indivíduo sente-se à vontade para agir de determinada forma (MEHRABIAN; RUSSELL, 1974).

O modelo CAT inseriu, nas discussões sobre aceitação de tecnologias pelo consumidor final, elementos que destacam o papel das emoções no processo de tomada de decisão. Comparando este modelo com o modelo TAM, os resultados indicaram que o modelo CAT foi capaz de explicar $53 \%$ das variações comportamentais ligadas à intenção de adotar uma tecnologia, ao passo que o potencial explicativo do modelo TAM foi de apenas $38 \%$, indicando que o modelo CAT se apresentava como um modelo mais adequado para explicar a aceitação de tecnologias (KULVIWAT et al., 2007).

\subsection{6}

\section{Prontidão para a Tecnologia - TRI}

No intuito de ampliar a investigação sobre a aceitação de tecnologias, Parasuraman (2000) desenvolveu o Índice de Prontidão à Tecnologia - TRI, do inglês Technology Readiness Index. A prontidão para a tecnologia pode ser definida como "a propensão das pessoas a adotar e usar novas tecnologias para o cumprimento de tarefas domésticas e profissionais" (PARASURAMAN, 2000). Em outras palavras, o autor define a prontidão para a tecnologia como um estado mental resultante da combinação de estimulantes e inibidores, que determinam a predisposição do indivíduo à utilização de novas tecnologias.

Neste sentido, Parasuraman (2000) apresenta a prontidão para a tecnologia como sendo composta de dois construtos estimulantes otimismo e inovatividade - e de dois construtos inibidores - desconforto e insegurança - cuja coexistência permite estimar a predisposição do indivíduo à adoção de tecnologias. 
No que diz respeito, aos construtos estimulantes do TRI, o otimismo pode ser definido como uma concepção positiva da tecnologia, de forma que esta oferece às pessoas aumento de controle, flexibilidade e eficiência em suas vidas. A inovatividade, por sua vez, indica a tendência do indivíduo em se tornar um pioneiro e um formador de opinião em termos de tecnologia (PARASURAMAN, 2000).

Quanto aos construtos inibidores da TRI, Parasuraman (2000) define o desconforto como sendo algo ligado à percepção de falta de domínio sobre a tecnologia, o que gera uma sensação de opressão pela mesma. Por fim, o autor define a insegurança como sendo a sensação de desconfiança e ceticismo em relação à tecnologia e sua habilidade de funcionar adequadamente.

Parasuraman (2000), inicialmente, mensurou o TRI por meio de uma escala de 36 itens baseados nos construtos já mencionados. Posteriormente, Parasuraman e Colby (2014) aprimoraram o TRI, sintetizando-o em 16 itens. A Figura 7 mostra os componentes do TRI e suas relações.

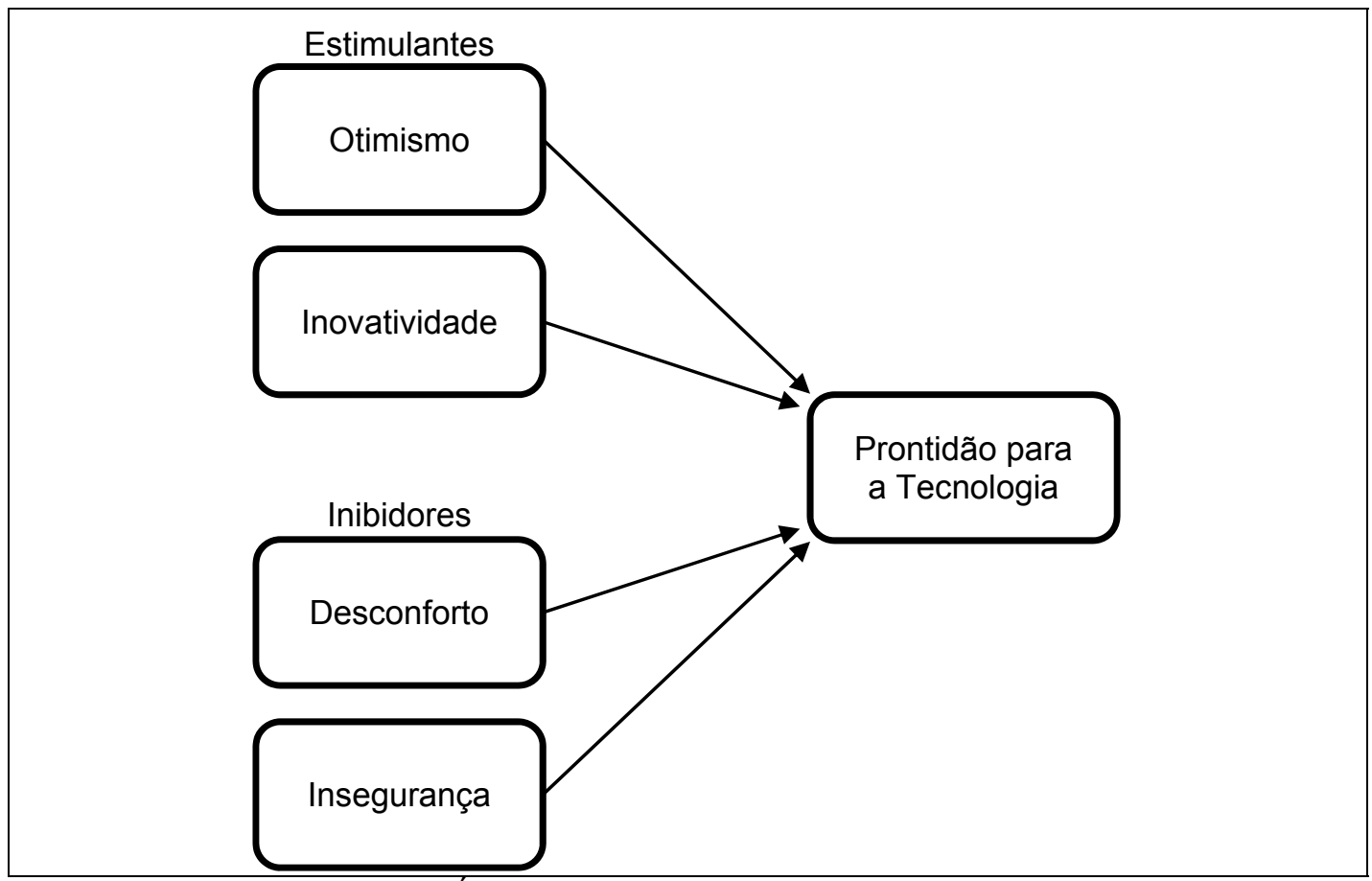

Figura 7: Conjuntura Teórica do Índice de Prontidão à Tecnologia - TRI

Fonte: adaptado de Parasuraman e Colby (2000). 


\subsection{7}

\section{Prontidão e Aceitação de Tecnologias pelo Consumidor - CART}

Partindo do pressuposto de que a compreensão dos fatores que conduzem à adoção de tecnologias é relevante tanto para a área acadêmica quanto para a área empresarial, Ferreira et al. (2014) investigaram as relações entre a prontidão para a tecnologia e fatores cognitivos e emocionais que os consumidores consideram ao decidir sobre a adoção de novas tecnologias.

O resultado desta investigação originou o Modelo de Prontidão e Aceitação de Tecnologias pelo Consumidor - CART, do inglês Consumer Acceptance and Readiness of Technology. O modelo, que tem como base o modelo CAT e o TRI, evidencia que a Prontidão para a Tecnologia está diretamente relacionada tanto com os construtos afetivos de Prazer e Excitação quanto com os construtos cognitivos de Vantagem Relativa, Utilidade Percebida e Facilidade Percebida de Uso (FERREIRA; ROCHA; SILVA, 2014). Como consequência, os autores demonstraram que os construtos cognitivos e afetivos possuem antecedentes passíveis de mensuração e análise, ampliando a discussão dos fatores que afetam a intenção de adoção de inovações.

Os resultados da aplicação do modelo CART - que pode ser visto na Figura 8 - indicaram que o mesmo foi capaz de explicar $71 \%$ da variância da atitude em relação à adoção. 


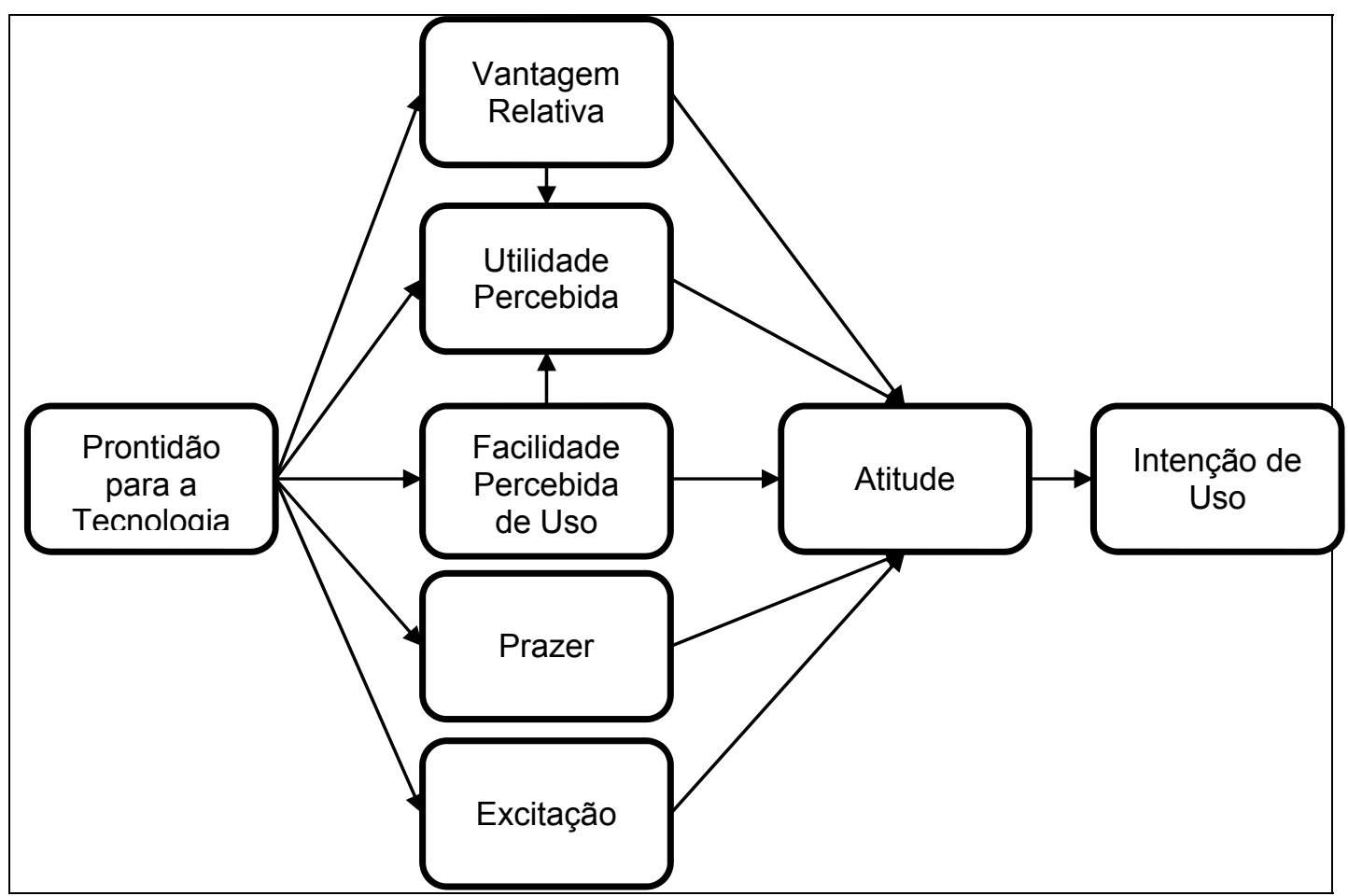

Figura 8: Modelo de Prontidão e Aceitação de Tecnologias pelo Consumidor - CART Fonte: adaptado de Ferreira et al. (2014).

\section{3}

\section{Serviços e tecnologia}

O Marketing de Serviços, enquanto área específica de pesquisa, iniciou sua produção de literatura especializada no final dos anos 1970, com trabalhos de diversos autores como John Bateson, Leonard Berry, Christopher Lovelock, G. Lynn Shostack e outros (FISK; BROWN; BITNER, 1993). No entanto, somente durante a década de 1980 o Marketing de Serviços se consolidou como uma área específica, após a publicação de diversos trabalhos que apresentavam, entre outros objetivos, as principais diferenças entre serviços e produtos, justificando a necessidade de pesquisas e teorias específicas para a melhor compreensão dos serviços.

As principais características únicas que diferenciam serviços de produtos foram sintetizadas por Zeithaml et al. (1985) e podem ser vistas no Quadro 1. 
Quadro 1: Características discriminantes dos serviços, em relação a produtos.

\begin{tabular}{|c|l|}
\hline Característica & \multicolumn{1}{|c|}{ Descrição da Característica } \\
\hline Intangibilidade & $\begin{array}{l}\text { Serviços são performances, e não objetos. Desta forma, eles } \\
\text { não podem ser vistos, sentidos, provados ou tocados da mesma } \\
\text { maneira que os produtos. }\end{array}$ \\
\hline $\begin{array}{c}\text { Inseparabilidade } \\
\text { produção-consumo }\end{array}$ & $\begin{array}{l}\text { Envolve a simultaneidade entre produção e consumo. No caso } \\
\text { de produtos, estes podem ser produzidos, posteriormente } \\
\text { vendidos e, por fim, consumidos. Os serviços, por sua vez, são } \\
\text { primeiramente vendidos, e então são produzidos e consumidos. }\end{array}$ \\
\hline Heterogeneidade & $\begin{array}{l}\text { Diz respeito ao potencial para a elevada variação no } \\
\text { desempenho dos serviços. A qualidade de um serviço varia de } \\
\text { acordo com o prestador do serviço, com cada cliente, com cada } \\
\text { dia, etc. }\end{array}$ \\
\hline Perecibilidade & $\begin{array}{l}\text { Os serviços não podem ser estocados, dificultando a } \\
\text { sincronização entre oferta e demanda pelos mesmos. }\end{array}$ \\
\hline
\end{tabular}

Fonte: adaptado de Zeithaml et al. (1985).

A intangibilidade é considerada a principal característica diferenciadora entre serviços e produtos (HELLÉN; GUMMERUS, 2013; JAN, 2012). No entanto, são raros no mercado um bem puro ou um serviço puro, de forma que predominam combinações de elementos tangíveis e intangíveis em um bem ou serviço, formando um espectro de tangibilidade (SHOSTACK, 1977). Neste sentido, portanto, deve-se afirmar que grande parte dos serviços se situa em condições onde predomina a intangibilidade.

A característica de inseparabilidade, segundo Zeithaml et al. (1985), "força o comprador a um contato íntimo com o processo de produção".

No que diz respeito à adoção de inovações, Soscia et al. (2011) afirmam que a possibilidade de teste prévio influencia significativamente a facilidade percebida de uso. Desta forma, pode-se inferir que na adoção de inovações em serviços a facilidade percebida de uso pode ser prejudicada em função da impossibilidade de teste prévio.

Em função da heterogeneidade - e, consequentemente, da existência de cocriação - é possível deduzir que o mesmo serviço é realizado de inúmeras maneiras diferentes, variando de cliente para cliente. Além disso, o serviço pode ser prestado de diferentes formas para o mesmo cliente (ZEITHAML; PARASURAMAN; BERRY, 1985). Tamanha variabilidade torna complexa a atividade de empresas prestadoras de serviços, contudo tal complexidade pode ser reduzida à medida que o serviço em questão se torna mais intensivo no uso de máquinas, em detrimento do uso de mão-de-obra (LOVELOCK; GUMMESSON, 2004). 
Por fim, no que diz respeito à perecibilidade, Jan (2012) afirma que o avanço tecnológico permitiu às empresas se estivessem mais preparadas para enfrentar eventuais desajustes entre oferta e demanda.

Segundo Rust e Chung (2006), apesar de diversas pesquisas retomarem a discussão quanto à utilização das principais características dos serviços a fim de diferenciar produtos e serviços - posto que a linha que os separa se tornou cada vez mais tênue - tais características ainda representam oportunidades e desafios de pesquisa na área de marketing. Além disso, posto que o conhecimento a respeito de uma tecnologia pode ser armazenado e repassado a outros, a contínua evolução tecnológica assegura a contínua expansão do setor de serviços (RUST; CHUNG, 2006).

A relação entre tecnologia e os serviços alterou substantivamente a forma de visualizar os serviços e suas especificidades. Rust e Huang (2014, p. 217) indicam que essa "revolução tecnológica" no marketing de serviços permitiu, entre outras coisas: melhor compreensão dos grandes clientes, melhor personalização do serviço, aumento de eficiência no trade-off entre qualidade e produtividade, melhor compreensão da tecnologia nas relações com clientes e do impacto destas relações sobre as tomadas de decisão da empresa.

\subsection{1}

\section{Aceitação de tecnologias no setor de serviços}

As discussões sobre aceitação de tecnologias foram aplicadas, por diversas vezes, a novos serviços, desde a criação do modelo TAM. Dishaw e Strong (1999), por exemplo, investigaram a adoção de serviços de suporte a sistemas de informação. Para tanto, os autores elaboraram um modelo utilizando construtos tanto do modelo TAM de Davis et al. (1989) quanto do modelo de Ajuste Tarefa-Tecnologia - TTF, do inglês Technology-Task Fit - de Goodhue e Thompson (1995) ${ }^{4}$.

\footnotetext{
${ }^{4} \mathrm{O}$ modelo TTF indica que uma tecnologia tende a ser utilizada - e aprimorar o desempenho do usuário - quanto maior o ajuste entre as características da tarefa a ser executada e as características da tecnologia em si (GOODHUE; THOMPSON, 1995).
} 
A integração destes dois modelos proporcionou, segundo Dishaw e Strong (1999), aumento no potencial preditivo sobre a adoção de tecnologias, quando comparado aos resultados obtidos com cada modelo, separadamente. Além disso, os autores identificaram que a funcionalidade da ferramenta, a experiência prévia com a mesma e o ajuste tarefa-tecnologia podem ser preditores da facilidade percebida de uso, ao passo que a utilidade percebida pode apresentar tanto a experiência prévia quanto o ajuste tarefa-tecnologia como antecedentes.

Venkatesh (1999, 2000) retoma, posteriormente, esta discussão, investigando a influência de outras relações sobre a adoção de diferentes serviços voltados para o contexto organizacional. Os resultados destas pesquisas, além de confirmarem a importância de fatores ligados à experiência anterior e ao nível de controle sobre a tecnologia, também indicaram que, quanto mais prazerosa a experiência durante o uso do serviço, maior a facilidade de uso percebida e, consequentemente, maior a intenção de adoção da tecnologia envolvida.

Venkatesh (2000) também identificou que, após um período de experiência com a tecnologia, a percepção de facilidade de uso se ajusta, sendo menos influenciada por crenças ligadas à tecnologias em geral e se tornando mais influenciada por crenças específicas em relação à tecnologia em questão.

Childers et al. (2001) investigaram a adoção de serviços de compras online, integrando construtos dos tradicionais modelos de aceitação de tecnologias - como facilidade percebida de uso, utilidade percebida e motivação hedônica (divertimento - enjoyment) - a construtos ligados ao uso da internet, como flexibilidade e conveniência. Além disso, os autores analisaram se os construtos investigados têm sua capacidade preditiva modificada em função do contexto da compra online (contexto mais utilitário ou mais prazeroso). 
Os resultados desta pesquisa indicaram que, em contextos mais utilitários, a percepção de utilidade é o preditor mais forte da atitude em relação ao uso da tecnologia. Por outro lado, em contextos mais prazerosos, o divertimento torna-se o melhor preditor da atitude (CHILDERS et al., 2001). Assim, os autores apontam para a necessidade de se observar melhor o contexto de utilização da tecnologia, de forma a estimular mais adequadamente o consumo da mesma.

O contexto dos serviços de compras online também foi observado por Chen et al. (2002), que testaram o modelo TAM de Davis et al. (1989), adicionado do construto Compatibilidade, advindo da IDT de Rogers (2003). A inclusão deste construto foi justificada pela intenção de se observar melhor a influência de normas sociais sobre a adoção de tecnologias (CHEN; GILLENSON; SHERRELL, 2002). A compatibilidade apresentou influência significativa tanto sobre a utilidade percebida quanto sobre a atitude em relação ao uso. Além disso, os resultados indicaram que os três construtos - compatibilidade, utilidade percebida e facilidade percebida de uso - apresentaram praticamente o mesmo potencial preditor em relação à atitude.

No sentido de evitar a multiplicidade de modelos e teorias sobre a aceitação de tecnologias, Venkatesh et al. (2003) e Venkatesh et al. (2012) buscaram elaborar uma teoria que unificasse os principais conceitos das principais teorias e modelos acerca da aceitação de tecnologias. A UTAUT, já abordada no tópico 2.2.4 - foi aplicada no contexto de uso de diversos serviços eletrônicos, indicando que a intenção de uso pode ser influenciada tanto por fatores cognitivos quanto por fatores emocionais, além de fatores ligados à experiência de uso e à influência social.

Buscando compreender fatores que levam à adoção de serviços de mobile commerce, Bruner II e Kumar (2005) identificaram que a diversão é um forte preditor da atitude em relação ao uso. Além disso, os autores também indicaram que o tipo de orientação da informação - informação visual ou verbalizada - influencia a facilidade de uso, ao passo que o tipo de aparelho móvel - telefone sem fio ou palmtop - influencia tanto a 
facilidade de uso quanto o nível de diversão envolvida no uso dos serviços de mobile commerce.

No Brasil, Püschel, Mazzon e Hernandez (2010) elaboraram um modelo integrado de aceitação de serviços de mobile banking, abrangendo construtos diversos, incluindo construtos do modelo TAM, da Teoria de Difusão de Inovações (IDT) e da Teoria do Comportamento Planejado (TPB). O modelo elaborado por Püschel et al. (2010) foi capaz de explicar $69 \%$ do comportamento de uso, e permitiu identificar, entre outros resultados, que determinados fatores - como facilidade percebida de uso e controle percebido - só influenciam a atitude em relação ao uso em indivíduos que já utilizaram o serviço.

Jin, Chai e Tan (2012), por sua vez, ao analisar adoção de serviços no contexto organizacional, definem as normas subjetivas como constituídas pelas pressões que a empresa sofre de fornecedores, concorrentes e clientes. Tal norma subjetiva organizacional mostra-se como forte influência da intenção de uso.

Yang et al. (2012) investigaram fatores que levam à adoção de serviços de pagamentos móveis ao longo do tempo, identificando que as influências sociais e as características pessoais influenciam a adoção do referido serviço. No entanto, na medida em que o indivíduo passa a utilizar o referido serviço, a influência social se reduz e a inovatividade passa a exercer maior influência sobre a intenção de uso (neste caso, continuação de uso).

Andreassen e Streukens (2013), ao analisar fatores que levam à adoção de serviços de atendimento online, identificaram a busca por interação social como determinantes da atitude, ao passo que a busca por novidades exerce influência sobre a intenção de uso.

De forma semelhante, Ayeh, Au e Law (2013) pesquisaram sobre a utilização de serviços virtuais de avaliação de viagens. Seus resultados indicaram, entre outras descobertas, uma forte influência da percepção de similaridade, implicando que quanto maior o nível de homofilia entre os clientes opinantes, maior a intenção de utilização do serviço. 
Gao et al. (2013), pesquisando fatores responsáveis pela adoção de diversos serviços por celular nos EUA, Europa e China, identificaram que o apego dos indivíduos em relação aos seus celulares exerce grande influência sobre a intenção de uso dos referidos serviços. Moraes et al. (2014), por sua vez, apresentam evidências de que a habilidade com o celular leva o indivíduo a reduzir sua ansiedade e ampliar sua percepção de utilidade em relação ao uso de serviços de compras online.

\subsubsection{1}

\section{Confiança e aceitação de tecnologias no setor de serviços}

Suh e Han (2002), ao investigar o contexto de serviços financeiros especificamente, o uso de internet banking - investigaram não somente a influência dos construtos já conhecidos do modelo TAM, mas também a influência da confiança sobre a aceitação de tecnologias.

Os resultados da pesquisa de Suh e Han (2002) indicaram que a confiança é um dos preditores mais significantes da atitude em relação ao uso de internet banking, indicando que os prestadores de serviços financeiros deveriam se atentar à sensação de confiança a ser fornecida a seus usuários, posto que se trata do processamento de informações sensíveis a estes. O modelo proposto por Suh e Han (2002) pode ser visto na Figura 9.

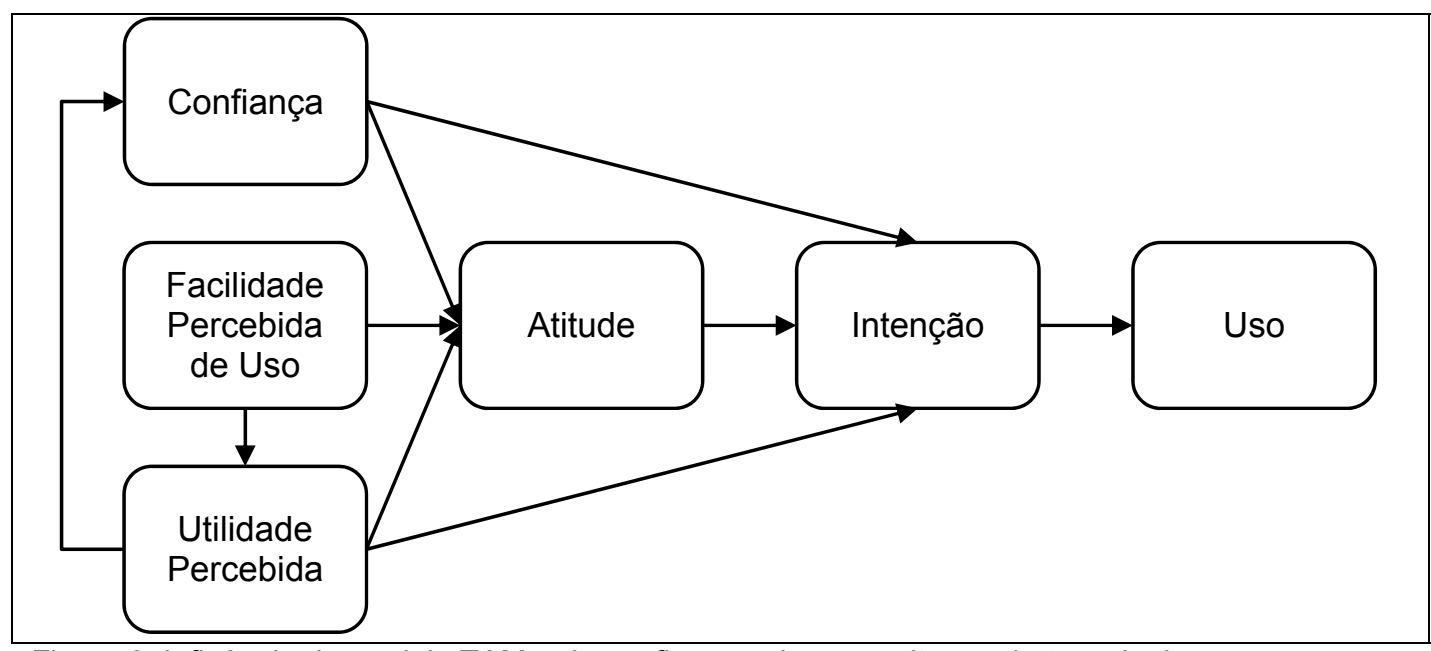

Figura 9: Influência do modelo TAM e da confiança sobre a aceitação de tecnologias Fonte: adaptado de Suh e Han (2002). 
Gefen et al. (2003), por sua vez, investigaram o uso de serviços de compras virtuais. No entanto, os autores analisaram a intenção de uso tanto em potenciais consumidores quanto em consumidores frequentes, a fim de observar eventuais mudanças de influências nos fatores observados.

Para Gefen et al. (2003), a intenção de uso pode ser explicada não pelos construtos já conhecidos do modelo TAM - facilidade percebida de uso e utilidade percebida - mas também pela confiança e pela familiaridade do indivíduo com a tecnologia em questão. De acordo com os autores, esta familiaridade tende a reduzir a percepção de complexidade e ampliar a facilidade percebida de uso. Além disso, a confiança pode ser explicada tanto pela familiaridade quanto pela disposição a confiar, que expressa uma predisposição individual a acreditar e confiar em outras pessoas. A Figura 10 a seguir ilustra o modelo elaborado por Gefen et al. (2003).

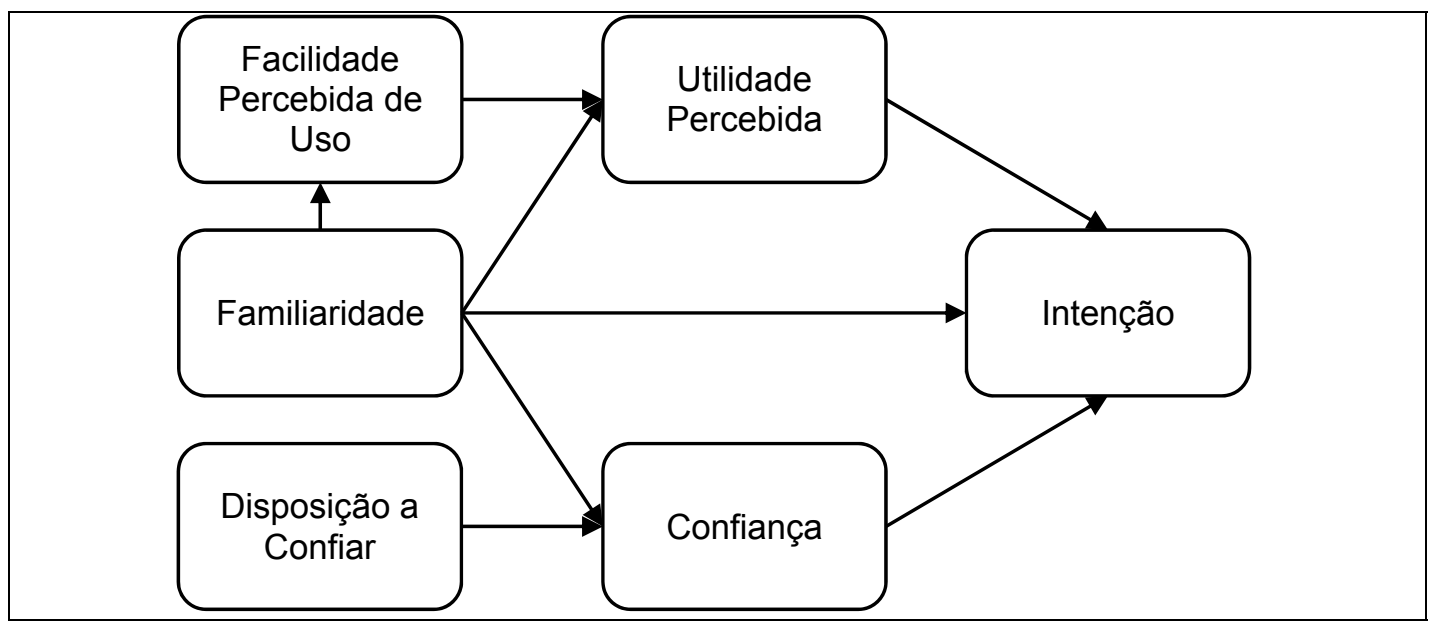

Figura 10: Influência da confiança e da familiaridade sobre a intenção de uso. Fonte: adaptado de Gefen et al. (2003)

Os resultados de Gefen et al. (2003) indicaram que a utilidade percebida só influencia a intenção de uso em consumidores frequentes. Por sua vez, a confiança exerce tal influência nos dois perfis de consumidores, porém apresentando maior influência em potenciais consumidores. Além disso, a influência da familiaridade sobre a facilidade percebida de uso foi maior em consumidores frequentes, o que pode ser explicado inclusive em função da curva de aprendizagem do indivíduo. 
Yu et al. (2005) também analisaram serviços de transações eletrônicas, porém buscando analisar a influência de aspectos cognitivos, emocionais e sociais sobre a intenção de uso. No que diz respeito aos aspectos sociais, evidências indicam que a opinião de familiares e amigos influenciam fortemente as normas subjetivas (pressão social) do indivíduo que, por sua vez, influenciam a intenção de uso.

No que diz respeito aos aspectos cognitivos, Yu et al. (2005) identificaram, além dos construtos do modelo TAM, influências da confiança sobre a atitude e sobre a intenção de uso. Por fim, os autores também identificaram influências da motivação intrínseca sobre a atitude e sobre a intenção de uso, caracterizando a influência dos aspectos emocionais sobre a aceitação de tecnologias.

A influência da confiança sobre a intenção de uso de internet banking e phone banking foi investigada por Dimitriadis e Kyrezis (2010). Para tanto, os autores buscaram discriminar componentes da confiança em dois grupos distintos: as crenças em relação à confiança (componente afetivo-cognitivo) e as intenções de confiança (componente comportamental). Após tal distinção, os autores buscaram investigar cada um destes componentes, encontrando evidências de que a intenção de confiança exerce um poderoso efeito moderador na relação entre a intenção de uso e as crenças ligadas à confiança.

Luo et al. (2010), investigando a aceitação do mobile banking, também optaram por decompor a confiança, porém discriminando-a em "crença em relação à confiança" e "pré-disposição a confiar". Nesse sentido, os autores observaram que o risco percebido era influenciado pelas crenças em relação à confiança e por uma estrutura de garantia formada pela disposição a confiar e pela experiência prévia do indivíduo com tecnologias semelhantes.

Kim et al. (2011), analisando a adoção de serviços de comunicação móvel multimídia, identificaram que a intenção de uso pode ser influenciada tanto pela atitude quanto pela percepção de controle e pelas normas subjetivas. Além disso, os resultados evidenciam que a percepção de credibilidade exerce influência positiva sobre a atitude em relação ao uso. 
Investigando a adoção de m-payments, Arvidsson (2014) verificou que os componentes do modelo TAM - Facilidade Percebida de Uso e Utilidade Percebida - exercem maior influência sobre a atitude em relação ao uso do que fatores ligados à confiança em relação aos atores envolvidos. Gurtner, Reinhardt e Soyez (2014) também indicam que estes construtos exercem maior influência sobre a intenção de uso e, além disso, também exercem fortemente influência indireta sobre a intenção de uso, por meio da influência da Facilidade Percebida de Uso sobre a motivação hedônica.

Investigando o contexto de m-payments, Dutot (2015) indicou que a influência social e a segurança são as maiores influências à adoção de tecnologias, sugerindo que as estratégias de comunicação das prestadoras deste serviço concentrem-se em passar uma imagem de segurança para os formadores de opinião da sociedade.

\subsubsection{2}

\section{Risco e aceitação de tecnologias no setor de serviços}

Wu e Wang (2005) também analisaram o contexto do uso dos serviços de mobile commerce. Neste sentido, os autores optaram por investigar a influência de fatores mais ligados a aspectos cognitivos sobre a intenção de uso, inclusive observando a influência do risco percebido sobre a aceitação de tecnologias.

Seus resultados indicaram que a compatibilidade exerceu a maior influência sobre a intenção de uso. Além disso, os resultados também indicaram que os custos envolvidos no uso de mobile commerce - custos do aparelho, de uso de internet e custos das transações envolvidas, por exemplo - influenciam negativamente a intenção de uso. Porém, ao contrário do esperado por Wu e Wang (2005), o risco percebido apresentou relação direta com a intenção de uso, não conseguindo justificativa para tal ocorrência. 
No que diz respeito a serviços de autoatendimento, Curran e Meuter (2005) investigaram o uso do mesmo em três distintos serviços - banco por telefone, caixas eletrônicos e internet banking. Os construtos utilizados apresentaram comportamentos significativamente diferentes para cada um dos serviços analisados: a facilidade percebida de uso se mostrou significativa apenas no uso dos caixas eletrônicos; a utilidade percebida não se mostrou significativa no uso de internet banking; o risco percebido só apresentou influência significativa sobre o uso de internet banking e, por fim, a necessidade de interação pessoal não se mostrou significativa em nenhum dos serviços observados.

Além disso, dos resultados obtidos por Curran e Meuter (2005), foi possível observar que, quando o serviço já é usado constantemente pelo consumidor - no caso dos caixas eletrônicos - o mesmo já não é influenciado pela percepção de risco ou a mesma já não existe. Já em casos de serviços ainda recentes para o consumidor - no caso do serviço de internet banking - a percepção de risco se sobressai e se mostra a única variável capaz de influenciar a decisão de uso do consumidor.

\subsubsection{3}

A prontidão para a tecnologia no setor de serviços

No contexto do consumidor final, Parasuraman (2000) e Parasuraman e Colby (2014) indicaram uma nova forma de se investigar a aceitação de novas tecnologias, por meio do Índice de Prontidão para a Tecnologia - TRI, já exposto em tópicos anteriores - que foi aplicado no contexto de diversos serviços de base tecnológica.

Cabe ressaltar que a prontidão para a tecnologia é de fundamental importância na adoção de novos serviços tecnológicos, posto que os sentimentos resultantes dos conflitos "otimismo $x$ insegurança" e "inovatividade $\mathrm{x}$ desconforto" definem a postura inicial que o indivíduo terá diante de um novo serviço tecnológico. 
Ainda no âmbito dos serviços de autoatendimento, Liljander et al. (2006) buscaram explicar a atitude e a adoção de tecnologias por meio da prontidão para a tecnologia (TR, do inglês Technology Readiness), construto este desenvolvido por Parasuraman (2000). Seus resultados indicaram que a TR, de forma geral, exerce uma influência positiva tanto sobre a atitude em relação ao uso quanto sobre a adoção de serviços de autoatendimento. Estes resultados são fortemente impulsionados pelas dimensões estimulantes da TR - otimismo e inovatividade - posto que os autores não conseguiram testar isoladamente os construtos inibidores desconforto e insegurança.

Lin, Shin e Sher (2007) também investigaram a influência da prontidão para a tecnologia na adoção de serviços eletrônicos, integrando tal construto ao modelo TAM. O modelo resultante desta integração modelo TRAM, do inglês Technology Readiness and Acceptance Model pode ser visto na Figura 11.

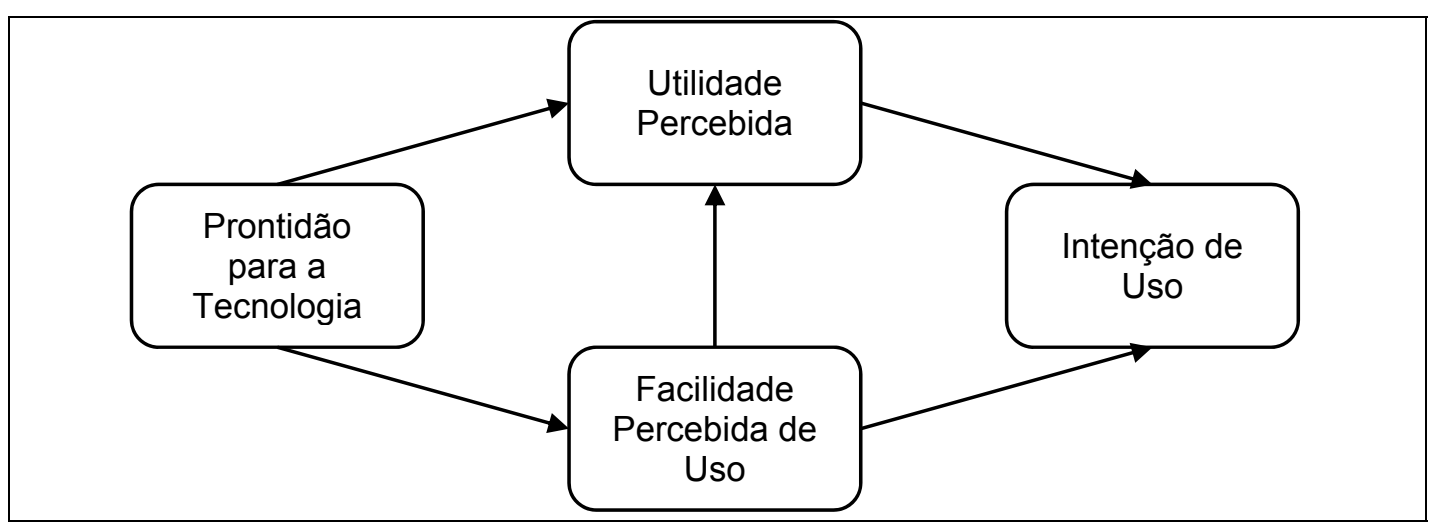

Figura 11: Modelo TRAM

Fonte: adaptado de Lin et al. (2007).

O modelo TRAM lançou luz sobre os trabalhos sobre difusão e adoção de tecnologias, ao clarificar o grande potencial da utilização da prontidão para a tecnologia enquanto antecedente de diversos fatores que levam à adoção de tecnologias. Além disso, trata-se de um construto voltado para a individualidade do potencial adotante, responsável por captar aspectos significativamente distintos dos captados pelos construtos apresentados pelo modelo TAM, que são orientados pelas especificidades da tecnologia a ser analisada (LIN et al., 2007). 
Walczuch, Lemmink e Streukens (2007) também investigaram a influência da prontidão para a tecnologia (TR) sobre a utilidade percebida (PU, do inglês Perceived Usefulness) e a facilidade percebida de uso (PEU, do inglês Perceived Ease of Use). Este trabalho diferencia-se da pesquisa de Lin et al. (2007) por analisar a influência da TR somente sobre PU e PEU, não analisando o modelo TAM em sua totalidade. No entanto, trata-se de um trabalho valioso por analisar a contribuição isolada de cada um dos componentes da TR sobre PU e PEU. Os resultados indicam que os componentes estimulantes da TR - otimismo e inovatividade - influenciam positivamente PU e PEU, ao passo que a insegurança influencia negativamente os referidos construtos e o desconforto somente exerce influência negativa sobre a facilidade percebida de uso.

Lin e Hsieh (2007) analisaram a influência da prontidão para a tecnologia no contexto de serviços de autoatendimento. Contudo, essa pesquisa utilizava somente a satisfação - além do construto já mencionado - como fator explicativo da intenção de uso. Seus resultados indicaram que a prontidão para a tecnologia influencia positivamente tanto a satisfação quanto a intenção de uso.

Lam, Chiang e Parasuraman (2008), por sua vez, investigaram a influência dos componentes da prontidão para a tecnologia tanto sobre o uso de tecnologias quanto sobre a variedade de utilização das tecnologias. Seus resultados indicaram, entre outras coisas, que a influência da insegurança se intensifica em contextos de uso que envolvem mais riscos, de forma que tanto o uso quanto a variedade de uso são negativamente influenciadas pela insegurança.

Chen et al. (2009) integraram a prontidão para a tecnologia à Teoria do Comportamento Planejado (TPB) e ao modelo TAM, definindo-os como determinantes da satisfação que, por sua vez, leva à intenção de continuação de uso de serviços de autoatendimento. O modelo proposto pelos autores foi capaz de explicar $69 \%$ da variação do comportamento de intenção de continuação de uso. Apesar disto, dentre os componentes da prontidão para a tecnologia, os construtos de insegurança e 
desconforto não apresentarem valores significativos para nenhuma das relações propostas no modelo.

\subsubsection{4}

\section{A percepção de qualidade e a aceitação de tecnologias no setor de serviços}

O uso dos serviços de lojas virtuais foi analisado por Chen e Tan (2004) que, para tanto, elaboraram o Modelo de Aceitação do Consumidor para Lojas Virtuais, que pode ser visto na Figura 12.

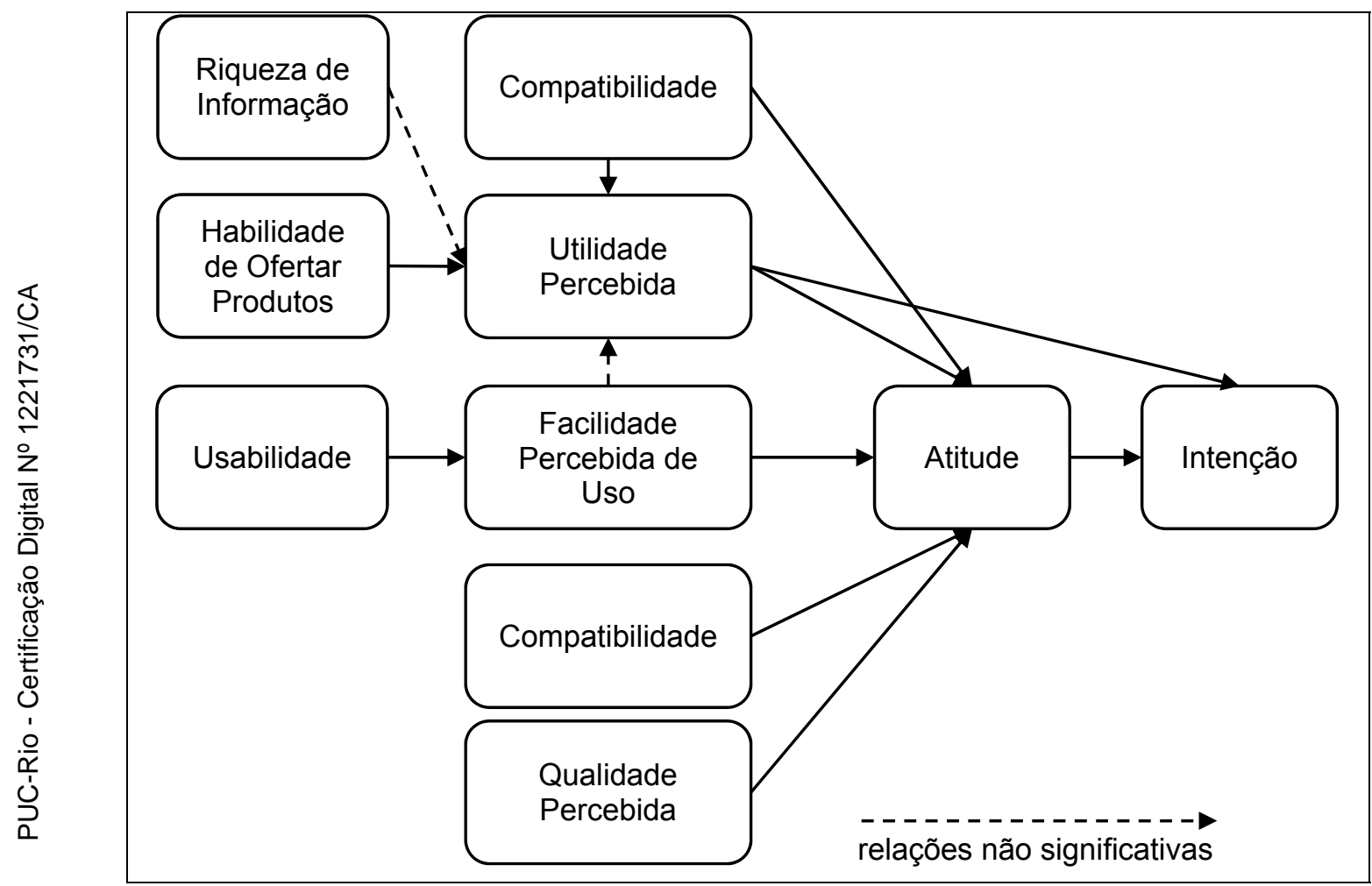

Figura 12: Modelo de Aceitação pelo Consumidor de Lojas Virtuais Fonte: adaptado de Chen e Tan (2004)

Os resultados de Chen e Tan (2004) evidenciaram que a qualidade percebida pode ser um bom preditor da atitude em relação ao uso de tecnologias. Além disso, os resultados também indicaram que a compatibilidade influencia significativamente tanto a utilidade percebida quanto a atitude em relação ao uso - resultado coincidente com os obtidos por Chen et al. (2002), mencionados anteriormente. 
No que diz respeito aos antecedentes dos construtos componentes do modelo TAM $^{5}$, Chen e Tan (2004) indicaram que a facilidade percebida de uso é fortemente influenciada pela usabilidade dos sites das lojas virtuais, ao passo que utilidade percebida é influenciada pela habilidade da loja em ofertar produtos compatíveis com a demanda do consumidor. No entanto, os autores não encontraram evidências significativas da influência da qualidade (riqueza) da informação disponível sobre a utilidade percebida, o que foi justificado em razão "mais em função de uma falha de mensuração do que de conceituação da referida relação" (CHEN; TAN, 2004).

Ahn, Ryu e Han (2007) investigaram fatores que levam à aceitação do uso dos serviços de compras online. Para tanto, além do modelo TAM, os autores investigaram a influência da diversão sobre a atitude e sobre a intenção de uso. Além disso, os autores também investigaram fatores ligados à qualidade do serviço como antecedentes dos demais construtos do modelo.

Os resultados de Ahn et al. (2007) confirmaram a influência da diversão tanto sobre a atitude quanto sobre a intenção de uso. Além disso, os autores também identificaram que todos os fatores ligados à qualidade do serviço que foram observados são bons preditores tanto da diversão quanto da utilidade percebida e da facilidade percebida de uso. Por fim, foi possível identificar que a qualidade do sistema é o mais forte antecedente da facilidade percebida de uso, ao passo que a qualidade da informação disponível é o mais forte preditor tanto da diversão quanto da utilidade percebida.

\footnotetext{
${ }^{5}$ Os antecedentes da utilidade percebida e da facilidade percebida de uso podem ser concebidos como componentes das "variáveis externas" indicadas por Davis et al. (1989).
} 


\subsubsection{5}

Influência combinada de risco, confiança e/ou prontidão para a tecnologia sobre outros construtos ligados à aceitação de tecnologias

Pavlou (2003) investigou o contexto de comércio eletrônico, buscando adicionar os construtos de confiança e risco ao modelo TAM, posto que a inserção destes construtos permite analisar com maior exatidão a incerteza existente no ambiente do comércio eletrônico.

Segundo o autor, a intenção de utilizar transações eletrônicas é influenciada não só pela utilidade percebida e pela facilidade percebida de uso, mas também pela percepção de risco. Esta, por sua vez, é influenciada pelo nível de confiança que o potencial usuário identifica no serviço em questão.

Desta forma, o modelo de Pavlou (2003) se diferencia do modelo de Suh e Han (2002) por apresentar a confiança como antecedente dos construtos do modelo TAM conforme é possível perceber na Figura 13.

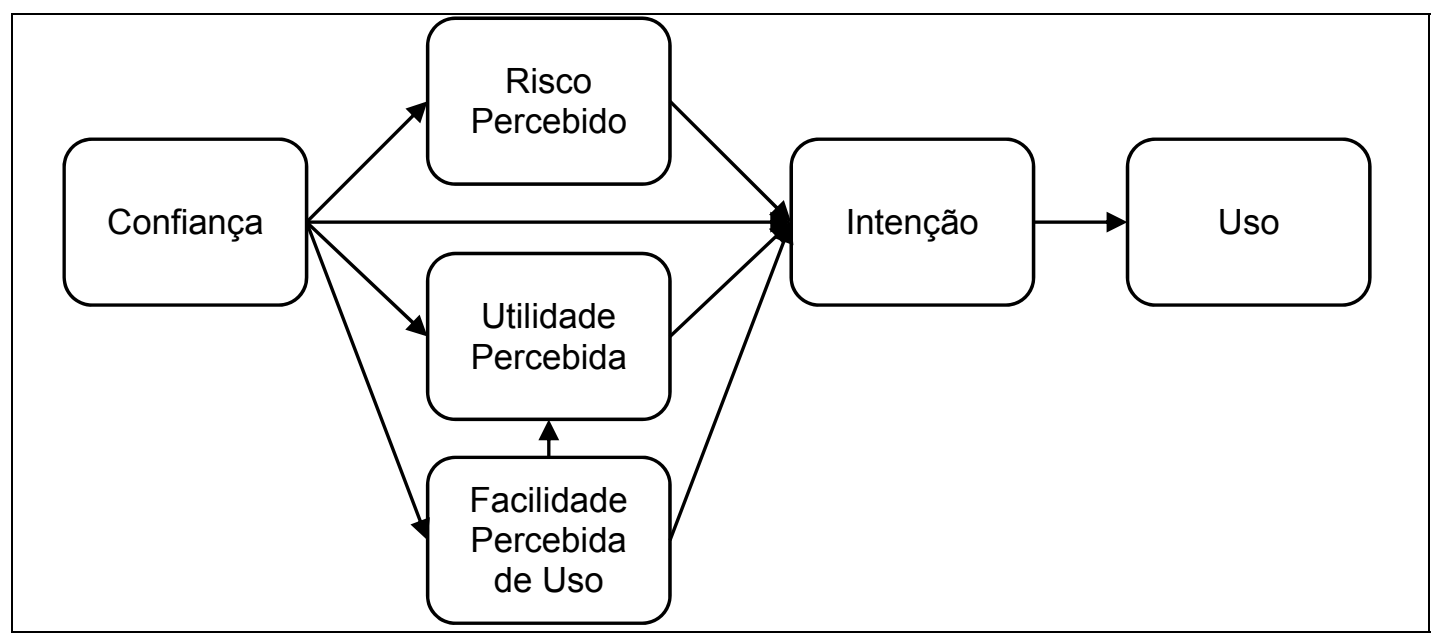

Figura 13: Fatores que influenciam a adoção de serviços de comércio eletrônico Fonte: adaptado de Pavlou (2003).

Ha e Stoel (2009) e Oh et al. (2009) também investigaram antecedentes na aceitação dos serviços de compras eletrônicas, chegando à elaboração de modelos muito semelhantes, agregando ao modelo TAM construtos não só ligados à qualidade percebida e à motivação hedônica, mas também ligados à confiança. Os dois modelos diferem basicamente pela forma de mensuração da motivação hedônica enquanto Oh et al. (2009) buscaram a mensuração do construto 
playfulness, Ha e Stoel (2009) investigaram a influência do construto enjoyment. A Figura 14 mostra uma síntese dos modelos de Ha e Stoel (2009) e Oh et al. (2009).

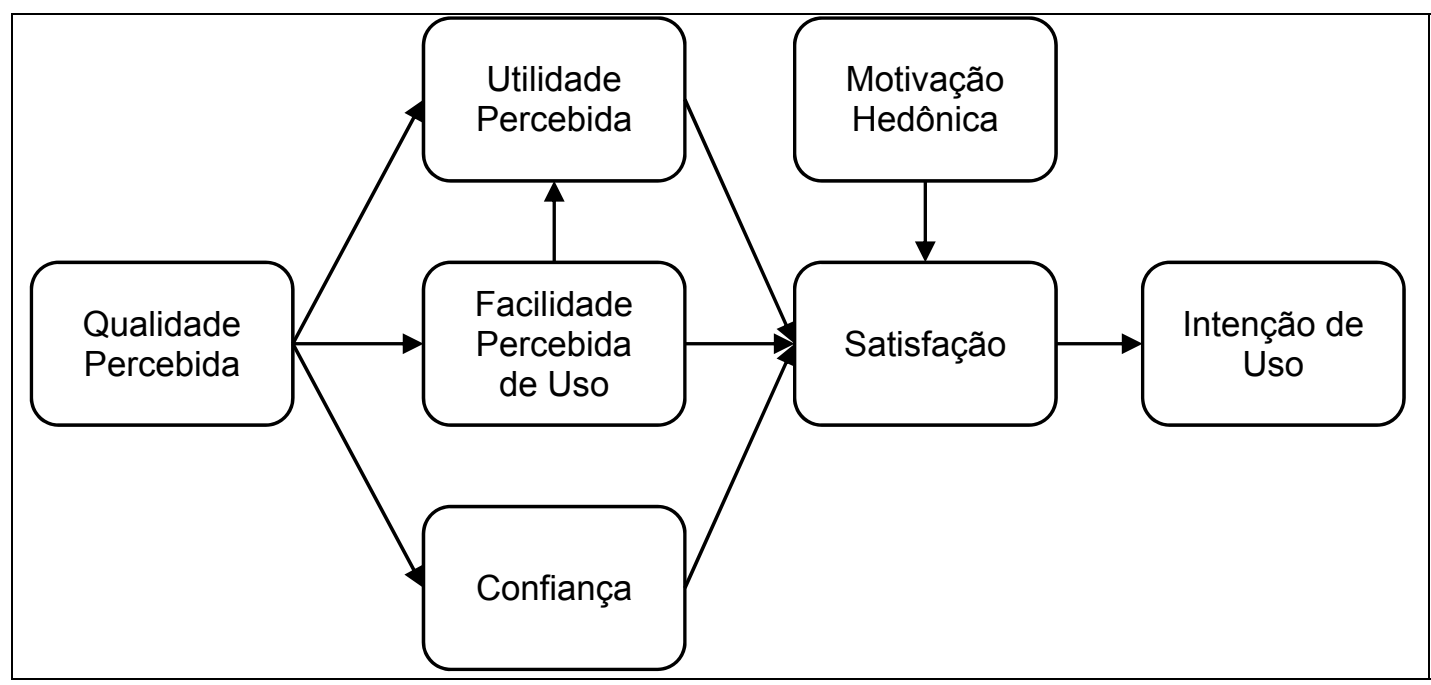

Figura 14: Influência da qualidade percebida, da confiança e da motivação hedônica na aceitação de tecnologias

Fonte: adaptado de Ha e Stoel (2009) e Oh et al. (2009).

Levando em conta o fato de que o consumo de serviços apresenta riscos de diferentes variedades e intensidades, quando comparados ao consumo de bens tangíveis em geral, Featherman, Myiazaki e Sprott (2010) examinaram formas de reduzir o risco na adoção de serviços eletrônicos que envolvam transações financeiras. Para tanto, os autores elaboraram um modelo que apresenta três componentes de segurança confiabilidade do serviço, segurança do serviço e confiabilidade / segurança da internet - como antecedentes do risco. O modelo elaborado pelos referidos autores pode ser observado na Figura 15 a seguir. 


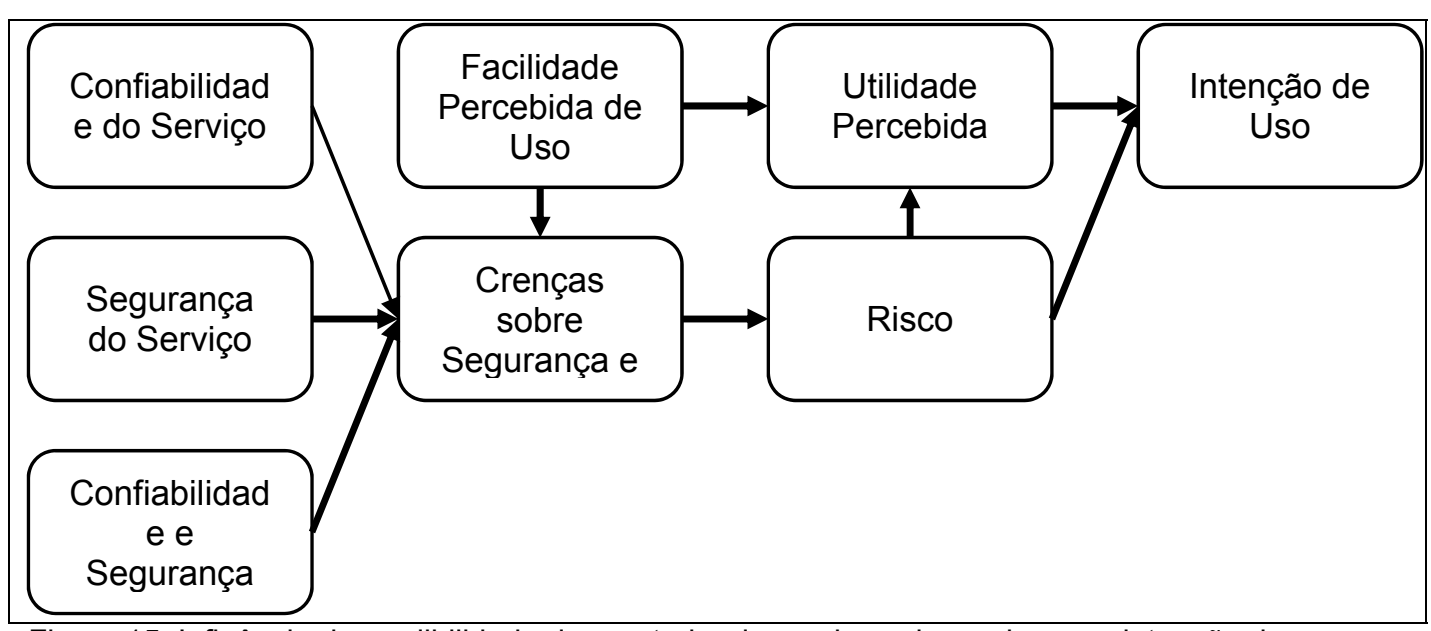

Figura 15: Influência da credibilidade do prestador de serviço sobre o risco e a intenção de uso. Fonte: adaptado de Featherman et al. (2010).

Uma vez que Featherman et al. (2010) evidenciam relações significativas entre os componentes de segurança e a percepção de risco, surge como grande implicação gerencial do referido trabalho a indicação de três componentes de segurança que podem ser controlados pelo fornecedor do serviço. Tais componente são importantes para ampliar a credibilidade da empresa e reduzir a incerteza acerca da transação financeira eletrônica.

Swilley (2010) investigou a adoção de m-payments, e seus resultados evidenciaram que apenas a percepção de risco e a percepção de segurança/privacidade influenciavam significativamente a atitude em relação à adoção deste serviço. Schierz, Schilke e Wirtz (2010) também pesquisaram sobre a adoção de m-payments, elaborando um modelo similar ao de Püschel et al. (2010), porém mais parcimonioso. Em seus resultados - ao contrário do observado na maioria dos trabalhos sobre transações eletrônicas - a percepção de segurança exerceu apenas uma leve influência sobre a atitude em relação ao uso. Neste caso, as maiores influências vieram da percepção de compatibilidade e mobilidade, além de fatores ligados à influência social. 
Bianchi e Andrews (2012) investigaram a influência do risco e da confiança sobre a intenção de uso dos serviços de compras online. Os autores encontraram evidências de que fatores culturais - como a propensão natural à confiança por um sistema social - são os componentes da confiança que mais influenciam a intenção de adoção de serviços de compras online no Chile. Zhou (2012), por sua vez, indicou que a qualidade do sistema e a experiência prévia com tecnologias similares são os fatores que exercem maior influência sobre a confiança inicial que um indivíduo sente a respeito do uso de mobile banking.

A influência da inovatividade sobre a adoção de tecnologias, por sua vez, foi evidenciada por Lee et al. (2012) e Yousafzai e Yani-de-Soriano (2012), sendo que esses últimos analisaram, na verdade, o construto prontidão para a tecnologia, enquanto moderador da facilidade percebida e da facilidade percebida de uso. Elliott, Hall e Meng (2013) também encontram evidências da prontidão para a tecnologia enquanto antecedente da confiabilidade e da motivação hedônica, ao investigar a utilização de serviços de autoatendimento.

Amaro e Duarte (2015) também encontraram evidências de que, no caso da intenção de uso de compras online de viagens, esta também sofre maior influência de PU, PEU e PC, ao passo que confiança e risco percebido exercem apenas uma pequena influência sobre a intenção de uso. Kaushik e Rahman (2015) também comprovaram a influência do risco percebido sobre a atitude, porém esta influência era muito fraca se comparada à influência exercida pela utilidade percebida sobre a atitude em relação ao uso de tecnologias de autoatendimento bancário.

Köster et al. (2016) identificaram que tanto a reputação do vendedor online quanto a reputação do prestador do serviço de pagamento móvel influenciam a intenção do consumidor em realizar a transação. No entanto, a predisposição deste em confiar em terceiros, bem como sua percepção de risco, podem exercer efeito moderador sobre a influência destas reputações sobre a adoção de m-payment. 
A intenção de adotar m-payments também pode ser influenciada pelas preocupações do indivíduo em relação à segurança, de acordo com Morosan e DeFranco (2016). Tais preocupações são expressas por meio das preocupações com a privacidade do sistema a ser utilizado para pagamentos que, por sua vez, é influenciado tanto pela preocupação com privacidade em geral quanto pela percepção de segurança pelo indivíduo.

\subsubsection{6}

Síntese da literatura investigada sobre aceitação de tecnologias no setor de serviços

É possível perceber, após revisão da literatura aplicada ao setor de serviços, que boa parte desta - principalmente no que diz respeito à aceitação de m-payments - apenas reafirmam relações já existentes. Como afirmam Dahlberg et al. (2015), por muitas vezes autores demandam o mérito da criação de modelos que já foram apresentados em pesquisas anteriores, portanto "reinventando a roda". Contudo, relações fundamentais na adoção de serviços financeiros são solenemente ignoradas em diversas pesquisas, levando a uma explicação ainda parcial do assunto.

De fato, serviços ligados à tecnologia móvel apresentam saturação quanto à influência de construtos como utilidade percebida, facilidade percebida de uso e confiança (SHAIKH; KARJALUOTO, 2015). Contudo, tanto na revisão de literatura de Shaikh e Karjaluoto (2015) quanto na realizada por Dahlberg et al. (2015), há pouca menção à investigação da prontidão para a tecnologia enquanto antecedente da intenção de uso de um serviço de pagamento móvel.

Analisando a literatura observada no referencial teórico, apenas oito trabalhos investigaram a prontidão para a tecnologia como um dos fatores que influenciam a adoção de tecnologias em serviços. Destes, seis analisaram serviços do tipo self-service, sendo que somente o trabalho de Walczuch et al. (2007) abordou a influência da prontidão para a tecnologia em um contexto de serviços financeiros. Contudo, sua pesquisa utilizou um ponto de vista organizacional, ao utilizar os funcionários da empresa prestadora de serviço como respondentes (CHEN; CHEN; CHEN, 2009; 
ELLIOTT; HALL; MENG, 2013; LILJANDER et al., 2006; LIN; SHIH; SHER, 2007; LIN; HSIEH, 2007; WALCZUCH; LEMMINK; STREUKENS, 2007).

Assim, pode-se afirmar que a influência da prontidão para a tecnologia sobre o uso de tecnologias ligadas ao setor de serviços financeiros, pela ótica do consumidor, ainda não foi investigada. Além disso é possível afirmar, ao observar a literatura analisada, que a influência da qualidade do serviço prestado, da confiança e da percepção de risco - construtos importantes ao se considerar o contexto de serviços de m-payments - ainda não foram exploradas à exaustão, permitindo a investigação de novas relações entre estes e outros fatores que afetam a adoção de tecnologias no setor de serviços de m-payments.

Baseado nesta lacuna o presente trabalho propõe um modelo que busca ampliar o conhecimento sobre a aceitação dos serviços financeiros de pagamentos móveis (m-payments). Desta forma, no próximo tópico serão apresentadas as questões de pesquisa e, em seguida, será apresentado uma proposta de modelo de prontidão e aceitação de $m$ payments.

O Quadro 2 mostra uma síntese com as pesquisas aqui descritas, contendo as relações investigadas no campo da aceitação de tecnologias aplicada ao setor de serviços. 
Quadro 2: Síntese da literatura analisada sobre aceitação de tecnologias no setor de serviços.

\begin{tabular}{|c|c|c|}
\hline Autores & Relações positivas (+) ou inversas (-) identificadas & Relações não comprovadas \\
\hline $\begin{array}{l}\text { Dishaw e } \\
\text { (1999) }\end{array}$ & $\begin{array}{ll}\text { - } & \text { Controle percebido } \rightarrow \text { Intenção }(+) \\
\text { - } & \text { Controle percebido } \rightarrow \text { Uso }(+) \\
\text { - } & \text { Facilidade Percebida de Uso } \rightarrow \text { Utilidade Percebida }(+) \\
\text { - } & \text { Utilidade Percebida } \rightarrow \text { Atitude }(+) \\
\text { - } & \text { Utilidade Percebida } \rightarrow \text { Intenção }(+) \\
\text { - } & \text { Utilidade Percebida } \rightarrow \text { Uso }(+) \\
\text { - } & \text { Atitude } \rightarrow \text { Intenção }(+) \\
\text { - } & \text { Intenção } \rightarrow \text { Uso }(+) \\
\text { - } & \text { Funcionalidade da Ferramenta } \rightarrow \text { Fac. Percebida de Uso (-) } \\
\text { - } & \text { Func. da Ferramenta } \rightarrow \text { Ajuste Tarefa-Tecnologia (+) } \\
\text { - } & \text { Experiência com a Ferramenta } \rightarrow \text { Fac. Percebida de Uso (+) } \\
\text { - } & \text { Exp. com a Ferramenta } \rightarrow \text { Utilidade Percebida (+) } \\
\text { - } & \text { Ajuste Tarefa-Tecnologia } \rightarrow \text { Fac. Percebida de Uso (+) } \\
\text { - } & \text { Ajuste Tarefa-Tecnologia } \rightarrow \text { Utilidade Percebida (-) } \\
\text { - } & \text { Características da Tarefa } \rightarrow \text { Ajuste Tarefa-Tecnologia (-) } \\
\text { - } & \text { Características da Tarefa } \rightarrow \text { Uso (-) }\end{array}$ & $\begin{array}{l}\text { - } \quad \text { Facilidade Percebida de Uso } \rightarrow \text { Atitude } \\
\text { - } \quad \text { Normas Subjetivas } \rightarrow \text { Intenção }\end{array}$ \\
\hline Venkatesh (1999) & 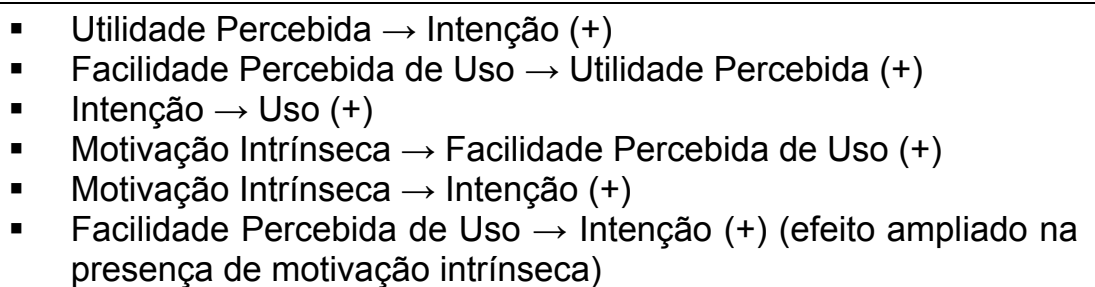 & - \\
\hline Venkatesh (2000) & 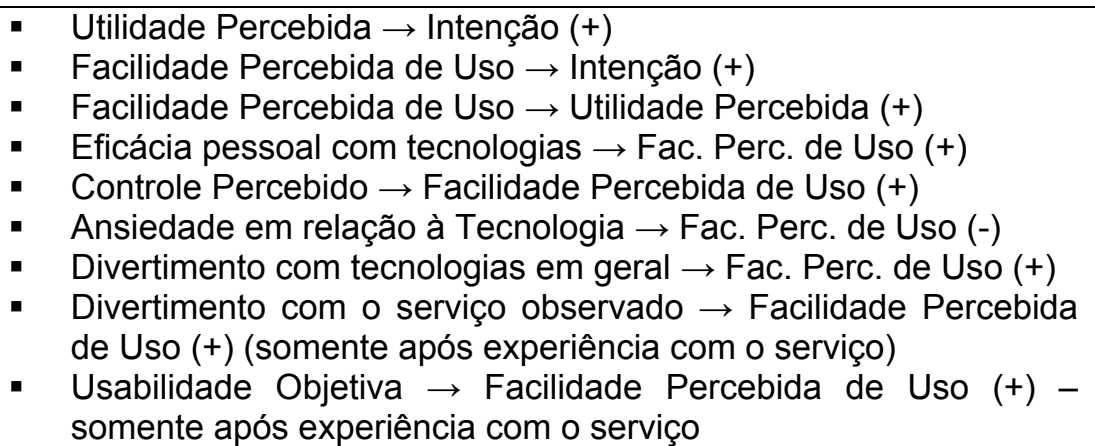 & $\begin{array}{l}\text { Divertimento com tecnologias em geral } \rightarrow \text { Facilidade } \\
\text { Percebida de Uso (+) (apenas após longa experiência } \\
\text { com o serviço) } \\
\text { Divertimento com o serviço observado } \rightarrow \text { Facilidade } \\
\text { Percebida de Uso (+) (somente antes da experiência } \\
\text { com o serviço) } \\
\text { Usabilidade Objetiva } \rightarrow \text { Facilidade Percebida de Uso } \\
(+) \text { (somente antes da experiência com o serviço) }\end{array}$ \\
\hline
\end{tabular}


Quadro 2: Síntese da literatura analisada sobre aceitação de tecnologias no setor de serviços (continuação).

\begin{tabular}{|c|c|c|}
\hline Autores & Relações positivas (+) ou inversas (-) identificadas & Relações não comprovadas \\
\hline $\begin{array}{l}\text { Parasuraman (2000) e } \\
\text { Parasuraman e Colby } \\
(2014)\end{array}$ & $\begin{array}{ll}\text { - } & \text { Otimismo } \rightarrow \text { Prontidão para a Tecnologia (+) } \\
\text { - } & \text { Inovatividade } \rightarrow \text { Prontidão para a Tecnologia (+) } \\
\text { - } & \text { Desconforto } \rightarrow \text { Prontidão para a Tecnologia (-) } \\
\text { - } & \text { Insegurança } \rightarrow \text { Prontidão para a Tecnologia (-) }\end{array}$ & - \\
\hline Childers et al. (2001) & 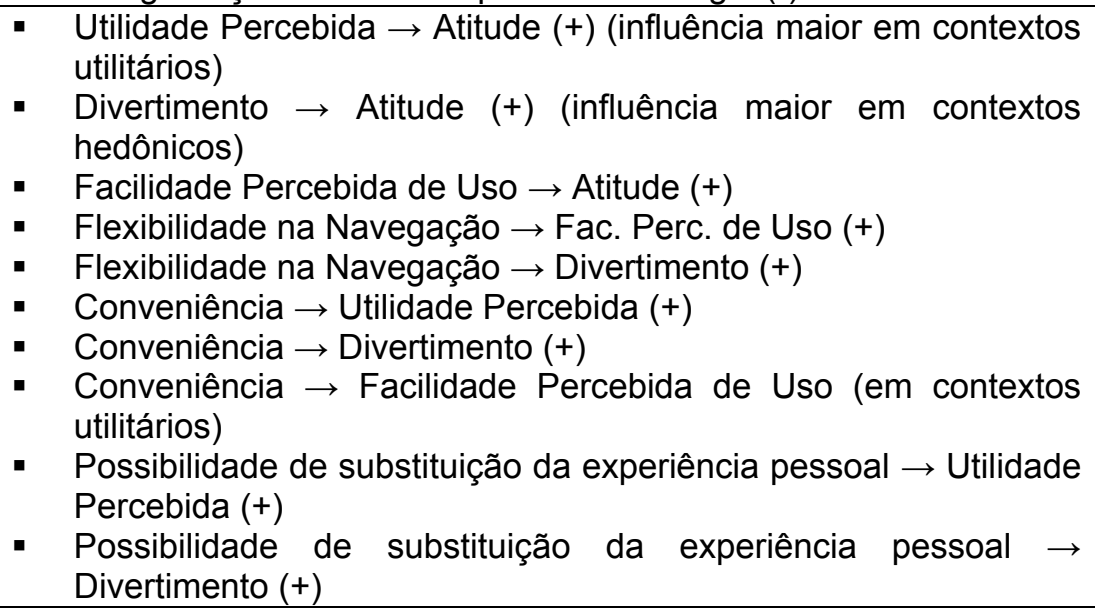 & $\begin{array}{l}\text { - Conveniência } \rightarrow \text { Facilidade Percebida de Uso (em } \\
\text { contextos hedônicos) }\end{array}$ \\
\hline Chen et al. (2002) & $\begin{array}{ll}\text { - } & \text { Intenção } \rightarrow \text { Uso }(+) \\
\text { - } & \text { Atitude } \rightarrow \text { Intenção }(+) \\
\text { - } & \text { Utilidade Percebida } \rightarrow \text { Atitude }(+) \\
\text { - } & \text { Facilidade Percebida de Uso } \rightarrow \text { Utilidade Percebida }(+) \\
\text { - } & \text { Facilidade Percebida de Uso } \rightarrow \text { Atitude }(+) \\
\text { - } & \text { Compatibilidade } \rightarrow \text { Utilidade Percebida }(+) \\
\text { - } & \text { Compatibilidade } \rightarrow \text { Atitude }(+)\end{array}$ & - Utilidade Percebida $\rightarrow$ Intenção \\
\hline Suh e Han (2002) & $\begin{array}{ll}\text { - } & \text { Confiança } \rightarrow \text { Intenção (+) } \\
\text { - } & \text { Confiança } \rightarrow \text { Atitude }(+) \\
\text { - } & \text { Utilidade Percebida } \rightarrow \text { Confiança }(+) \\
\text { - } & \text { Utilidade Percebida } \rightarrow \text { Atitude }(+) \\
\text { - } & \text { Utilidade Percebida } \rightarrow \text { Intenção }(+) \\
\text { - } & \text { Facilidade Percebida de Uso } \rightarrow \text { Utilidade Percebida }(+) \\
\text { - } & \text { Facilidade Percebida de Uso } \rightarrow \text { Atitude }(+) \\
\text { - } & \text { Atitude } \rightarrow \text { Intenção }(+) \\
\text { - } & \text { Intenção } \rightarrow \text { Uso }(+)\end{array}$ & - \\
\hline
\end{tabular}


Quadro 2: Síntese da literatura analisada sobre aceitação de tecnologias no setor de serviços (continuação).

\begin{tabular}{|c|c|c|}
\hline Autores & Relações positivas (+) ou inversas (-) identificadas & Relações não comprovadas \\
\hline Pavlou (2003) & $\begin{array}{ll}\text { - } & \text { Confiança } \rightarrow \text { Risco Percebido }(-) \\
\text { - } & \text { Confiança } \rightarrow \text { Utilidade Percebida }(+) \\
\text { - } & \text { Confiança } \rightarrow \text { Facilidade Percebida de Uso }(+) \\
\text { - } & \text { Confiança } \rightarrow \text { Intenção }(+) \\
\text { - } & \text { Risco Percebido } \rightarrow \text { Intenção }(-) \\
\text { - } & \text { Utilidade Percebida } \rightarrow \text { Intenção }(+) \\
\text { - } & \text { Facilidade Percebida de Uso } \rightarrow \text { Utilidade Percebida }(+) \\
\text { - } & \text { Intenção } \rightarrow \text { Uso }(+)\end{array}$ & - $\quad$ Facilidade Percebida de Uso $\rightarrow$ Intenção \\
\hline Gefen et al. (2003) & $\begin{array}{ll}\text { - } & \text { Facilidade Percebida de Uso } \rightarrow \text { Utilidade Percebida }(+) \\
\text { Utilidade Percebida } \rightarrow \text { Intenção }(+) \text { (efeito ampliado em } \\
\text { - } \quad \text { Fansumiliaridades frequentes) } \rightarrow \text { Facilidade Percebida de Uso }(+) \text { (efeito } \\
\text { ampliado em consumidores frequentes) } \\
\text { - } \quad \text { Familiaridade } \rightarrow \text { Intenção }(+) \\
\text { - } \text { Familiaridade } \rightarrow \text { Confiança }(+) \\
\text { - Disposição a Confiar } \rightarrow \text { Confiança }(+) \text { (efeito ampliado em } \\
\text { potenciais consumidores) } \\
\text { Confiança } \rightarrow \text { Intenção }(+) \text { (efeito ampliado em potenciais } \\
\text { consumidores) }\end{array}$ & $\begin{array}{l}\text { - Utilidade Percebida } \rightarrow \text { Intenção (somente em potenciais } \\
\text { consumidores) }\end{array}$ \\
\hline Venkatesh et al. (2003) & $\begin{array}{ll}\text { - } & \text { Expectativa de Desempenho } \rightarrow \text { Intenção }(+) \\
\text { - } & \text { Expectativa de Efeito } \rightarrow \text { Intenção }(+) \\
\text { - } & \text { Influência Social } \rightarrow \text { Intenção }(+) \\
\text { - } & \text { Condições de Facilitação } \rightarrow \text { Uso }(+) \\
\text { - } & \text { Intenção } \rightarrow \text { Uso }(+)\end{array}$ & $\begin{array}{ll}\text { - } & \text { Condições de Facilitação } \rightarrow \text { Intenção } \\
\text { - } & \text { Habilidade com tecnologias semelhantes } \rightarrow \text { Intenção } \\
\text { - } & \text { Reações emotivas com a tecnologia } \rightarrow \text { Intenção } \\
\text { - } & \text { Atitude } \rightarrow \text { Intenção }\end{array}$ \\
\hline Venkatesh et al. (2012) & $\begin{array}{ll}\text { - } & \text { Expectativa de Desempenho } \rightarrow \text { Intenção }(+) \\
\text { - } & \text { Expectativa de Efeito } \rightarrow \text { Intenção }(+) \\
\text { - } & \text { Influência Social } \rightarrow \text { Intenção }(+) \\
\text { - } & \text { Condições de Facilitação } \rightarrow \text { Intenção }(+) \\
\text { - } & \text { Motivação Hedônica } \rightarrow \text { Intenção }(+) \\
\text { - } & \text { Valor do Preço } \rightarrow \text { Intenção }(+) \\
\text { - } & \text { Hábito } \rightarrow \text { Intenção }(+) \\
\text { - } & \text { Hábito } \rightarrow \text { Uso }(+) \\
\text { - } & \text { Intenção } \rightarrow \text { Uso }(+) \\
\end{array}$ & - \\
\hline
\end{tabular}


Quadro 2: Síntese da literatura analisada sobre aceitação de tecnologias no setor de serviços (continuação).

\begin{tabular}{|c|c|c|}
\hline Autores & Relações positivas (+) ou inversas (-) identificadas & Relações não comprovadas \\
\hline Chen e Tan (2004) & $\begin{array}{ll}\text { - } & \text { Confiança percebida } \rightarrow \text { Atitude }(+) \\
\text { - } & \text { Compatibilidade } \rightarrow \text { Atitude }(+) \\
\text { - } & \text { Compatibilidade } \rightarrow \text { Utilidade Percebida }(+) \\
\text { - } & \text { Utilidade Percebida } \rightarrow \text { Atitude }(+) \\
\text { - } & \text { Utilidade Percebida } \rightarrow \text { Intenção }(+) \\
\text { - } & \text { Habilidade de Ofertar Produtos } \rightarrow \text { Utilidade Percebida }(+) \\
\text { - } & \text { Usabilidade } \rightarrow \text { Facilidade Percebida de Uso (+) } \\
\text { - } & \text { Facilidade Percebida de Uso } \rightarrow \text { Atitude }(+) \\
\text { - } & \text { Qualidade Percebida do Serviço } \rightarrow \text { Atitude }(+) \\
\text { - } & \text { Atitude } \rightarrow \text { Intenção }(+)\end{array}$ & $\begin{array}{l}\text { - } \text { Facilidade Percebida de Uso } \rightarrow \text { Utilidade Percebida } \\
\text { - } \quad \text { Riqueza da Informação } \rightarrow \text { Utilidade Percebida }\end{array}$ \\
\hline $\begin{array}{l}\text { Bruner II e Kumar } \\
(2005)\end{array}$ & $\begin{array}{ll}\text { - } & \text { Atitude } \rightarrow \text { Intenção }(+) \\
\text { - } & \text { Utilidade } \rightarrow \text { Atitude }(+) \\
\text { - } & \text { Diversão } \rightarrow \text { Atitude }(+) \\
\text { - } & \text { Facilidade de Uso } \rightarrow \text { Utilidade }(+) \\
\text { - } & \text { Facilidade de Uso } \rightarrow \text { Diversão }(+) \\
\text { - } & \text { Tipo de Orientação da Informação } \rightarrow \text { Facilidade de Uso }(+) \\
\text { - } \quad \text { Tipo de Aparelho } \rightarrow \text { Facilidade de Uso }(+) \\
\text { - } \quad \text { Tipo de Aparelho } \rightarrow \text { Diversão }(+)\end{array}$ & - \\
\hline Wu e Wang (2005) & $\begin{array}{ll}\text { - } & \text { Facilidade Percebida de Uso } \rightarrow \text { Utilidade Percebida }(+) \\
\text { - } & \text { Utilidade Percebida } \rightarrow \text { Intenção }(+) \\
\text { - } & \text { Compatibilidade } \rightarrow \text { Utilidade Percebida }(+) \\
\text { - } & \text { Compatibilidade } \rightarrow \text { Intenção }(+) \\
\text { - } & \text { Custo } \rightarrow \text { Intenção }(-) \\
\text { - } & \text { Risco Percebido } \rightarrow \text { Intenção }(+) \text { (sinal oposto ao esperado) } \\
\text { - } & \text { Intenção } \rightarrow \text { Uso }(+)\end{array}$ & - $\quad$ Facilidade Percebida de Uso $\rightarrow$ Intenção \\
\hline Yu et al. (2005) & $\begin{array}{ll}\text { - } & \text { Motivação Intrínseca } \rightarrow \text { Intenção (+) } \\
\text { - } & \text { Motivação Intrínseca } \rightarrow \text { Atitude }(+) \\
\text { - } & \text { Utilidade Percebida } \rightarrow \text { Intenção }(+) \\
\text { - } & \text { Utilidade Percebida } \rightarrow \text { Atitude }(+) \\
\text { - } & \text { Facilidade Percebida de Uso } \rightarrow \text { Utilidade Percebida }(+) \\
\text { - } & \text { Facilidade Percebida de Uso } \rightarrow \text { Atitude }(+) \\
\text { - } & \text { Confiança } \rightarrow \text { Atitude }(+) \\
\text { - } & \text { Confiança } \rightarrow \text { Intenção (+) } \\
\text { - } & \text { Crenças de Familiares e Amigos } \rightarrow \text { Norma Subjetiva }(+) \\
\text { - } & \text { Norma Subjetiva } \rightarrow \text { Intenção (+) }\end{array}$ & - \\
\hline
\end{tabular}


Quadro 2: Síntese da literatura analisada sobre aceitação de tecnologias no setor de serviços (continuação).

\begin{tabular}{|c|c|c|}
\hline Autores & Relações positivas (+) ou inversas (-) identificadas & Relações não comprovadas \\
\hline Curran e Meuter (2005) & $\begin{array}{ll}\text { - } & \text { Atitude } \rightarrow \text { Intenção }(+) \\
\text { - } & \text { Facilidade de Uso } \rightarrow \text { Atitude }(+) \text { (somente no uso de caixa } \\
\text { eletrônico) } & \\
\text { - } & \text { Utilidade } \rightarrow \text { Atitude }(+) \text { (exceto no uso de internet banking) } \\
\text { - } & \text { Risco } \rightarrow \text { Atitude }(+) \text { (somente no uso de internet banking) }\end{array}$ & $\begin{array}{l}\text { - Facilidade de Uso } \rightarrow \text { Atitude (no uso tanto de banco } \\
\text { - } \quad \text { Utilidade } \rightarrow \text { Atitude (somente no uso de internet } \\
\text { banking) } \\
\text { - Necessidade de Interação } \rightarrow \text { Atitude } \\
\text { - Risco } \rightarrow \text { Atitude (no uso tanto de caixa eletrônico } \\
\text { quanto de banco por telefone) }\end{array}$ \\
\hline Liljander et al. (2006) & $\begin{array}{l}\text { - } \quad \text { Prontidão para a Tecnologia } \rightarrow \text { Atitude }(+) \\
\text { - } \quad \text { Otimismo }(\text { TR }) \rightarrow \text { Atitude }(+) \\
\text { - } \quad \text { Otimismo e Inovatividade }(\text { TR }) \rightarrow \text { Uso }(+) \\
\text { - } \quad \text { Prontidão para a Tecnologia } \rightarrow \text { Qualidade Percebida }(+) \\
\text { - } \quad \text { Otimismo }(\text { TR }) \rightarrow \text { Qualidade Percebida }(+) \\
\text { - } \quad \text { Prontidão para a Tecnologia } \rightarrow \text { Satisfação }(+) \\
\text { - } \quad \text { Otimismo }(\text { TR }) \rightarrow \text { Satisfação }(+) \\
\text { - } \quad \text { Prontidão para a Tecnologia } \rightarrow \text { Fidelidade }(+) \\
\text { - } \quad \text { Otimismo }(\text { TR }) \rightarrow \text { Fidelidade }(+)\end{array}$ & 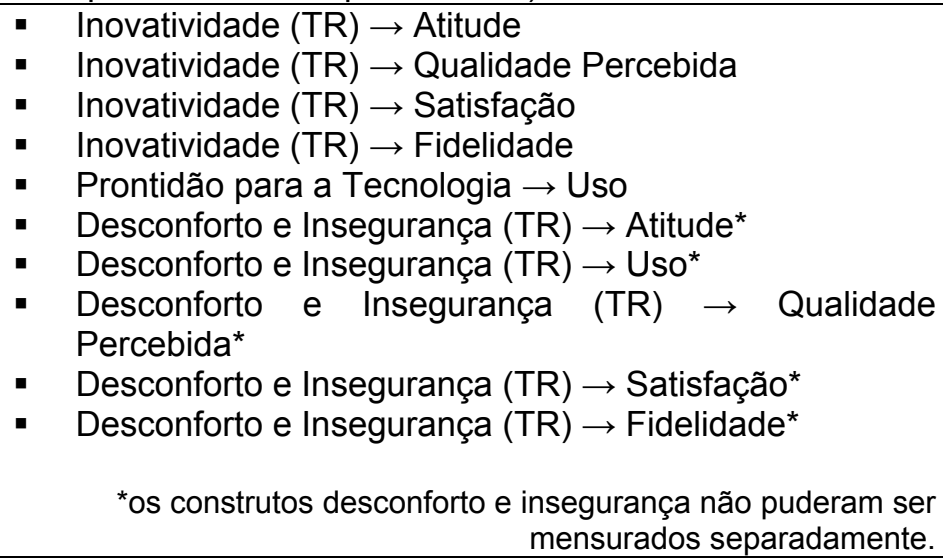 \\
\hline Lin et al. (2007) & $\begin{array}{l}\text { - } \quad \text { Prontidão para a Tecnologia } \rightarrow \text { Utilidade Percebida }(+) \\
\text { - } \quad \text { Prontidão para a Tecnologia } \rightarrow \text { Fac. Percebida de Uso }(+) \\
\text { - } \quad \text { Utilidade Percebida } \rightarrow \text { Intenção }(+) \\
\text { - } \quad \text { Facilidade Percebida de Uso } \rightarrow \text { Intenção }(+) \\
\text { - } \quad \text { Facilidade Percebida de Uso } \rightarrow \text { Utilidade Percebida }(+)\end{array}$ & - $\quad$ Prontidão para a Tecnologia $\rightarrow$ Intenção \\
\hline Walczuch et al. (2007) & $\begin{array}{ll}\text { - } & \text { Otimismo (TR) } \rightarrow \text { Facilidade de Uso (+) } \\
\text { - } & \text { Inovatividade (TR) } \rightarrow \text { Facilidade de Uso (+) } \\
\text { - } & \text { Insegurança (TR) } \rightarrow \text { Facilidade de Uso (-) } \\
\text { - } & \text { Desconforto (TR) } \rightarrow \text { Facilidade de Uso (-) } \\
\text { - } & \text { Otimismo (TR) } \rightarrow \text { Utilidade (+) } \\
\text { - } & \text { Inovatividade (TR) } \rightarrow \text { Utilidade (-) (sinal oposto ao } \\
& \text { esperado) } \\
\text { - } & \text { Insegurança (TR) } \rightarrow \text { Utilidade (-) } \\
\text { - } & \text { Desconforto (TR) } \rightarrow \text { Utilidade (-) } \\
\text { - } & \text { Facilidade de Uso } \rightarrow \text { Utilidade (+) } \\
\end{array}$ & - \\
\hline
\end{tabular}


Quadro 2: Síntese da literatura analisada sobre aceitação de tecnologias no setor de serviços (continuação).

\begin{tabular}{|c|c|c|}
\hline Autores & Relações positivas (+) ou inversas (-) identificadas & Relações não comprovadas \\
\hline Lin e Hsieh (2007) & $\begin{array}{l}\text { - } \quad \text { Prontidão para a Tecnologia } \rightarrow \text { Intenção (+) } \\
\text { - } \quad \text { Prontidão para a Tecnologia } \rightarrow \text { Satisfação }(+) \\
\text { - } \quad \text { Satisfação } \rightarrow \text { Intenção }(+)\end{array}$ & (1) s \\
\hline Lam et al. (2008) & $\begin{array}{ll}\text { - } & \text { Otimismo (TR) } \rightarrow \text { Uso (+) } \\
\text { - } & \text { Otimismo (TR) } \rightarrow \text { Variedade de Uso }(+) \\
\text { - } & \text { Inovatividade }(T R) \rightarrow \text { Uso (+) } \\
\text { - } & \text { Inovatividade }(\text { TR }) \rightarrow \text { Variedade de Uso }(+) \\
\text { - } & \text { Insegurança (TR) } \rightarrow \text { Uso (-) } \\
\text { - } & \text { Insegurança (TR) } \rightarrow \text { Variedade de Uso }(-)\end{array}$ & $\begin{array}{l}\text { - } \quad \text { Desconforto }(T R) \rightarrow \text { Uso } \\
\text { - } \quad \text { Desconforto }(T R) \rightarrow \text { Variedade de Uso }\end{array}$ \\
\hline Chen et al. (2009) & 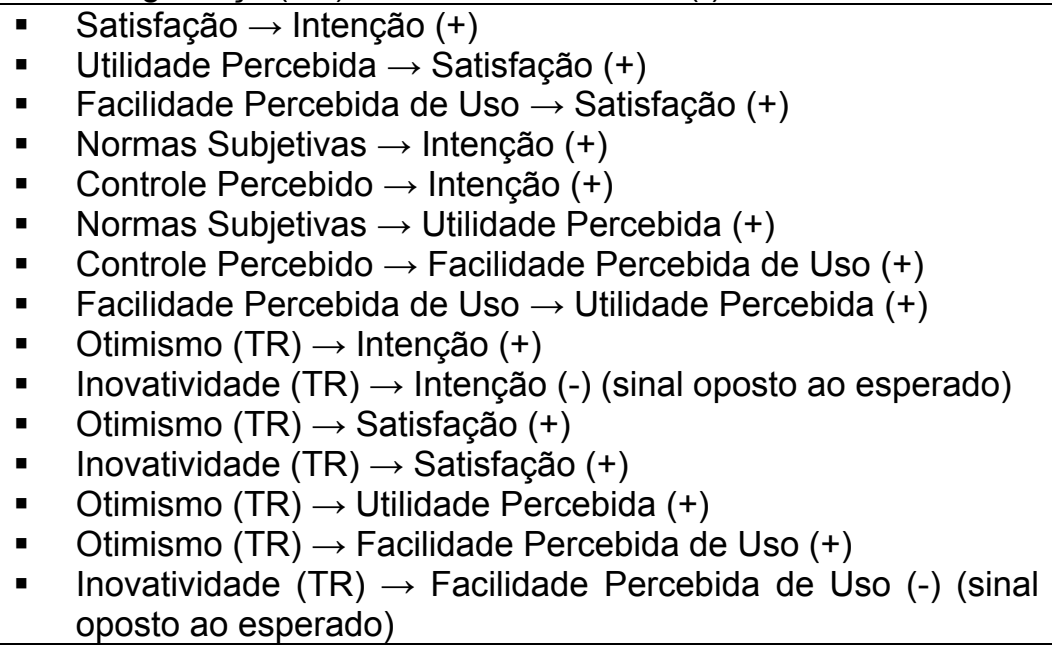 & $\begin{array}{ll}\text { - } & \text { Desconforto }(T R) \rightarrow \text { Intenção } \\
\text { - } & \text { Insegurança }(T R) \rightarrow \text { Intenção } \\
\text { - } & \text { Desconforto }(T R) \rightarrow \text { Satisfação } \\
\text { - } & \text { Insegurança }(T R) \rightarrow \text { Satisfação } \\
\text { - } & \text { Inovatividade }(T R) \rightarrow \text { Utilidade Percebida } \\
\text { - } \quad & \text { Desconforto }(T R) \rightarrow \text { Utilidade Percebida } \\
\text { - } \quad \text { Insegurança }(T R) \rightarrow \text { Utilidade Percebida } \\
\text { - } \quad \text { Desconforto }(T R) \rightarrow \text { Facilidade Percebida de Uso } \\
\text { - } \quad \text { Insegurança }(T R) \rightarrow \text { Facilidade Percebida de Uso }\end{array}$ \\
\hline Ahn et al. (2007) & $\begin{array}{ll}\text { - } & \text { Qualidade do Serviço } \rightarrow \text { Diversão }(+) \\
\text { - } & \text { Qualidade do Serviço } \rightarrow \text { Facilidade Percebida de Uso }(+) \\
\text { - } & \text { Qualidade do Serviço } \rightarrow \text { Utilidade Percebida }(+) \\
\text { - } & \text { Diversão } \rightarrow \text { Atitude }(+) \\
\text { - } & \text { Diversão } \rightarrow \text { Intenção }(+) \\
\text { - } & \text { Facilidade Percebida de Uso } \rightarrow \text { Diversão }(+) \\
\text { - } & \text { Facilidade Percebida de Uso } \rightarrow \text { Utilidade Percebida }(+) \\
\text { - } & \text { Facilidade Percebida de Uso } \rightarrow \text { Atitude }(+) \\
\text { - } & \text { Utilidade Percebida } \rightarrow \text { Atitude }(+) \\
\text { - } & \text { Utilidade Percebida } \rightarrow \text { Intenção }(+) \\
\text { - } & \text { Atitude } \rightarrow \text { Intenção }(+)\end{array}$ & - \\
\hline
\end{tabular}


Quadro 2: Síntese da literatura analisada sobre aceitação de tecnologias no setor de serviços (continuação).

\begin{tabular}{|c|c|c|}
\hline Autores & Relações positivas (+) ou inversas (-) identificadas & Relações não comprovadas \\
\hline Ha e Stoel (2009) & $\begin{array}{ll}\text { - } & \text { Qualidade do Serviço } \rightarrow \text { Confiança }(+) \\
\text { - } & \text { Qualidade do Serviço } \rightarrow \text { Facilidade de Uso }(+) \\
\text { - } & \text { Qualidade do Serviço } \rightarrow \text { Diversão }(+) \\
\text { - } & \text { Confiança } \rightarrow \text { Utilidade }(+) \\
\text { - } & \text { Confiança } \rightarrow \text { Atitude }(+) \\
\text { - } & \text { Facilidade de Uso } \rightarrow \text { Utilidade }(+) \\
\text { - } & \text { Diversão } \rightarrow \text { Utilidade }(+) \\
\text { - } & \text { Diversão } \rightarrow \text { Atitude }(+) \\
\text { - } & \text { Utilidade } \rightarrow \text { Atitude }(+) \\
\text { - } & \text { Atitude } \rightarrow \text { Intençãão }(+)\end{array}$ & - Facilidade de Uso $\rightarrow$ Atitude \\
\hline Oh et al. (2009) & $\begin{array}{ll}\text { - } & \text { Atitude } \rightarrow \text { Intenção }(+) \\
\text { - } & \text { Utilidade } \rightarrow \text { Atitude }(+) \\
\text { - } & \text { Facilidade de Uso } \rightarrow \text { Atitude }(+) \\
\text { - } & \text { Diversão } \rightarrow \text { Atitude } \\
\text { - } & \text { Confiança } \rightarrow \text { Atitude }(+) \\
\text { - } & \text { Riqueza de Informação } \rightarrow \text { Diversão }(+) \\
\text { - } & \text { Riqueza de Informação } \rightarrow \text { Utilidade }(+) \\
\text { - } & \text { Qualidade do Sistema } \rightarrow \text { Utilidade }(+) \\
& \text { Qualidade do Sistema } \rightarrow \text { Facilidade de Uso }(+)\end{array}$ & $\begin{array}{l}\text { - } \quad \text { Facilidade de Uso } \rightarrow \text { Utilidade } \\
\text { - } \quad \text { Riqueza de Informação } \rightarrow \text { Facilidade de Uso } \\
\text { - } \quad \text { Qualidade do Sistema } \rightarrow \text { Confiança }\end{array}$ \\
\hline $\begin{array}{l}\text { Dimitriadis e Kyrezis } \\
(2010)\end{array}$ & 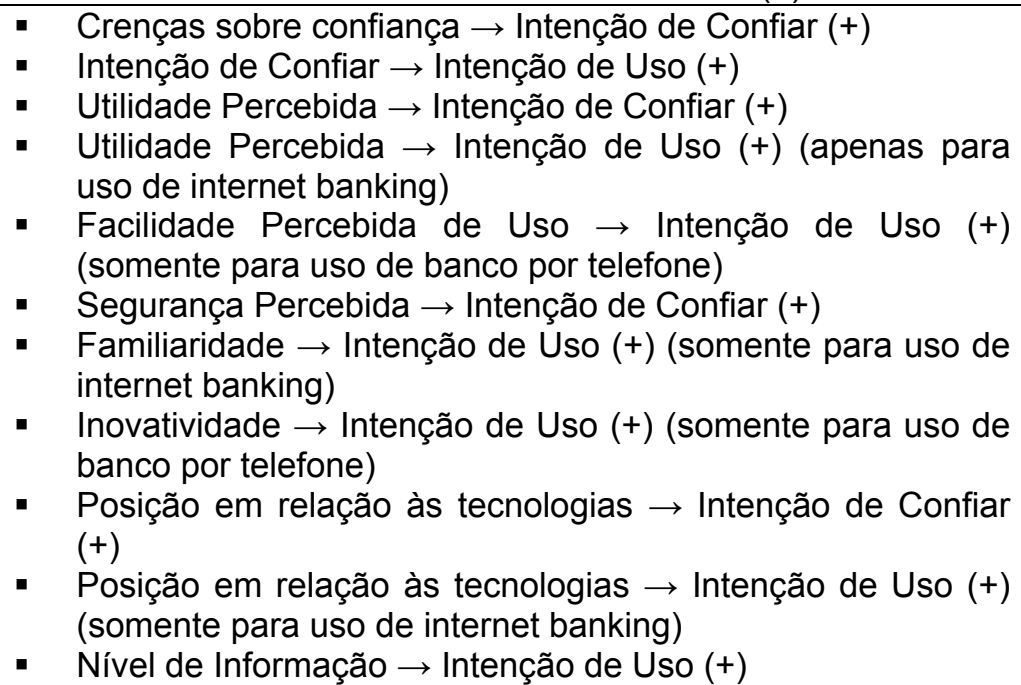 & $\begin{array}{l}\text { - Utilidade Percebida } \rightarrow \text { Intenção de Uso (somente para } \\
\text { uso de banco por telefone) } \\
\text { - } \quad \text { Facilidade Percebida de Uso } \rightarrow \text { Intenção de Confiar } \\
\text { - } \quad \text { Facilidade Percebida de Uso } \rightarrow \text { Intenção de Uso } \\
\text { (somente para uso de internet banking) } \\
\text { - } \quad \text { Segurança Percebida } \rightarrow \text { Intenção de Uso } \\
\text { - } \quad \text { Privacidade Percebida } \rightarrow \text { Intenção de Confiar } \\
\text { - } \quad \text { Privacidade Percebida } \rightarrow \text { Intenção de Uso } \\
\text { - } \quad \text { Familiaridade } \rightarrow \text { Intenção de Confiar } \\
\text { - } \quad \text { Familiaridade } \rightarrow \text { Intenção de Uso (somente para uso de } \\
\text { banco por telefone) } \\
\text { - Inovatividade } \rightarrow \text { Intenção de Confiar } \\
\text { Inovatividade } \rightarrow \text { Intenção de Uso (somente para uso de } \\
\text { internet banking) } \\
\text { Posição em relação às tecnologias } \rightarrow \text { Intenção de Uso } \\
\text { (somente para uso de banco por telefone) }\end{array}$ \\
\hline
\end{tabular}


Quadro 2: Síntese da literatura analisada sobre aceitação de tecnologias no setor de serviços (continuação).

\begin{tabular}{|c|c|c|}
\hline Autores & Relações positivas (+) ou inversas (-) identificadas & Relações não comprovadas \\
\hline Luo et al. (2010) & $\begin{array}{ll}\text { - } & \text { Expectativa de Desempenho } \rightarrow \text { Intenção (+) } \\
\text { - } & \text { Risco Percebido } \rightarrow \text { Intenção }(-) \\
\text { - } & \text { Risco Percebido } \rightarrow \text { Expectativa de Desempenho }(-) \\
\text { - } & \text { Habilidade com Tecnologias } \rightarrow \text { Estrutura de Garantia (+) } \\
\text { - } & \text { Disposição a Confiar } \rightarrow \text { Estrutura de Garantia }(+) \\
\text { - } & \text { Estrutura de Garantia } \rightarrow \text { Risco Percebido }(-)\end{array}$ & $\begin{array}{l}\text { - } \text { Crenças sobre confiança } \rightarrow \text { Intenção } \\
\text { - Crenças sobre confiança } \rightarrow \text { Expectativa de } \\
\text { Desempenho } \\
\text { - } \quad \text { Crenças sobre Confiança } \rightarrow \text { Risco Percebido } \\
\text { - } \quad \text { Habilidades com Tecnologias } \rightarrow \text { Risco Percebido }\end{array}$ \\
\hline $\begin{array}{l}\text { Featherman et al. } \\
(2010)\end{array}$ & 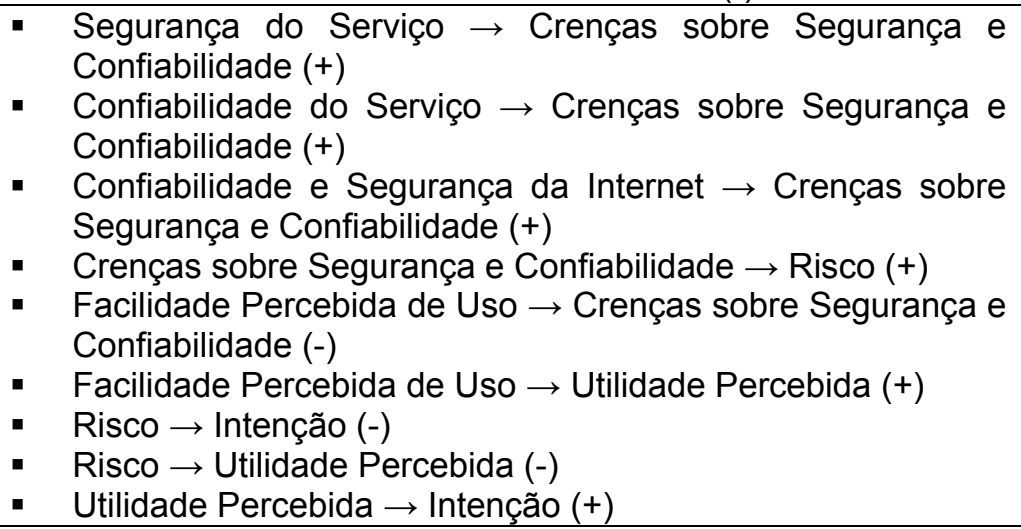 & $\begin{array}{l}\text { - } \quad \text { Facilidade Percebida de Uso } \rightarrow \text { Risco } \\
\text { - } \quad \text { Facilidade Percebida de Uso } \rightarrow \text { Intenção }\end{array}$ \\
\hline Püschel et al. (2010) & $\begin{array}{ll}\text { - } & \text { Atitude } \rightarrow \text { Intenção }(+) \\
\text { - } & \text { Condições de Facilitação Tecnológica } \rightarrow \text { Controle } \\
& \text { Percebido }(+) \\
\text { - } & \text { Habilidade com Tecnologias } \rightarrow \text { Controle Percebido }(+) \\
\text { - } & \text { Vantagem Relativa } \rightarrow \text { Atitude }(+) \\
\text { - } & \text { Compatibilidade } \rightarrow \text { Atitude }(+) \\
\text { - } & \text { Normas Subjetivas } \rightarrow \text { Intenção }(+) \\
\text { - } \quad \text { Facilidade Percebida de Uso } \rightarrow \text { Atitude (somente para } \\
\text { usuários) } \\
\text { - } \quad \text { Visibilidade } \rightarrow \text { Atitude (somente para usuários) } \\
\text { - } \quad \text { Controle Percebido } \rightarrow \text { Intenção (somente para usuários) } \\
\text { Condições de Facilitação de Recursos } \rightarrow \text { Controle } \\
\text { Percebido (somente para usuários) }\end{array}$ & $\begin{array}{l}\text { - } \quad \text { Visibilidade } \rightarrow \text { Atitude (somente para não usuários) } \\
\text { - } \quad \text { Demonstrabilidade de Resultados } \rightarrow \text { Atitude } \\
\text { - } \quad \text { Controle Percebido } \rightarrow \text { Intenção (somente para não } \\
\text { - } \quad \text { Facilios) } \\
\text { não usuários) } \\
\text { - } \quad \text { Imagem } \rightarrow \text { Atitude } \\
\text { - Possibilidade de Teste Prévio } \rightarrow \text { Atitude } \\
\text { - Condições de Facilitação de Recursos } \rightarrow \text { Controle } \\
\text { Percebido (somente para não usuários) }\end{array}$ \\
\hline
\end{tabular}


Quadro 2: Síntese da literatura analisada sobre aceitação de tecnologias no setor de serviços (continuação)

\begin{tabular}{|c|c|c|}
\hline Autores & Relações positivas (+) ou inversas (-) identificadas & Relações não comprovadas \\
\hline Swilley (2010) & $\begin{array}{ll}\text { - } & \text { Facilidade Percebida de Uso } \rightarrow \text { Utilidade Percebida }(+) \\
\text { - } & \text { Atitude } \rightarrow \text { Intenção }(-) \text { (sinal oposto ao esperado) } \\
\text { - } & \text { Risco Percebido } \rightarrow \text { Atitude }(+) \\
\text { Segurança/Privacidade } \rightarrow \text { Atitude }(-)\end{array}$ & $\begin{array}{l}\text { - } \quad \text { Facilidade Percebida de Uso } \rightarrow \text { Atitude } \\
\text { - } \quad \text { Utilidade Percebida } \rightarrow \text { Atitude } \\
\text { - } \quad \text { Normas Sociais } \rightarrow \text { Atitude } \\
\text { - Segurança/Privacidade } \rightarrow \text { Intenção }\end{array}$ \\
\hline Schierz et al. (2010) & $\begin{array}{ll}\text { - } & \text { Compatibilidade } \rightarrow \text { Utilidade Percebida }(+) \\
\text { - } & \text { Compatibilidade } \rightarrow \text { Atitude }(+) \\
\text { - } & \text { Compatibilidade } \rightarrow \text { Intenção }(+) \\
\text { - } & \text { Segurança Percebida } \rightarrow \text { Atitude }(+) \\
\text { - } & \text { Facilidade Percebida } \rightarrow \text { Atitude }(+) \\
\text { - } & \text { Facilidade Percebida de Uso } \rightarrow \text { Utilidade Percebida de Uso } \rightarrow \text { Atitude }(+) \\
\text { - } & \text { Mobilidade Individual } \rightarrow \text { Utilidade Percebida }(+) \\
\text { - } & \text { Mobilidade Individual } \rightarrow \text { Atitude }(+) \\
\text { - } & \text { Mobilidade Individual } \rightarrow \text { Intenção }(+) \\
\text { - } & \text { Normas Subjetivas } \rightarrow \text { Atitude }(+) \\
\text { - } & \text { Atitude } \rightarrow \text { Intenção }(+)\end{array}$ & 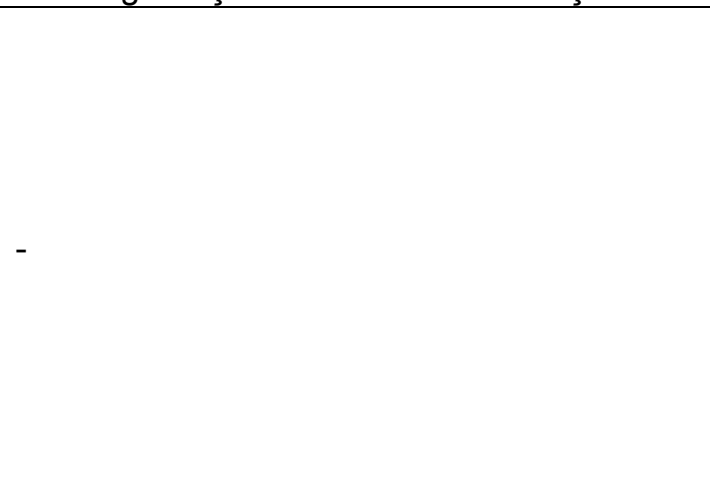 \\
\hline Kim et al. (2011) & $\begin{array}{ll}\text { - } & \text { Credibilidade } \rightarrow \text { Atitude }(+) \\
\text { - } & \text { Vantagem Relativa } \rightarrow \text { Atitude }(+) \\
\text { - } & \text { Facilidade Percebida de Uso } \rightarrow \text { Atitude }(+) \\
\text { - } & \text { Facilidade Percebida de Uso } \rightarrow \text { Vantagem Relativa }(+) \\
\text { - } & \text { Influência Social } \rightarrow \text { Normas Subjetivas }(+) \\
\text { - } & \text { Habilidade com Tecnologias } \rightarrow \text { Controle Percebido }(+) \\
\text { - } & \text { Condições de Facilitação } \rightarrow \text { Controle Percebido }(+) \\
\text { - } & \text { Atitude } \rightarrow \text { Intenção }(+) \\
\text { - } & \text { Normas Subjetivas } \rightarrow \text { Intenção }(+) \\
\text { - } & \text { Controle Percebido } \rightarrow \text { Intenção }(+) \\
\text { - } & \text { Intenção } \rightarrow \text { Uso }(+)\end{array}$ & - Custos Percebidos $\rightarrow$ Atitude \\
\hline $\begin{array}{l}\text { Bianchi e Andrews } \\
(2012)\end{array}$ & $\begin{array}{ll}\text { - } & \text { Atitude } \rightarrow \text { Intenção (+) } \\
\text { - } & \text { Risco Percebido } \rightarrow \text { Atitude }(-) \\
\text { - } & \text { Ambiente cultural de confiança } \rightarrow \text { Intenção (+) }\end{array}$ & $\begin{array}{l}\text { - } \quad \text { Confiança } \rightarrow \text { Atitude } \\
\text { - } \quad \text { Propensão a Confiar } \rightarrow \text { Intenção }\end{array}$ \\
\hline Zhou (2012) & $\begin{array}{ll}\text { - } & \text { Qualidade da Informação } \rightarrow \text { Confiança }(+) \\
\text { - } & \text { Qualidade do Sistema } \rightarrow \text { Confiança }(+) \\
\text { - } & \text { Estrutura de Garantias } \rightarrow \text { Confiança }(+) \\
\text { - } & \text { Habilidade com Tecnologias } \rightarrow \text { Confiança }(+)\end{array}$ & $\begin{array}{l}\text { - } \text { Qualidade do Serviço } \rightarrow \text { Confiança } \\
\text { - } \quad \text { Reputação } \rightarrow \text { Confiança }\end{array}$ \\
\hline
\end{tabular}


Quadro 2: Síntese da literatura analisada sobre aceitação de tecnologias no setor de serviços (continuação).

\begin{tabular}{|c|c|c|}
\hline Autores & Relações positivas (+) ou inversas (-) identificadas & Relações não comprovadas \\
\hline Jin et al. (2012) & $\begin{array}{ll}\text { - } & \text { Atitude } \rightarrow \text { Intenção }(+) \\
\text { - } & \text { Normas Subjetivas } \rightarrow \text { Intenção }(+) \\
\text { - } & \text { Controle Percebido } \rightarrow \text { Intenção }(+) \\
\text { - } & \text { Facilidade Percebida } \rightarrow \text { Atitude }(+) \\
\text { - } & \text { Pressão da Concorreberncia } \rightarrow \text { Normas Subjetivas }(+) \\
\text { - } & \text { Compatibilidade } \rightarrow \text { Controle Percebido }(+) \\
\text { - } & \text { Comprometimento de Recursos } \rightarrow \text { Controle Percebido }(+)\end{array}$ & $\begin{array}{l}\text { - } \quad \text { Pressão do Fornecedor } \rightarrow \text { Normas Subjetivas } \\
\text { - } \quad \text { Pressão do Consumidor } \rightarrow \text { Normas Subjetivas }\end{array}$ \\
\hline Yang et al. (2012) & 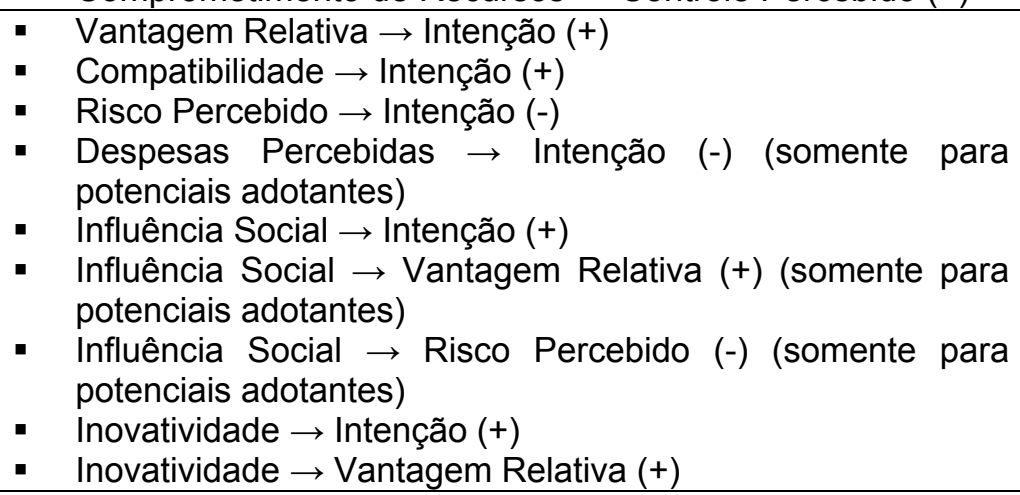 & $\begin{array}{l}\text { - Despesas Percebidas } \rightarrow \text { Intenção (-) (somente para } \\
\text { indivíduos já usuários) } \\
\text { - } \quad \text { Influência Social } \rightarrow \text { Vantagem Relativa }(+) \text { (somente } \\
\text { para indivíduos já usuários) } \\
\text { - Influência Social } \rightarrow \text { Risco Percebido (-) (somente para } \\
\text { indivíduos já usuários) } \\
\text { - Inovatividade } \rightarrow \text { Risco Percebido }\end{array}$ \\
\hline Lee et al. (2012) & $\begin{array}{ll}\text { - } & \text { Ajuste à Tarefa } \rightarrow \text { Utilidade Percebida }(+) \\
\text { - } & \text { Valor Monetário } \rightarrow \text { Utilidade Percebida }(+) \\
\text { - } & \text { Conectividade } \rightarrow \text { Facilidade Percebida de Uso }(+) \\
\text { - } & \text { Inovatividade } \rightarrow \text { Facilidade Percebida de Uso }(+) \\
\text { - } & \text { Utilidade Percebida } \rightarrow \text { Intenção }(+) \\
\text { - } & \text { Facilidade Percebida de Uso } \rightarrow \text { Intenção }(+) \\
\text { - } & \text { Capacidade de Absorção de Informação } \rightarrow \text { Intenção }(+)\end{array}$ & - \\
\hline Elliott et al. (2013) & $\begin{array}{ll}\text { - } & \text { Prontidão para a Tecnologia } \rightarrow \text { Confiabilidade }(+) \\
\text { - } & \text { Prontidão para a Tecnologia } \rightarrow \text { Diversão }(+) \\
\text { - } & \text { Confiabilidade } \rightarrow \text { Intenção }(+) \\
\text { - } & \text { Diversão } \rightarrow \text { Intenção }(+)\end{array}$ & - Prontidão para a Tecnologia $\rightarrow$ Intenção \\
\hline
\end{tabular}


Quadro 2: Síntese da literatura analisada sobre aceitação de tecnologias no setor de serviços (continuação).

\begin{tabular}{|c|c|c|}
\hline Autores & Relações positivas (+) ou inversas (-) identificadas & Relações não comprovadas \\
\hline $\begin{array}{ll}\text { Andreassen } & \text { e } \\
\text { Streukens (2013) }\end{array}$ & $\begin{array}{ll}\text { - } & \text { Facilidade de Uso } \rightarrow \text { Atitude }(+) \\
\text { - } & \text { Utilidade } \rightarrow \text { Atitude }(+) \\
\text { - } & \text { Diversão } \rightarrow \text { Atitude }(+) \\
\text { - } & \text { Busca por Interações Sociais } \rightarrow \text { Atitude }(-) \\
\text { - } & \text { Expectativas de Resultados } \rightarrow \text { Intenção }(+) \\
\text { - } & \text { Busca por Novidades } \rightarrow \text { Intenção }(+) \\
\text { - } & \text { Atitude } \rightarrow \text { Intenção }(+)\end{array}$ & $\begin{array}{l}\text { - } \quad \text { Busca por Novidades } \rightarrow \text { Atitude } \\
\text { - } \quad \text { Intensidade da Insatisfação } \rightarrow \text { Atitude } \\
\text { - } \quad \text { Expectativa de Resultados } \rightarrow \text { Atitude } \\
\text { - } \quad \text { Busca por Interações Sociais } \rightarrow \text { Intenção } \\
\text { - Intensidade da Insatisfação } \rightarrow \text { Intenção }\end{array}$ \\
\hline Ayeh et al. (2013) & $\begin{array}{ll}\text { - } & \text { Utilidade } \rightarrow \text { Atitude }(+) \\
\text { - } & \text { Utilidade } \rightarrow \text { Intenção }(+) \\
\text { - } & \text { Facilidade de Uso } \rightarrow \text { Atitude }(+) \\
\text { - } & \text { Facilidade de Uso } \rightarrow \text { Intenção }(+) \\
\text { - } & \text { Facilidade de Uso } \rightarrow \text { Utilidade }(+) \\
\text { - } & \text { Atitude } \rightarrow \text { Intenção }(+) \\
\text { - } & \text { Diversão } \rightarrow \text { Facilidade de Uso }(+) \\
\text { - } & \text { Diversão } \rightarrow \text { Atitude }(+) \\
\text { - } & \text { Diversão } \rightarrow \text { Intenção }(+) \\
\text { - } & \text { Confiabilidade } \rightarrow \text { Utilidade }(+) \\
\text { - } & \text { Confiabilidade } \rightarrow \text { Atitude }(+) \\
\text { - } & \text { Similaridade } \rightarrow \text { Confiabilidade }(+) \\
\text { - } & \text { Similaridade } \rightarrow \text { Intenção } \\
\end{array}$ & $\begin{array}{l}\text { - } \quad \text { Confiabilidade } \rightarrow \text { Intenção } \\
\text { - } \quad \text { Similaridade } \rightarrow \text { Atitude }\end{array}$ \\
\hline Gao et al. (2013) & $\begin{array}{ll}\text { - } & \text { Utilidade Percebida } \rightarrow \text { Atitude }(+) \\
\text { - } & \text { Facilidade Percebida de Uso } \rightarrow \text { Utilidade Percebida }(+) \\
\text { - } & \text { Inovatividade } \rightarrow \text { Atitude }(+) \\
\text { - } & \text { Aversão ao Risco } \rightarrow \text { Atitude }(-) \text { (somente China e Europa) } \\
\text { - } & \text { Apego } \rightarrow \text { Atitude }(+) \\
\text { - } & \text { Atitude } \rightarrow \text { Nível de Atividade no Celular }(+) \\
\text { - } & \text { Atitude } \rightarrow \text { Nível de Permissão (para receber marketing } \\
& \text { móvel) }(+)\end{array}$ & - $\quad$ Aversão ao Risco $\rightarrow$ Atitude (EUA) \\
\hline Moraes et al. (2014) & $\begin{array}{ll}\text { - } & \text { Ansiedade } \rightarrow \text { Intenção de Compra (-) } \\
\text { - } & \text { Habilidade com Celular } \rightarrow \text { Ansiedade }(-) \\
\text { - } & \text { Habilidade com Celular } \rightarrow \text { Diversão }(+) \\
\text { - } & \text { Habilidade com Celular } \rightarrow \text { Utilidade }(+) \\
\text { - } & \text { Facilidade de Acesso } \rightarrow \text { Diversão }(+) \\
\text { - } & \text { Utilidade } \rightarrow \text { Intenção de Compra }(+) \\
\text { - } & \text { Compatibilidade } \rightarrow \text { Intenção de Compra (+) }\end{array}$ & $\begin{array}{l}\text { - } \quad \text { Facilidade de Acesso } \rightarrow \text { Intenção de Compra } \\
\text { - } \quad \text { Facilidade de Acesso } \rightarrow \text { Utilidade } \\
\text { - } \quad \text { Diversão } \rightarrow \text { Intenção de Compra }\end{array}$ \\
\hline
\end{tabular}


Quadro 2: Síntese da literatura analisada sobre aceitação de tecnologias no setor de serviços (continuação)

\begin{tabular}{|c|c|c|}
\hline Autores & Relações positivas (+) ou inversas (-) identificadas & Relações não comprovadas \\
\hline Arvidsson (2014) & $\begin{array}{l}\text { - } \quad \text { Vantagem Relativa } \rightarrow \text { Atitude }(+) \\
\text { - } \quad \text { Facilidade de Uso } \rightarrow \text { Atitude }(+) \\
\text { - } \quad \text { Confiança Percebida } \rightarrow \text { Atitude }(+)\end{array}$ & $\begin{array}{ll}\text { - } & \text { Custo Percebido } \rightarrow \text { Atitude } \\
\text { - } & \text { Compatibilidade } \rightarrow \text { Atitude } \\
\text { - } & \text { Externalidades da Rede de Contatos } \rightarrow \text { Atitude } \\
\text { - } & \text { Risco Percebido } \rightarrow \text { Atitude } \\
\text { - } & \text { Idade } \rightarrow \text { Atitude } \\
\text { - } & \text { Renda } \rightarrow \text { Atitude } \\
\text { - } & \text { Frequência de Uso de Cartão de Crédito } \rightarrow \text { Atitude }\end{array}$ \\
\hline Gurtner et al. (2014) & $\begin{array}{ll}\text { - } & \text { Qualidade Percebida } \rightarrow \text { Diversão }(+) \\
\text { - } & \text { Conveniência } \rightarrow \text { Utilidade Percebida }(+) \\
\text { - } & \text { Conveniência } \rightarrow \text { Diversão }(+) \\
\text { - } & \text { Facilidade Percebida de Uso } \rightarrow \text { Utilidade Percebida }(+) \\
\text { - } & \text { Facilidade Percebida de Uso } \rightarrow \text { Diversão }(+) \\
\text { - } & \text { Facilidade Percebida de Uso } \rightarrow \text { Intenção (+) } \\
\text { - } & \text { Facilidade Percebida de Uso } \rightarrow \text { Uso (+) } \\
\text { - } & \text { Utilidade Percebida } \rightarrow \text { Intenção }(+) \\
\text { - } & \text { Diversão } \rightarrow \text { Utilidade Percebida }(+) \\
\text { - } & \text { Diversão } \rightarrow \text { Intenção (+) } \\
\text { - } & \text { Intenção } \rightarrow \text { Uso }(+)\end{array}$ & - $\quad$ Qualidade Percebida $\rightarrow$ Utilidade Percebida \\
\hline Amaro e Duarte (2015) & $\begin{array}{ll}\text { - } & \text { Confiança } \rightarrow \text { Intenção (-) (sinal oposto do esperado) } \\
\text { - } & \text { Confiança } \rightarrow \text { Atitude }(+) \\
\text { - } & \text { Confiança } \rightarrow \text { Risco Percebido }(-) \\
\text { - } & \text { Risco Percebido } \rightarrow \text { Intenção (-) } \\
\text { - } & \text { Conplexidade } \rightarrow \text { Atitude }(-) \\
\text { - } & \text { Controle Percebido } \rightarrow \text { Complexidade }(-) \\
\text { - } & \text { Vantagem Relativa } \rightarrow \text { Intenção }(+) \\
\text { - } & \text { Vantagem Relança }(+) \\
\text { - } & \text { Compatibilidade } \rightarrow \text { Atitude }(+) \\
\text { - } & \text { Compatibilidade } \rightarrow \text { Intenção }(+) \\
\text { - } & \text { Atitude } \rightarrow \text { Intenção }(+)\end{array}$ & $\begin{array}{l}\text { - } \quad \text { Risco Percebido } \rightarrow \text { Atitude } \\
\text { - } \quad \text { Comunicabilidade } \rightarrow \text { Risco Percebido } \\
\text { - } \quad \text { Comunicabilidade } \rightarrow \text { Intenção } \\
\text { - } \quad \text { Vantagem Relativa } \rightarrow \text { Intenção }\end{array}$ \\
\hline $\begin{array}{l}\text { Kaushik e Rahman } \\
(2015)\end{array}$ & $\begin{array}{ll}\text { - } & \text { Facilidade de Uso } \rightarrow \text { Atitude }(+) \\
\text { - } & \text { Utilidade Percebida } \rightarrow \text { Atitude }(+) \\
\text { - } & \text { Risco Percebido } \rightarrow \text { Atitude } \\
\text { Atitude } \rightarrow \text { Intenção }(+)\end{array}$ & $\begin{array}{l}\text { - Necessidade de Interação Social } \rightarrow \text { Atitude } \\
\text { - } \quad \text { Risco Percebido } \rightarrow \text { Atitude }\end{array}$ \\
\hline
\end{tabular}


Quadro 2: Síntese da literatura analisada sobre aceitação de tecnologias no setor de serviços (continuação).

\begin{tabular}{|c|c|c|}
\hline Autores & Relações positivas (+) ou inversas (-) identificadas & Relações não comprovadas \\
\hline Dutot (2015) & $\begin{array}{ll}\text { - } & \text { Confiança } \rightarrow \text { Utilidade Percebida }(+) \\
\text { - } & \text { Influência Social } \rightarrow \text { Utilidade Percebida }(+) \\
\text { - } & \text { Segurança } \rightarrow \text { Utilidade Percebida }(+) \\
\text { - } & \text { Segurança } \rightarrow \text { Facilidade Percebida de Uso }(+) \\
\text { - } & \text { Disponibilidade da Tecnologia } \rightarrow \text { Utilidade Percebida }(+) \\
\text { - } & \text { Facilidade Percebida de Uso } \rightarrow \text { Utilidade Percebida }(+) \\
\text { - } & \text { Facilidade Percebida de Uso } \rightarrow \text { Intenção }(+) \\
\text { - } & \text { Intenção } \rightarrow \text { Uso }(+)\end{array}$ & $\begin{array}{l}\text { - } \quad \text { Confiança } \rightarrow \text { Facilidade Percebida de Uso } \\
\text { - } \quad \text { Influência Social } \rightarrow \text { Facilidade Percebida de Uso } \\
\text { Disponibilidade da Tecnologia } \rightarrow \text { Facilidade Percebida } \\
\text { de Uso } \\
\text { - Utilidade Percebida } \rightarrow \text { Intenção }\end{array}$ \\
\hline Köster et al. (2016) & $\begin{array}{ll}\text { - } & \text { Reputação do Vendedor Online } \rightarrow \text { Risco Percebido }(-) \\
\text { - } & \text { Reputação do Vendedor Online } \rightarrow \text { Intenção }(+) \\
\text { - } & \text { Reputação do Provedor do Serviço de Pagamento } \rightarrow \text { Risco } \\
& \text { Percebido (-) } \\
\text { - } & \text { Disposição a Confiar } \rightarrow \text { Risco Percebido }(-) \\
\text { - } & \text { Disposição a Confiar } \rightarrow \text { Intenção }(+)\end{array}$ & $\begin{array}{l}\text { - Reputação do Provedor do Serviço de Pagamento } \rightarrow \\
\text { Intenção }\end{array}$ \\
\hline $\begin{array}{l}\text { Morosan e DeFranco } \\
(2016)\end{array}$ & $\begin{array}{ll}\text { - } & \text { Expectativa de Desempenho } \rightarrow \text { Intenção }(+) \\
\text { - } & \text { Influências Sociais } \rightarrow \text { Intenção }(+) \\
\text { - } & \text { Condições de Facilitação } \rightarrow \text { Intenção }(+) \\
\text { - } & \text { Motivação Hedônica } \rightarrow \text { Intenção }(+) \\
\text { - } & \text { Hábito } \rightarrow \text { Intenção }(+) \\
& \text { Preocupações com Privacidade em Geral } \rightarrow \text { Preocupações } \\
\text { - } & \text { Preocupações com Privacidade do Sistema } \rightarrow \text { Intenção (-) } \\
\text { - } & \text { Segurança Percebida } \rightarrow \text { Preocupações com Privacidade do } \\
& \text { Sistema (-) }\end{array}$ & $\begin{array}{l}\text { - } \quad \text { Expectativa de Efeito } \rightarrow \text { Intenção } \\
\text { - } \quad \text { Preocupações com Privacidade em Geral } \rightarrow \text { Intenção } \\
\text { - } \quad \text { Segurança Percebida } \rightarrow \text { Intenção }\end{array}$ \\
\hline
\end{tabular}

Fonte: Elaborado pelo Autor 


\section{4}

\section{Formulação do modelo conceitual e hipóteses de pesquisa}

Em busca de responder às questões propostas, esta pesquisa apresenta um modelo de aceitação de inovações direcionado para a aceitação de serviços de m-payments. Este modelo busca unificar os construtos cognitivos utilizados no modelo CART, de Ferreira et al. (2014) a construtos ligados à percepção de risco, qualidade e confiança, com o intuito de aprimorar a explicação acerca da adoção de serviços financeiros. Além disso, também é utilizado o construto Fruição, a fim de observar a influência da motivação intrínseca na aceitação do consumidor de serviços financeiros.

A Figura 16 apresenta o Modelo de Prontidão e Aceitação de Mobile Payments, cujos construtos, e respectivas hipóteses e justificativas para utilização são descritos a seguir.

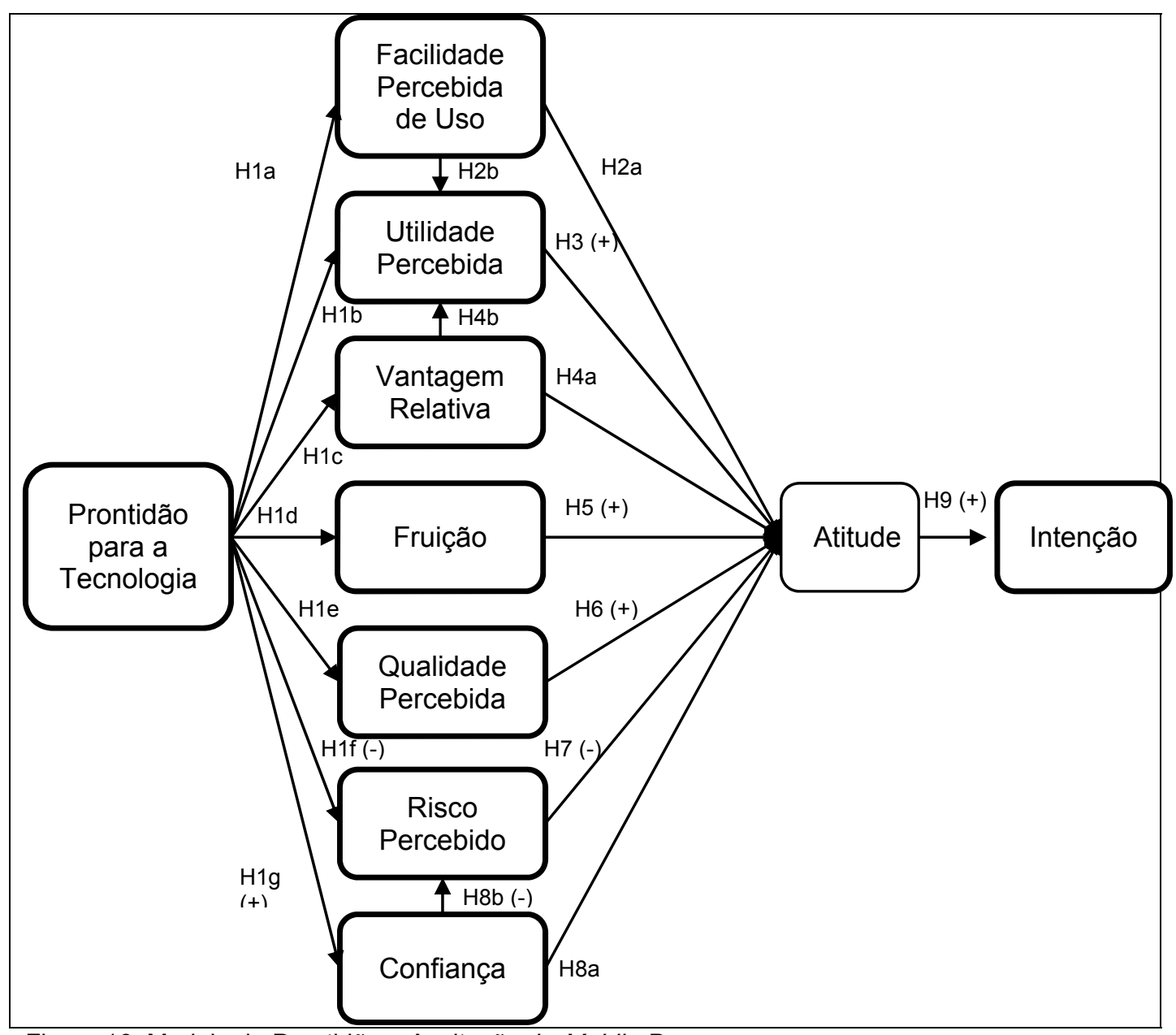

Figura 16: Modelo de Prontidão e Aceitação de Mobile Payments.

Fonte: Elaborada pelo autor. 


\subsection{1}

\section{Prontidão para a Tecnologia - TRI}

A prontidão para a tecnologia pode ser definida como o nível de propensão dos indivíduos a adotar e utilizar novas tecnologias, a fim de cumprir determinados objetivos na vida profissional e pessoal (PARASURAMAN, 2000). Tal propensão está fortemente relacionada à combinação que cada indivíduo apresenta de sentimentos positivos e negativos sobre novas tecnologias em geral.

Nesse sentido, Parasuraman (2000) apresenta quatro dimensões que permitem identificar a prontidão para a tecnologia de cada indivíduo, sendo duas dimensões estimulantes desta prontidão - otimismo e inovatividade - enquanto as outras duas dimensões - desconforto e insegurança - atuam como inibidoras. O Quadro 3 apresenta a descrição resumida de cada uma das dimensões que compõem o construto Prontidão para a Tecnologia.

Quadro 3: As quatro dimensões da Prontidão para a Tecnologia.

\begin{tabular}{|l|l|}
\hline \multicolumn{1}{|c|}{ Dimensão } & \multicolumn{1}{c|}{ Característica } \\
\hline Otimismo & $\begin{array}{l}\text { Uma visão positiva da tecnologia e uma crença de que esta } \\
\text { oferece às pessoas um aumento de controle, flexibilidade e } \\
\text { eficiência em suas vidas. }\end{array}$ \\
\hline Inovatividade & $\begin{array}{l}\text { Uma tendência de ser um pioneiro (em termos de tecnologia) } \\
\text { e um líder de opinião. }\end{array}$ \\
\hline Desconforto & $\begin{array}{l}\text { Percepção de falta de controle sobre a tecnologia e um } \\
\text { sentimento de ser oprimido por ela. }\end{array}$ \\
\hline Insegurança & $\begin{array}{l}\text { Desconfiança em relação à tecnologia e ceticismo sobre a } \\
\text { capacidade desta de funcionar adequadamente. }\end{array}$ \\
\hline
\end{tabular}

Fonte: adaptado de Parasuraman (2000).

Segundo Parasuraman e Colby (2001), o fato de as quatro dimensões da Propensão para a Tecnologia (TR) se apresentarem de forma bem distinta sugere que este construto pode ser usado como base para a segmentação de clientes. Parasuraman e Colby (2014) identificaram cinco segmentos de clientes: exploradores, pioneiros, hesitantes, resistentes e céticos. Estes segmentos apresentam certas semelhanças com as categorias definidas por Rogers (2003), e apresentam traços únicos em relação às dimensões da $T R$ (PARASURAMAN; COLBY, 2014): 
- Céticos (38\% dos consumidores): tendem a uma visão distanciada da tecnologia, com crenças positivas e negativas menos extremistas;

- Exploradores (18\% dos consumidores): alto nível de motivação e baixo nível de resistência;

- Resistentes (16\% dos consumidores): alto nível de resistência e baixo nível de motivação;

- Pioneiros (16\% dos consumidores): mantém fortes opiniões tanto positivas quanto negativas em relação à tecnologia;

- Hesitantes (13\% dos consumidores): destacam-se em função de seu baixo nível de inovatividade.

A TR apresenta forte influência sobre as respostas do consumidor diante de serviços - percepção de qualidade, satisfação e lealdade (LILJANDER et al., 2006). Consequentemente, a TR tende a apresentarse como um significativo determinante da atitude em relação ao uso de serviços financeiros. Lam et al. (2008) mostraram que a TR influencia diretamente o tempo gasto para um indivíduo adotar uma tecnologia otimismo e inovatividade reduzindo este tempo, insegurança e desconforto ampliando-o. Além disso, estes autores indicaram que, quanto maior o risco envolvido no serviço, maior será a influência da insegurança sobre o tempo de adoção.

Além disso, a TR apresenta-se como antecedente de diversos fatores responsáveis pela aceitação de tecnologias. Lin et al. (2007) indicaram que a TR pode influenciar tanto a utilidade percebida quanto a facilidade percebida de uso, os principais construtos do modelo TAM. Jin (2013) expandiu o modelo TRAM de Lin et al. (2007), ao mostrar evidências da relação entre TR e a motivação hedônica. Elliott et al. (2013), além de indicar esta última relação, ampliaram a contribuição da $T R$, indicando sua influência sobre a percepção de confiança do indivíduo.

Lin et al. (2007) e Ferreira et al. (2014) investigaram a influência da prontidão para a tecnologia sobre os construtos cognitivos do modelo TAM, sugerindo as seguintes hipóteses a serem testadas. 
H1a: A prontidão para a tecnologia possui um efeito direto e positivo sobre a percepção de facilidade de uso de tecnologias aplicadas a um serviço de m-payment.

H1b: A prontidão para a tecnologia possui um efeito direto e positivo sobre a percepção de utilidade de tecnologias aplicadas a um serviço de m-payment.

H1c: A prontidão para a tecnologia possui um efeito direto e positivo sobre a percepção de vantagem relativa de tecnologias aplicadas a um serviço de m-payment.

Diversos autores encontraram relações positivas entre a prontidão para a tecnologia e construtos de natureza emocional, como diversão, prazer e excitação (ELLIOTT; HALL; MENG, 2013; FERREIRA; ROCHA; SILVA, 2014; JIN, 2013). Diante destas evidências, esta pesquisa propõe a hipótese $\mathrm{H} 1 \mathrm{~d}$ :

H1d: A prontidão para a tecnologia possui um efeito direto e positivo sobre a fruição em relação a tecnologias aplicadas a um serviço de m-payment.

Parasuraman (2000) já sugeria uma investigação futura sobre a influência da prontidão para a tecnologia sobre a qualidade e a satisfação do consumidor. Baseados nisso, Zeithaml et al. (2002) propõem a existência de uma influência positiva da Prontidão para a Tecnologia sobre a percepção sobre a qualidade de serviços eletrônicos, mas não testam a validade desta relação. Esta relação foi confirmada, posteriormente, por Liljander et al. (2006). Diante disto, esta pesquisa propõe uma hipótese semelhante à testada por Liljander et al. (2006):

H1e: A prontidão para a tecnologia possui um efeito direto e positivo sobre a percepção de qualidade de tecnologias aplicadas a um serviço de m-payment. 
A percepção de risco já é observada por Parasuraman (2000), de forma que alguns aspectos desta percepção compõem, inclusive, o domínio da insegurança do construto da prontidão para a tecnologia (TR). A relação entre a insegurança e o risco percebido levou Liljander et al. (2006) a sugerirem uma futura pesquisa avaliando a relação entre TR e outras medidas de insegurança e percepção de risco.

Apesar de alguns autores, como Lam et al. (2008), observarem que o componente da TR referente à insegurança exerce maior influência sobre a intenção de adoção em cenários de maior risco envolvido. Contudo, levando-se em conta que o componente da insegurança é inerente ao indivíduo, é possível inferir que um maior nível de insegurança - e, portanto, uma menor TR - leva a uma maior percepção do risco envolvido. Diante disso, formula-se a seguinte hipótese:

H1f: A prontidão para a tecnologia possui um efeito direto e negativo sobre a percepção de risco em relação a tecnologias aplicadas a um serviço de m-payment.

No que diz respeito à confiança e à intenção de confiar, Elliott et al. (2013) avaliaram a influência da prontidão para a tecnologia sobre a confiança em relação a um serviço. Além disso, Koufaris e Hampton-Sosa (2004), bem como Luo et al. (2010), indicam que a intenção de confiar em um determinado produto ou serviço pode ser influenciada por uma propensão inicial a confiar, o que evidencia uma possível relação entre a prontidão para tecnologia e a confiança. Baseado nessas evidências, a pesquisa propõe a seguinte hipótese:

H1g: A prontidão para a tecnologia possui um efeito direto e positivo sobre a confiança em relação a um serviço de m-payment. 


\subsection{2}

\section{Facilidade de Uso Percebida - PEU}

A percepção de facilidade de uso indica o nível no qual o indivíduo crê que o uso da nova tecnologia não lhe demande esforços físicos ou mentais (DAVIS, 1986). Apesar de compor a maioria dos modelos de aceitação de tecnologias - assim como o construto de utilidade percebida, como visto no tópico anterior - a influência da facilidade de uso não é alvo de consenso. Após análise de diversas pesquisas que utilizaram o modelo TAM, Yousafzai et al. (2007) mostram que, se por um lado, muitos trabalhos comprovam a influência significativa de PEU sobre PU e sobre a atitude em relação ao uso, por outro lado também existem diversos trabalhos mostrando que tais relações podem não se mostrar estatisticamente significativas.

Esta falta de consenso sobre a influência de PEU pode ser justificada pelos múltiplos contextos onde ela é aplicada. Segundo Hess et al (2014), o potencial de confiabilidade da PEU varia de acordo com o propósito da tecnologia estudada, sendo considerada um construto mais confiável em contextos utilitários do que em contextos hedônicos.

Kulviwat et al. (2007) e Ferreira et al. (2014) analisaram as relações previamente estabelecidas por Davis et al. (1989), de forma que são apresentadas as seguintes hipóteses:

H2a: A percepção da facilidade de uso possui um efeito direto e positivo sobre a percepção de utilidade de tecnologias aplicadas a um serviço de m-payment.

H2b: A percepção de facilidade de uso possui um efeito direto e positivo sobre a atitude em relação ao uso de tecnologias aplicadas a um serviço de m-payment. 


\subsection{3}

\section{Utilidade Percebida - PU}

A utilidade percebida indica o nível no qual o indivíduo acredita que o uso de uma nova tecnologia aprimorará sua performance na execução de determinadas atividades (DAVIS; BAGOZZI; WARSHAW, 1989). Apesar de definido incialmente, para contextos organizacionais, o construto utilidade percebida passou a ser amplamente utilizado também em contextos não-organizacionais, sendo considerado um determinante chave para a aceitação de tecnologias (YOUSAFZAl; FOXALL; PALLISTER, 2007).

A utilidade percebida apresenta-se como um determinante chave para a aceitação de tecnologias, sendo frequentemente apresentado como o elemento mais importante do modelo TAM (SHAIKH; KARJALUOTO, 2015; YOUSAFZAI; FOXALL; PALLISTER, 2007). Dahlberg et al. (2015) indica que PU e PEU são os construtos mais utilizados nas pesquisas sobre $m$-payments, o que não surpreende, posto que o modelo TAM já foi mencionado mais de 2400 vezes em diversas pesquisas (HESS; MCNAB; BASOGLU, 2014). Com base nisto, a seguinte hipótese é apresentada:

H3: A percepção de utilidade possui um efeito direto e positivo sobre a atitude em relação ao uso de tecnologias aplicadas a um serviço de m-payment.

\subsection{4}

\section{Vantagem Relativa - RA}

Conforme abordado na revisão sobre a Teoria de Difusão de Inovações de Rogers (2003), a vantagem relativa expressa o nível no qual uma determinada inovação é percebida como sendo superior, após comparação em relação à ideia a ser sucedida. Desta forma, quanto maior a percepção de vantagem relativa, maior será a intenção de adotar a tecnologia em questão. 
De caráter essencialmente cognitivo, o construto de vantagem relativa tende a refletir a análise comparativa do indivíduo entre a tecnologia usada atualmente e a inovação que eventualmente a sucederá, em termos de custos e benefícios esperados. Tal análise de custobenefício pode levar em conta fatores econômicos ou sociais, entre outros (ROGERS, 2003).

Hameed e Counsell (2014) indicam que a vantagem relativa é dos fatores de maior influência na adoção de novas tecnologias, justamente por sua característica de avaliação em termos de custos e benefícios. Os referidos autores também indicam que frequentemente o construto de vantagem relativa é apresentado sob o nome de benefícios percebidos.

Desta forma, são apresentadas as seguintes hipóteses:

H4a: A percepção de vantagem relativa possui um efeito direto e positivo sobre a percepção de utilidade de tecnologias aplicadas a um serviço de m-payment.

H4b: A percepção de vantagem relativa possui um efeito direto $e$ positivo sobre a atitude em relação ao uso de tecnologias aplicadas a um serviço de m-payment.

\subsection{5}

\section{Fruição - ENJ}

A motivação intrínseca, segundo Venkatesh e Spier (1999, p. 2), se refere ao "prazer e inerente satisfação derivados de uma atividade específica". Nesse sentido, a motivação intrínseca é um importante componente do comportamento do consumidor, no que tange à aceitação de tecnologias e, nesse sentido, o uso do construto no presente modelo busca identificar os aspectos emotivos que levam o indivíduo a adotar um serviço financeiro, apenas pela experiência em si.

No entanto, existem diferentes construtos na literatura que buscam mensurar a influência da motivação intrínseca - playfulness, pleasure e enjoyment, entre outros - cabendo aqui uma tentativa de esclarecimento sobre a diversidade de conceitos. 
Tal necessidade se deve ao fato de serem observadas, na literatura, inúmeras ocorrências de discrepância entre a nomenclatura do construto e sua respectiva definição, conforme se pode observar em Igbaria et al. (1995), Oh et al. (2009) e Lin et al (2005), entre outros. Contudo, ao longo da tentativa de diferenciação a seguir, os referidos construtos foram mencionados no idioma original (inglês), devido ao fato da língua portuguesa permitir a tradução destes como sinônimos.

Venkatesh (2000) tentou, em sua pesquisa, diferenciar playfulness e enjoyment. Para ele, playfulness é uma forma de motivação intrínseca que não é inerente à inovação em questão, por se tratar do "nível de espontaneidade cognitiva" nas interações com a inovação a ser avaliada (VENKATESH, 2000, p. 348). Ainda segundo o autor, indivíduos com maior nível de playfulness tendem a subestimar eventuais dificuldades na adoção de uma inovação, pois tendem a apreciar mais o processo de aprendizagem e acabam por considerar tal processo não tão penoso quanto indivíduos com menor nível de playfulness.

Por outro lado, Venkatesh (2000) identifica enjoyment como sendo uma dimensão inerente à inovação, ao retomar a definição de Davis et al. (1992), na qual enjoyment é o nível no qual uma atividade é percebida como prazerosa por si só, independentemente de quaisquer consequência, em termos de desempenho.

É possível perceber que o conceito de playfulness apresentado por Venkatesh (2000) é muito semelhante a conceitos ligados à inovatividade e à curiosidade em $\mathrm{si}$, posto que, de acordo com o autor, à medida em que o indivíduo adquire experiência de uso com a tecnologia, a influência de playfulness se reduz e a influência de enjoyment sobre a intenção de continuação de uso aumenta. Ainda segundo as descrições supracitadas, conclui-se que o conceito de enjoyment de Davis et al. (1992) apresentase de forma muito similar ao conceito da própria motivação intrínseca. 
Segundo o Oxford Learner's Dictionary (2015), também podem existir diferenças entre pleasure e enjoyment, de acordo com a forma de interpretação. Se, por um lado, enjoyment é definido como "o prazer obtido com alguma coisa", indicando a equivalência dos conceitos, o conceito de pleasure mostra-se mais amplo, ao ser definido como "um estado de se sentir ou estar feliz ou satisfeito". Blythe e Hassenzahl (2003) corroboram esta definição, indicando que pleasure, na verdade, é uma forma profunda de enjoyment quase nunca alcançada, por se tratar do auge de uma experiência de total absorção pela atividade em questão. Mehrabian e Russel (1974) também indicam esta diferenciação, conceituando pleasure como sendo um amplo nível de enjoyment e gratificação.

Com isto, pode-se entender que pleasure deveria compreender um estado de sentimento mais amplo, que não depende necessariamente de nenhuma habilidade específica para executar tarefa alguma, ao passo que enjoyment, por depender da execução de alguma atividade, pode ser condicionado à dependência de um nível mínimo de habilidade necessária.

Entretanto, após tais considerações, conclui-se que o conceito de enjoyment mostra-se como o mais adequado para esta pesquisa uma vez que, de acordo com Davis et al. (1992) e Venkatesh et al. (2003), ele se apresenta como o de maior similaridade ao conceito de motivação intrínseca. Na língua portuguesa, o conceito que mais se aproxima de enjoyment é o conceito de fruição que, segundo o Dicionário Michaelis (2016), significa ato ou efeito de desfrutar.

Partindo desta definição, portanto, a presente pesquisa apresenta a seguinte hipótese:

H5: A fruição possui um efeito direto e positivo sobre a atitude em relação ao uso de tecnologias aplicadas a um serviço de $\mathrm{m}$ payment. 


\subsection{6}

\section{Qualidade Percebida - PQ}

A percepção de qualidade necessita ser discutida de forma distinta quando aplicada ao contexto dos serviços, assim como seu conceito em si. Parasuraman et al. (1985) indicam que as características únicas dos serviços devem ser levadas em conta no processo de compreensão da qualidade em serviços, pois estas tornam o processo de percepção e avaliação de qualidade em serviços mais complexo em relação aos mesmos processos para bens tangíveis. Com isso, identificaram alguns fatores determinantes da percepção da qualidade em serviços (PARASURAMAN; ZEITHAML; BERRY, 1988).

Segundo Parasuraman et al. (1988), por qualidade percebida do serviço entende-se o julgamento do consumidor em relação à excelência geral de um serviço, sob a forma de uma atitude resultante da comparação entre expectativas e desempenho. Em busca de mensurar tal percepção por parte do consumidor, os autores elaboraram a escala SERVQUAL, composta de dois conjuntos de 22 itens que refletiam cinco potenciais dimensões da qualidade de um serviço, que estão dispostas no Quadro 4 a seguir.

Quadro 4: Potenciais dimensões da qualidade de um serviço.

\begin{tabular}{|c|c|}
\hline $\begin{array}{l}\text { Dimensões da } \\
\text { SERVQUAL }\end{array}$ & Descrição \\
\hline Aspectos tangíveis & Facilidades físicas, equipamentos e aparência do pessoal \\
\hline Confiabilidade & $\begin{array}{l}\text { Habilidade de executar o serviço prometido de forma } \\
\text { precisa }\end{array}$ \\
\hline Responsividade & $\begin{array}{l}\text { Boa vontade em ajudar e fornecer um serviço rápido aos } \\
\text { clientes }\end{array}$ \\
\hline Segurança & $\begin{array}{c}\text { Conhecimento, cortesia e habilidade dos funcionários em } \\
\text { inspirar confiança }\end{array}$ \\
\hline Empatia & Atenção individualizada aos clientes \\
\hline
\end{tabular}

Fonte: adaptado de Parasuraman et al. (1988). 
Cronin Jr. e Taylor (1992), adaptaram a escala SERVQUAL, de forma que a mesma não se baseasse mais no gap entre expectativa e desempenho, passando a se basear somente no desempenho. Assim, os autores reduziram a escala em $50 \%$, usando apenas um conjunto de 22 itens, e a renomearam como SERVPERF. Além disso, os autores indicam que a percepção de qualidade é um antecedente da satisfação que, por sua vez, exerce elevada influência sobre a intenção de compra do consumidor.

O trabalho de Cronin Jr. e Taylor (1992) iniciou o debate sobre a necessidade de se mensurar as expectativas na análise de percepção de qualidade. Parasuraman et al. (1994) apresentaram argumentos sustentando a significância estatística e a importância prática de analisar a questão das expectativas na avaliação da qualidade do serviço, enquanto Schembri e Sandberg (2011) indicam que outros autores também defendem a posição de Cronin Jr. e Taylor (1992) de que os modelos baseados na não-confirmação das expectativas são inadequados.

Quanto às dimensões que compõem a percepção de qualidade, Brady e Cronin Jr. (2001) sugerem que pesquisas indicam de três a dez diferentes dimensões para a percepção de qualidade do serviço. Para manter a parcimônia do modelo conceitual, esta pesquisa adotará a definição de Shih (2004) que define a percepção de qualidade em três dimensões: qualidade percebida da informação, qualidade percebida do sistema em si e qualidade percebida do serviço.

A percepção da qualidade da informação avalia o efeito do uso de fontes de informação, quando consumidores e firmas trocam e compartilham informações durante as transações em lojas virtuais. A qualidade percebida do sistema, por sua vez, diz respeito às percepções quanto às características do sistema de informação em si. Por fim, a percepção da qualidade do serviço é apresentada nos mesmos moldes teóricos propostos por Parasuraman et al. (1988), porém contextualizada ao uso de websites (SHIH, 2004). 
A influência da percepção da qualidade sobre a intenção de uso foi investigada por diversos autores que, no entanto, investigaram sua influência indireta - analisando a influência da percepção da qualidade sobre os construtos cognitivos do modelo TAM (CHANG et al., 2012; PAl; HUANG, 2011). No entanto, Shih (2004) indica a existência da relação direta entre percepção de qualidade e atitude em relação ao uso, de forma que a presente pesquisa propõe a seguinte hipótese:

H6: A percepção da qualidade possui um efeito direto e positivo sobre a atitude em relação ao uso de tecnologias aplicadas a um serviço de m-payment.

\subsection{7 \\ Risco Percebido - PR}

A literatura relacionando a percepção de risco à intenção de adoção não é recente. Popielarz (1967) já buscava diferenciar a intenção de experimentar novos produtos, de acordo com diferentes formas de risco. Segundo o autor, indivíduos com maior propensão a adquirir novos produtos preferem o erro por ação - adquirir e não ficar satisfeito - do que o erro por omissão - não adquirir para não correr o risco de arrepender.

Roselius (1971), investigando eventuais estratégias para o consumidor reduzir o risco envolvido em uma compra, estratificou o risco em quatro grandes categorias de perda: perda de tempo, perda de saúde (ou de segurança), perda de ego e perda financeira, que foram respectivamente definidos no

Quadro 5.

Quadro 5: Tipos de Perda

\begin{tabular}{|c|l|}
\hline $\begin{array}{c}\text { Categoria de } \\
\text { Perda }\end{array}$ & \multicolumn{1}{c|}{ Descrição } \\
\hline Perda de tempo & $\begin{array}{l}\text { Quando ocorre a falha de algum produto, há a perda de tempo, } \\
\text { conveniência e esforço para reparar, ajustar ou repor o produto em } \\
\text { questão. }\end{array}$ \\
\hline $\begin{array}{c}\text { Perda de saúde } \\
\text { ou de segurança }\end{array}$ & $\begin{array}{l}\text { Alguns produtos, ao falhar, colocam em risco a saúde ou a } \\
\text { segurança do usuário. }\end{array}$ \\
\hline Perda de ego & $\begin{array}{l}\text { Ao adquirir um produto que se mostra defeituoso, o consumidor } \\
\text { pode se sentir tolo, ou outras pessoas podem fazê-lo se sentir } \\
\text { desta forma. }\end{array}$ \\
\hline Perda financeira & $\begin{array}{l}\text { Diante da falha de um produto, o consumidor pode perder recursos } \\
\text { a fim de fazer o produto funcionar corretamente, ou para substituí- } \\
\text { lo por um produto satisfatório. }\end{array}$ \\
\hline
\end{tabular}


Fonte: adaptado de Roselius (1971).

Ram e Sheth (1989) identificaram a percepção de risco como um dos empecilhos à adoção de inovações. Segundo os mesmos, todas as inovações representam algum nível de incerteza e potenciais efeitos colaterais que não podem ser antecipados. Em função deste risco, clientes podem resistir à adoção, postergando a tomada de decisão - até que novas informações reduzam a incerteza - ou até mesmo decidindo por não adotar definitivamente a inovação.

Em busca de aprofundar a discussão sobre as influências do risco sobre a adoção de inovações, Ram e Sheth (1989) identificam quatro diferentes tipos de risco, conforme a Quadro 6 a seguir.

Quadro 6: Tipos de Risco

\begin{tabular}{|c|l|}
\hline $\begin{array}{c}\text { Categoria de } \\
\text { Risco }\end{array}$ & \multicolumn{1}{c|}{ Descrição } \\
\hline Risco Físico & $\begin{array}{l}\text { A inovação pode oferecer risco à saúde ou à segurança de um } \\
\text { consumidor. }\end{array}$ \\
\hline Risco Econômico & $\begin{array}{l}\text { Quanto maior o custo de uma inovação, maior o risco econômico } \\
\text { percebido. Este risco é particularmente significante ao se analisar } \\
\text { produtos baseados em tecnologias totalmente inovadoras. }\end{array}$ \\
\hline Risco Funcional & $\begin{array}{l}\text { A incerteza acerca do desempenho de uma inovação e da } \\
\text { possibilidade de falhas da mesma pode levar os consumidores a } \\
\text { adiar a decisão de adotar a inovação, até que novas informações } \\
\text { reduzam esta incerteza. }\end{array}$ \\
\hline Risco Social & $\begin{array}{l}\text { Consumidores podem resistir a uma inovação em função da } \\
\text { reação de seu círculo social. }\end{array}$ \\
\hline
\end{tabular}

Fonte: adaptado de Ram e Sheth (1989).

Especificamente no caso da percepção de risco em serviços, Laroche et al. (2004) indicam que o nível de intangibilidade dos mesmos influencia significativamente a percepção de risco, em função da dificuldade do consumidor em mentalizar e descrever com precisão o serviço em questão.

Em termos de reações diante da percepção do risco. Slovic e Peters (2006), partindo da premissa que o indivíduo absorve a realidade à sua volta de duas maneiras distintas - uma intuitiva e natural, e outra analítica e deliberativa - indicam que o risco é percebido de ambas as formas. A percepção afetiva do risco diz respeito à reação intuitiva ao perigo, 
enquanto a percepção analítica avalia a relação entre risco e benefício, para uma eventual tomada de decisão.

Além disso, é possível identificar que os diferentes tipos de risco geram diferentes respostas no consumidor. De acordo com Hirunyawipada e Paswan (2006), o risco percebido pode não afetar o comportamento de adoção, mas levar o consumidor a buscar maiores informações sobre a inovação, levando ou não a uma adoção posterior. Klerck e Sweeney (2007) indicaram, por sua vez, que enquanto o risco de desempenho (funcional) influencia a propensão pela busca de maiores informações, o risco psicológico (perda de ego) influencia tanto a propensão de adoção quanto a propensão de busca por maiores informações.

Posteriormente, Kleijnen et al. (2009) aprofundam a questão das diferentes reações diante de diferentes tipos de risco, ao mostrar que o adiamento da tomada de decisão quanto à adoção é influenciado, entre outros fatores, pelo risco econômico. Além disso, o risco econômico juntamente com o risco funcional e o social - influenciam a rejeição a uma inovação. Por fim, os autores identificaram que a total oposição a uma inovação pode ser influenciada pela percepção dos riscos físicos, funcionais e sociais.

Crespo et al. (2009) expandiram a definição de percepção de risco com a integração de 6 fatores, unindo os conceitos de Roselius (1971) de risco de tempo, risco psicológico (perda de ego) e risco financeiro, aos conceitos de Ram e Sheth (1989) de risco de desempenho e risco social. Além disso, Crespo et al. (2009) adicionaram o conceito de risco de privacidade, que diz respeito à percepção de potencial perda de controle sobre informações pessoais ou do uso destas sem a devida permissão. A Figura 17 mostra os tipos de risco percebido, de acordo com estes autores. 


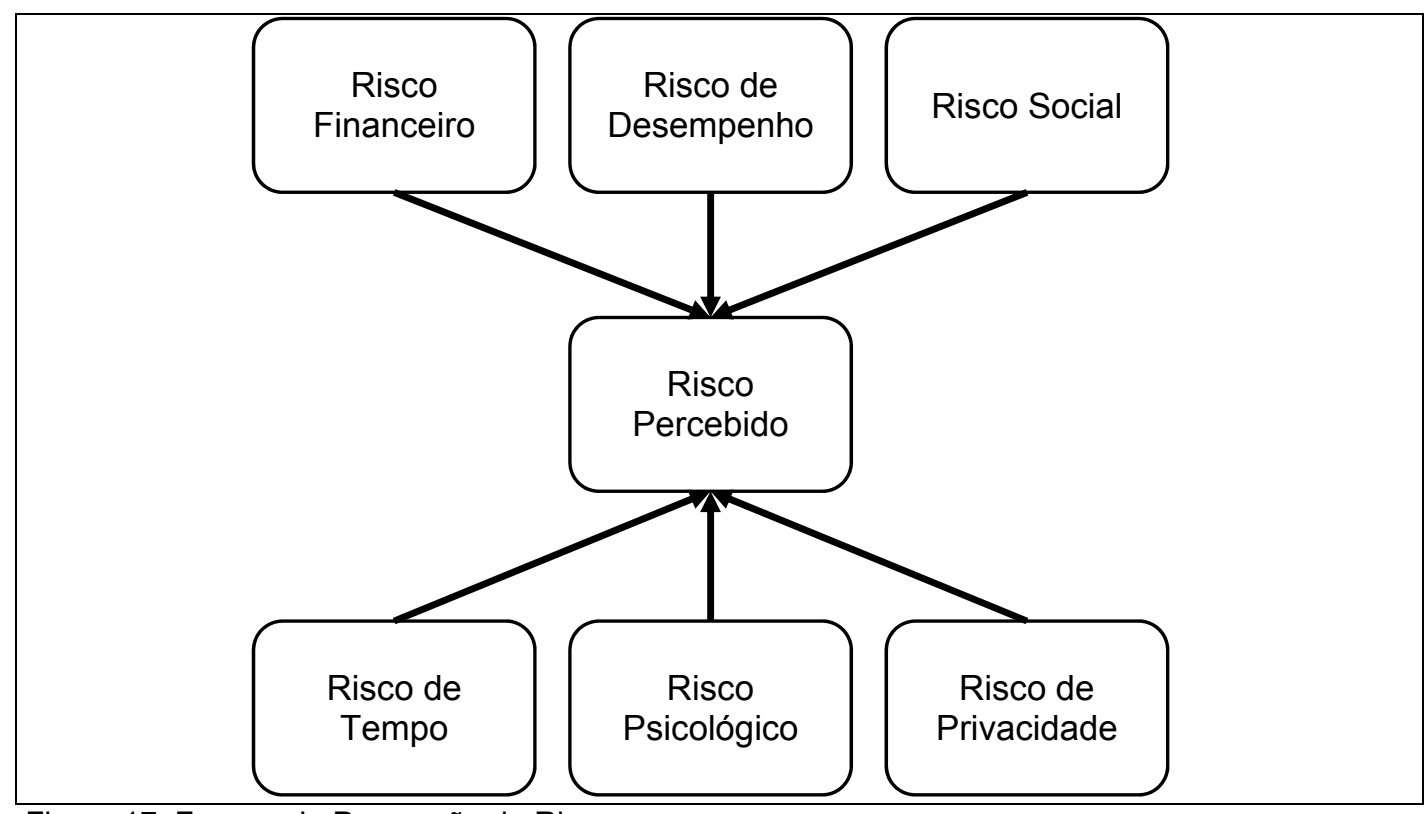

Figura 17: Formas de Percepção de Risco

Fonte: adaptado de Crespo et al. (2009).

Analisando os fatores antecedentes da prontidão do consumidor à experiência com um novo serviço, Meuter et al. (2005) identificaram que a percepção de risco influencia indiretamente a adoção, por meio de influências negativas sobre a clareza do cliente sobre seu próprio papel na cocriação e sobre a habilidade deste em cumprir suas responsabilidades.

Investigando fatores que possam reduzir a percepção do risco de privacidade, Featherman et al. (2010) confirmam a influência deste tipo de risco sobre a intenção de uso e sobre a utilidade percebida. Seus resultados indicam que o risco de privacidade pode ser reduzido, entre outras medidas, com o aprimoramento da credibilidade da organização.

A hipótese $\mathrm{H} 7$ reproduz a relação entre percepção de risco e a atitude em relação ao uso, que foi anteriormente analisada por Arvidsson (2014), Crosno e Cui (2014) e Amaro e Duarte (2015).

H7: A percepção de risco possui um efeito direto e negativo sobre a atitude em relação ao uso de tecnologias aplicadas a um serviço de m-payment. 


\subsection{8}

\section{Confiança - TRU}

A utilização de construtos ligados à percepção de risco e percepção de confiança se justifica no contexto de adoção de serviços, posto que a ausência de teste prévio prejudica a avaliação do potencial adotante em relação à qualidade do serviço a ser prestado. Além disso, como a maioria dos serviços observados na literatura lidam com alguma espécie de transação financeira - compras online, internet banking, mobile commerce e/ou mobile payment, entre outros - aspectos ligados à confiança e percepção de risco tendem a influenciar significativamente a intenção de uso dos referidos serviços.

A confiança é um construto muito utilizado na literatura sobre adoção de tecnologias, sendo menos utilizado apenas que os construtos componentes do modelo TAM (DAHLBERG; GUO; ONDRUS, 2015; SHAIKH; KARJALUOTO, 2015). Além disso, a literatura evidencia que a confiança pode exercer influência tanto sobre os construtos do modelo TAM quanto sobre construtos diversos - como percepção de risco e motivação intrínseca, dependendo da inovação a ser utilizada.

Apesar de muitos trabalhos apresentarem os construtos de confiança e percepção de risco como sinônimos, Kim et al. (2008) indica que normalmente os dois conceitos são tratados de forma distinta, inclusive evidenciando que confiança e risco percebido frequentemente coexistem em pesquisas, alternando posições de antecedência. Por exemplo, Huijts et al. (2014) indicam que a confiança atua como um antecedente das percepções de risco, ao passo que Hong e Cha (2013) apresentam a percepção de risco como antecedente da confiança.

A fim de discriminar o conceito de risco percebido - definido no tópico anterior - do conceito de confiança, define-se este último como sendo uma crença na competência de uma pessoa para executar uma tarefa específica ou uma expectativa de que uma promessa individual possa ser confiável (DIMITRIADIS; KYREZIS, 2010, p. 802).

No entanto, Suh e Han (2002) indicam que a confiança pode ser classificada em quatro tipos distintos: 
- Disposição a confiar: disposição individual de se colocar em uma situação de dependência em relação a terceiros;

- Confiança institucional: crença que as condições propícias para uma situação de sucesso estão ocorrendo;

- Crença confiante: crença individual de que a outra parte possui uma ou mais características benéficas para si mesmo;

- Intenção de confiar: disposição para depender - ou intenção de depender - de terceiros, mesmo quando não é possível controlalos.

É possível perceber que, na prática, estes quatro pontos de vista podem ser condensados em somente dois - crença confiante e intenção de confiar - sendo o primeiro de caráter cognitivo e o segundo de caráter comportamental (DIMITRIADIS; KYREZIS, 2010). Como a adoção de inovações caracteriza-se como uma relação entre consumidor e fornecedor, é comum analisar, nesta área, a influência da confiança pela ótica da intenção de confiar, e o presente trabalho também analisa a confiança sob este ponto de vista.

A literatura indica que a confiança pode exercer tanto efeito direto quanto indireto (por meio da percepção de risco) sobre a atitude em relação ao uso (DIMITRIADIS; KYREZIS, 2010; GRABNER KRÄUTER; FAULLANT, 2008; KIM; FERRIN; RAO, 2008). Desta forma, duas hipóteses são apresentadas em relação à influência da confiança sobre a aceitação de serviços financeiros:

H8a: A intenção de confiar possui um efeito direto e negativo sobre a percepção de risco quanto ao uso de tecnologias aplicadas a um serviço de m-payment.

H8b: a intenção de confiar possui um efeito direto e positivo sobre a atitude em relação à adoção de tecnologias aplicadas a um serviço de m-payment. 


\subsection{9}

\section{Atitude em relação ao uso - ATT}

A atitude pode ser descrita como sendo um sentimento - positivo ou negativo - de um indivíduo, como resposta ao estímulo provocado por algum objeto, ação ou evento (FISHBEIN; AJZEN, 1975).

Seu papel dentro dos modelos de aceitação de tecnologias não é objeto de consenso nas pesquisas sobre aceitação de tecnologias. Isto ocorre devido ao fato que alguns modelos optaram por desconsiderar tal construto, em busca de um modelo mais parcimonioso, como o próprio modelo TAM, após reformulação proposta por Davis et al. (1989). No entanto, muitos outros modelos que buscaram expandir o potencial explicativo do modelo TAM - com a inserção de construtos ligados à motivação intrínseca - acabaram por reinserir o construto atitude no modelo, obtendo resultados significativos (KULVIWAT et al., 2007; FERREIRA; ROCHA; SILVA, 2014).

Portanto, a pesquisa apresenta a seguinte hipótese, anteriormente analisada por diversos autores, como Davis et al. (1989), Kulviwat et al. (2007) e Ferreira et al. (2014).

H9: $A$ atitude em relação ao uso possui um efeito direto e positivo sobre a intenção de uso de tecnologias aplicadas a um serviço de m-payment.

\subsubsection{0}

\section{Intenção de Uso - INT}

Fishbein e Ajzen (1975) definem a intenção como sendo a probabilidade subjetiva de que um indivíduo apresente determinado comportamento.

A intenção de uso não foi utilizada por Davis (1986) no modelo TAM original, pois o mesmo analisou tecnologias que já estavam sendo utilizadas pelos respondentes. Já Davis et al. (1989) inseriram o construto da intenção, por buscarem prever o uso futuro da tecnologia, após um curto contato dos respondentes com a mesma. Da mesma forma, diversas pesquisas investigaram o uso futuro de tecnologias com respondentes que não possuíam experiência prévia com as mesmas, validando a 
utilização do construto intenção de uso (KULVIWAT et al., 2007; YOUSAFZAI; FOXALL; PALLISTER, 2007; VENKATESH; L. THONG; XU, 2012; FERREIRA; ROCHA; SILVA, 2014).

\subsubsection{1}

\section{Síntese do modelo utilizado na pesquisa}

O Quadro 7 apresenta um resumo das hipóteses testadas na pesquisa.

Quadro 7: Síntese das hipóteses propostas pela pesquisa.

\begin{tabular}{|c|c|c|}
\hline \multicolumn{2}{|r|}{ Hipótese a ser testada } & $\begin{array}{l}\text { Base Teórica (principais } \\
\text { e/ou mais recentes) }\end{array}$ \\
\hline H1a: & $\begin{array}{l}\text { Prontidão para a Tecnologia } \rightarrow \text { Facilidade } \\
\text { Percebida de Uso }(+)\end{array}$ & $\begin{array}{l}\text { Lin et al. (2007); Ferreira et } \\
\text { al. (2014) }\end{array}$ \\
\hline H1b: & $\begin{array}{l}\text { Prontidão para a Tecnologia } \rightarrow \text { Utilidade } \\
\text { Percebida }(+)\end{array}$ & $\begin{array}{l}\text { Lin et al. (2007); Ferreira et } \\
\text { al. (2014) }\end{array}$ \\
\hline H1c: & $\begin{array}{l}\text { Prontidão para a Tecnologia } \rightarrow \text { Vantagem } \\
\text { Relativa }(+)\end{array}$ & Ferreira et al. (2014) \\
\hline H1d: & Prontidão para a Tecnologia $\rightarrow$ Fruição (+) & $\begin{array}{l}\text { Elliott et al. (2013); Ferreira } \\
\text { et al. (2014); Jin (2013) }\end{array}$ \\
\hline H1e: & $\begin{array}{l}\text { Prontidão para a Tecnologia } \rightarrow \text { Qualidade } \\
\text { Percebida }(+)\end{array}$ & $\begin{array}{l}\text { Zeithaml et al. (2002), } \\
\text { Liljander et al. (2006) }\end{array}$ \\
\hline H1f: & $\begin{array}{l}\text { Prontidão para a Tecnologia } \rightarrow \text { Risco Percebido } \\
(-)\end{array}$ & $\begin{array}{l}\text { Parasuraman } \\
\text { Liljander et al. (2006) }\end{array}$ \\
\hline H1g: & Prontidão para a Tecnologia $\rightarrow$ Confiança $(+)$ & $\begin{array}{l}\text { Gefen et al. }(2003) ; \\
\text { Dimitriadis e Kyrezis(2010). }\end{array}$ \\
\hline H2a: & Facilidade Percebida de Uso $\rightarrow$ Atitude $(+)$ & $\begin{array}{l}\text { Davis et al. (1989); Ferreira } \\
\text { et al. (2014) }\end{array}$ \\
\hline H2b: & $\begin{array}{l}\text { Facilidade Percebida de Uso } \rightarrow \text { Utilidade } \\
\text { Percebida }(+)\end{array}$ & $\begin{array}{l}\text { Davis et al. (1989); Ferreira } \\
\text { et al. (2014) }\end{array}$ \\
\hline H3: & Utilidade Percebida $\rightarrow$ Atitude $(+)$ & $\begin{array}{l}\text { Davis et al. (1989); Ferreira } \\
\text { et al. (2014) }\end{array}$ \\
\hline H4a: & Vantagem Relativa $\rightarrow$ Atitude $(+)$ & $\begin{array}{l}\text { Kulviwat et al. } \\
\text { Ferreira et al. (2007); }\end{array}$ \\
\hline H4b: & Vantagem Relativa $\rightarrow$ Utilidade Percebida $(+)$ & $\begin{array}{l}\text { Kulviwat et al. } \\
\text { Ferreira et al. (2007); }\end{array}$ \\
\hline & Fruição $\rightarrow$ Atitude $(+)$ & $\begin{array}{l}\text { Davis et al. (1992); } \\
\text { Venkatesh et al. (2012) }\end{array}$ \\
\hline H6: & Qualidade Percebida $\rightarrow$ Atitude $(+)$ & $\begin{array}{l}\text { Shih (2004); Pai e Huang } \\
\text { (2011) }\end{array}$ \\
\hline H7: & Risco Percebido $\rightarrow$ Atitude (-) & $\begin{array}{l}\text { Crosno e Cui (2014); Amaro } \\
\text { e Duarte (2015) }\end{array}$ \\
\hline H8a: & Confiança $\rightarrow$ Atitude $(+)$ & Dimitriadis e Kyrezis (2010) \\
\hline H8b: & Confiança $\rightarrow$ Risco Percebido (-) & $\begin{array}{l}\text { Kim et al. (2008); Grabner- } \\
\text { Kraüter e Faullant (2008) }\end{array}$ \\
\hline & Atitude $\rightarrow$ Intenção (+) & $\begin{array}{l}\text { Davis et al. (1989); Ferreira } \\
\text { et al. (2014) }\end{array}$ \\
\hline
\end{tabular}

Fonte: Elaborado pelo autor. 


\section{3. \\ Metodologia}

Neste capítulo são descritas as principais características dos métodos adotados, bem como as principais informações referentes à definição da população e delimitação da amostra, além da definição dos instrumentos de coleta e tratamento de dados.

\section{1}

\section{Tipo de pesquisa}

Apesar da existência de algumas pesquisas sobre adoção de inovações que possuem natureza interpretativa, como Schembri e Sandberg (2011), a maioria das pesquisas sobre adoção de inovações são de natureza positivista e apresentam abordagem empírica que, segundo Remenyi et al. (1998), são baseadas ou orientadas pelos resultados de observações ou experimentos.

Esta pesquisa se apresenta como um estudo cross-sectional - cuja principal característica, segundo Remanyi et al. (1998), é a observação de determinado fenômeno em um único momento temporal - que se utiliza da aplicação de surveys em uma amostra não-probabilística. A operacionalização das variáveis que compõem a survey é o tema do próximo tópico.

\section{2}

\section{Operacionalização das variáveis}

Esta pesquisa utilizou escalas elaboradas e aplicadas previamente por diversos autores para mensuração de seus construtos. Além disso, certos construtos foram mensurados pela escala definida pelos autores originais do construto - como no caso da escala de prontidão para a tecnologia, de Parasuraman e Colby (2014) - para que se tenha a máxima preservação das propriedades e da estrutura do construto, conforme sugere Ferreira (2010). 
Desta forma, o Quadro 8 a seguir apresenta as escalas para a mensuração de seus construtos, bem como a quantidade de itens utilizados e os autores de origem.

Quadro 8: Escalas utilizadas na definição dos construtos do modelo da pesquisa.

\begin{tabular}{|c|c|c|c|}
\hline Construto & Itens & $\begin{array}{c}\text { Localização no } \\
\text { questionário }\end{array}$ & Fonte \\
\hline Prontidão para a Tecnologia & 16 & Questões 01 a 16 & $\begin{array}{c}\text { Parasuraman e Colby } \\
(2014)\end{array}$ \\
\hline Facilidade de Uso Percebida & 5 & Questões 17 a 21 & Kulviwat et al. (2007) \\
\hline Utilidade Percebida & 5 & Questões 22 a 26 & Kulviwat et al. (2007) \\
\hline Vantagem Relativa & 5 & Questões 30 a 31 & Moore e Benbasat (1991) \\
\hline Fruição & 3 & Questões 32 a 34 & Venkatesh et al. (2012) \\
\hline Qualidade Percebida & 3 & Questões 35 a 37 & Oh et al. (2009) \\
\hline Risco Percebido & 5 & Questões 38 a 42 & Amaro e Duarte (2015) \\
\hline Confiança & 3 & Questões 43 a 45 & Malaquias e Hwang (2016) \\
\hline Atitude em relação ao uso & 3 & Questões 46 a 48 & Lee (2005) \\
\hline Intenção de uso & 3 & Questões 49 a 51 & Khalifa e Shen (2008) \\
\hline
\end{tabular}

Fonte: Elaborado pelo autor.

Cabe ressaltar que as escalas referentes aos construtos Intenção de Adoção, Atitude, Facilidade de Uso Percebida, Utilidade Percebida e Vantagem Relativa já possuíam tradução adequada para a língua portuguesa, tradução esta realizada para a pesquisa de Ferreira (2010) na elaboração do modelo CART.

Os demais construtos foram traduzidos por especialistas para a língua portuguesa e depois traduzidos novamente para a língua inglesa, a fim de verificar a exatidão da tradução.

O questionário final, contendo 51 questões, foi submetido a prétestes tanto com estudantes de graduação quanto com docentes da área de Administração. Os pré-testes tiveram tanto o objetivo de identificar alguma dificuldade em responder o questionário (quando aplicado aos estudantes) quanto o de identificar alguma eventual inconsistência na concepção e/ou tradução do mesmo (quando aplicado a docentes de Administração). O questionário final encontra-se no Apêndice. 


\section{3}

\section{População e amostragem}

A população alvo envolveu estudantes - ou recém-formados - de cursos de graduação ou pós-graduação. Esta delimitação se justifica pelo fato de a maioria das pesquisas sobre adoção de produtos e serviços de alta tecnologia utilizar dados obtidos a partir deste tipo de população (AMARO; DUARTE, 2015; DAHLBERG; GUO; ONDRUS, 2015; SHAIKH; KARJALUOTO, 2015; YANG et al., 2015).

No que diz respeito à amostragem, esta foi realizada por conveniência e por bola de neve, em função das limitações de recursos e de tempo. A amostragem por conveniência, segundo Black (2011), tende a apresentar menor variação de seus indivíduos em relação à população, posto que a amostragem tende a selecionar os indivíduos mais "comuns", próximos à média da população. No entanto, segundo Malhotra (2011), a amostragem por conveniência é a menos dispendiosa e a que demanda menos tempo de execução.

Por sua vez, na amostragem por bola de neve, após a escolha inicial dos respondentes, solicita-se ao mesmo que identifiquem outros indivíduos que pertençam à mesma população-alvo e que possam participar da pesquisa (MALHOTRA, 2011). Além disso, Hair et al. (2014) indicam que a amostragem por bola de neve produz bons resultados em um prazo menor de tempo e permite a respondentes qualificados o contato com potenciais respondentes semelhantes.

Os respondentes receberam um e-mail contendo o link para o questionário, bem como um pedido para que pudessem encaminhar 0 referido link para outros estudantes conhecidos que se interessassem em participar voluntariamente da pesquisa. Com isto, a amostra obtida foi de 452 respondentes, sendo que 50 questionários foram eliminados por apresentarem dados ausentes, restando 402 questionários válidos. O tamanho da amostra não atingiu o mínimo sugerido por Hair et al. (2009) de $[n \times(n+1) \div 2]$, onde $n$ representa o número de parâmetros. No caso desta pesquisa, seria necessária uma amostra de 1326 respondentes, o que inviabilizaria a pesquisa em termos de tempo e dinheiro necessários. No entanto, os próprios autores indicam que, em casos de modelos com 
elevado número de construtos, amostras de tamanho entre 400 e 500 se mostram adequadas para estimações por máxima verossimilhança.

Dos 402 respondentes, 290 estudantes (72\%) residem no estado de Minas Gerais, enquanto 92 estudantes (23\%) residem no Rio de Janeiro. Além disso, 20 estudantes (5\%) são estudantes que residem em outros estados do país. No que diz respeito à escolaridade, $65 \%$ dos respondentes estão cursando a graduação, ao passo que $11 \%$ são recém-graduados. Além disso, 18\% dos respondentes estão cursando alguma modalidade de pós-graduação, enquanto $6 \%$ são recém formados nestas modalidades.

\section{4}

\section{Coleta de dados}

Como apresentado anteriormente, o instrumento de coleta de dados utilizado foi um questionário composto por 51 questões. Um convite, contendo o link para acessar o questionário, foi enviado aos respondentes por e-mail, redes sociais e aplicativos de mensagens instantâneas. O questionário ficou disponível para acesso entre março e abril de 2016.

Os respondentes, inicialmente, assistiram um vídeo introdutório com duração de um minuto e quarenta e quatro segundos - cuja função foi a de apresentação dos serviços de m-payments em geral e de seus principais atributos. Somente após a exibição os respondentes preencheram o questionário. A Figura 18 mostra algumas cenas observadas no vídeo introdutório. 


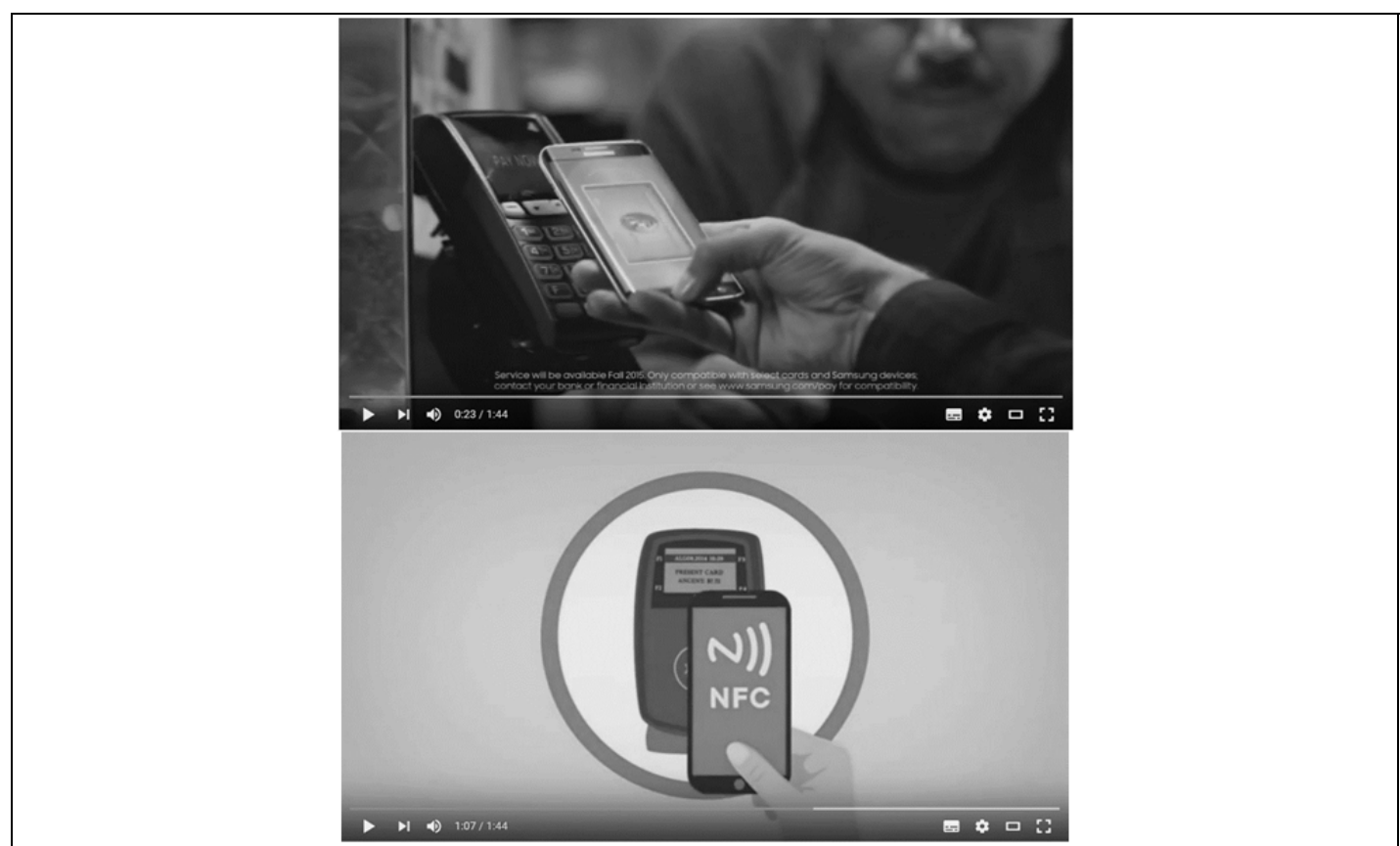

Figura 18: Cenas extraídas do vídeo introdutório do questionário de pesquisa.

Fonte: Elaborado pelo autor.

\section{5}

\section{Tratamento dos dados}

Após a tabulação dos dados, foi realizada a análise multivariada dos mesmos que, por sua vez, envolve o tratamento por meio da Modelagem de Equações Estruturais (SEM).

De acordo com Hair et al. (2009), a SEM analisa a estrutura das relações entre os construtos definidos, por meio do exame das diversas equações envolvidas nesta estrutura. O Quadro 9 exibe os seis estágios do processo de análise por SEM.

Quadro 9: Estágios do processo de modelagem de equações estruturais (SEM).

\begin{tabular}{|c|c|}
\hline Estágio & Descrição resumida \\
\hline $\begin{array}{l}\text { 1. Definição de construtos } \\
\text { individuais }\end{array}$ & $\begin{array}{c}\begin{array}{c}\text { Seleção dos componentes da escala de mensuração e aplicação do } \\
\text { pré-teste. }\end{array}\end{array}$ \\
\hline $\begin{array}{l}\text { 2. Desenvolvimento do } \\
\text { modelo de mensuração } \\
\text { geral }\end{array}$ & $\begin{array}{l}\text { Identificação dos construtos e dos itens designados para cada } \\
\text { construto. Tal identificação é geralmente realizada por meio de um } \\
\text { diagrama, onde o modelo de mensuração apresenta todos os } \\
\text { construtos com relações causais e não causais entre eles. }\end{array}$ \\
\hline $\begin{array}{l}\text { 3. Planejamento do estudo } \\
\text { para produção de } \\
\text { resultados empíricos }\end{array}$ & $\begin{array}{c}\text { Verificação de problemas ligados ao tipo de dado analisado, à } \\
\text { ausência de dados, ao tamanho amostral, à estrutura do modelo, às } \\
\text { técnicas de estimação utilizadas e ao programa computacional } \\
\text { utilizado. }\end{array}$ \\
\hline $\begin{array}{l}\text { 4. Avaliação da validade do } \\
\text { modelo de mensuração }\end{array}$ & $\begin{array}{l}\text { Verificação da validade, unidimensionalidade e confiabilidade dos } \\
\text { construtos. }\end{array}$ \\
\hline $\begin{array}{l}\text { 5. Especificação do modelo } \\
\text { estrutural }\end{array}$ & $\begin{array}{c}\text { Designação do modelo estrutural que, com base na teoria estrutural, } \\
\text { define a relação existente entre os construtos e a natureza destas } \\
\text { relações. }\end{array}$ \\
\hline $\begin{array}{l}\text { 6. Avaliação e validação do } \\
\text { modelo estrutural }\end{array}$ & $\begin{array}{c}\text { Avaliar as relações estruturais e comparação com modelos } \\
\text { alternativos. }\end{array}$ \\
\hline
\end{tabular}

Fonte: adaptado de Hair Jr. et al. (2009). 
O primeiro estágio, identificado pela seleção dos componentes da escala de mensuração, foi detalhado no tópico 3.2. A estimação e avaliação do modelo de mensuração foi conduzida por meio da Análise Fatorial Confirmatória (CFA), enquanto o teste das hipóteses foi realizado por meio de modelagem de equações estruturais (SEM), de forma que ambas as análises utilizaram os softwares estatísticos SPSS 20 e AMOS 20.

A verificação da validade dos construtos, segundo Hair et al (2009), foi realizada por meio da verificação da validade convergente, validade discriminante, validade de face e validade nomológica.

A validade convergente diz respeito ao compartilhamento de variância comum entre itens componentes de um mesmo construto (HAIR et al., 2009). Para indicação de validade convergente adequada, o construto deve apresentar valor da variância extraída média (AVE) superior a 0.5, segundo Parasuraman e Colby (2014).

A validade discriminante indica a medida em que os itens de um construto diferem dos demais construtos (HAIR et al., 2009). Ainda segundo estes autores, sua avaliação é feita por meio da análise das cargas fatoriais de cada item, que devem apresentar maiores valores em relação ao construto para o qual foi designado do que em relação aos demais construtos. Outra forma de comprovar a validade discriminante é por meio da comparação do quadrado das correlações entre construtos e a AVE pois, segundo Gupta e Jain (2014), se a AVE para o construto for superior do que a variância compartilhada entre construtos, então o construto em questão apresenta validade discriminante.

A validade de face, segundo Malhotra (2011), retrata uma avaliação subjetiva - porém sistemática - a respeito da consistência de cada item em relação ao construto no qual foi utilizado. Tal validade será garantida por meio da utilização de escalas já validadas anteriormente, bem como por meio da tradução adequada para a língua portuguesa e por meio dos pré-testes. 
Por fim, a validade nomológica examina se existe sentido entre as correlações entre os construtos e a teoria de mensuração (HAIR et al., 2009). Uma vez que as relações foram estabelecidas em função da literatura analisada, a pesquisa verificará se a matriz de correlações de construtos corrobora as relações supostas no modelo de mensuração.

Uma vez validado o modelo de mensuração, a avaliação do modelo estrutural foi realizada por meio da Modelagem de Equações Estruturais (SEM), cujo uso é amplamente identificado em pesquisas sobre a adoção de inovações. A SEM fornece uma forma adequada de examinar empiricamente um modelo teórico, ao inserir tanto o modelo de mensuração quanto o modelo estrutural em uma única análise (HAIR et al., 2009).

A pesquisa utilizou a abordagem SEM de dois estágios, a fim de verificar a validade tanto do modelo de mensuração quanto do modelo estrutural, pois Hair et al.(2009) apontam que testes de validade da teoria estrutural não podem ser conduzidos se o mesmo apresenta medidas de má qualidade. A avaliação de ambos os modelos foi realizada de acordo com o procedimento sugerido por Hair et al (2009), por meio da análise da estatística qui-quadrado (associada aos graus de liberdade), um índice de ajuste incremental (TLI), um índice de qualidade de ajuste (CFI) e um índice de má qualidade de ajuste (RMSEA). Hair et al. (2009) indica que, para um ajuste satisfatório do modelo, a razão entre o qui-quadrado e os graus de liberdade deve apresentar valor inferior a 3 . Além disso, os índices CFI e TLI devem apresentar valores superiores a 0.9 , ao passo que o RMSEA deve apresentar valor inferior a 0.08 . 


\section{4. \\ Resultados e discussões}

\section{1}

\section{Modelo de mensuração}

O modelo de mensuração, segundo Hair et al. (2009), tem como finalidade indicar as relações entre as variáveis medidas e os construtos latentes (não observados). Foi realizada uma Análise Fatorial Confirmatória para verificar o quão bem a especificação dos fatores condiz com a realidade mostrada pelos dados coletados.

Inicialmente, foram analisados indicadores para verificar a validade dos construtos utilizados. De acordo com Hair et al. (2009), a validade de construto é formada por quatro componentes: validade convergente, validade discriminante, validade nomológica e validade de face.

\subsection{1}

\section{Validade convergente}

A validade convergente sugere que os indicadores de um construto compartilham elevada proporção de variância em comum (HAIR et al., 2009). A validade convergente pode ser avaliada por meio da análise das cargas fatoriais, análise da variância média extraída (AVE) ou por meio da análise de confiabilidade.

A análise das cargas fatoriais padronizadas, segundo $\mathrm{Xu}$ et al. (2013) , Oliveira et al. (2014) e Paul et al. (2016), deve ser realizada de forma a considerar cargas padronizadas acima de 0,5 no mínimo. Nesta fase da análise, três indicadores não obtiveram valores satisfatórios e foram retirados da análise, sendo um indicador do Risco Percebido, um indicador da Vantagem Relativa e um indicador e Utilidade Percebida. 
Além disso, treze indicadores da Prontidão para a Tecnologia apresentaram valores inferiores ao recomendado. Este tipo de inconveniente teve como causa provável as diferenças conceituais entre as dimensões do construto de Prontidão para a Tecnologia. Diante disso, o modelo de mensuração foi reelaborado, de forma a apresentar um modelo de segunda ordem, com construtos representando as dimensões da Prontidão para a Tecnologia - Otimismo, Inovatividade, Desconforto e Insegurança. De acordo com Ferreira (2010), a solução de segunda ordem para a Prontidão para a Tecnologia é adequada, por mostrar-se consistente com a teoria da mesma (posto que tal construto é definido por dimensões distintas).

Apesar disto, alguns indicadores das dimensões da Prontidão para a Tecnologia ainda não apresentaram valores satisfatórios, de forma que foram retirados dois indicadores do Otimismo, um da Insegurança, dois do Desconforto e dois da Insegurança. A Tabela 1 a seguir indica as cargas fatoriais padronizadas para os indicadores selecionados.

Tabela 1: Cargas fatoriais padronizadas

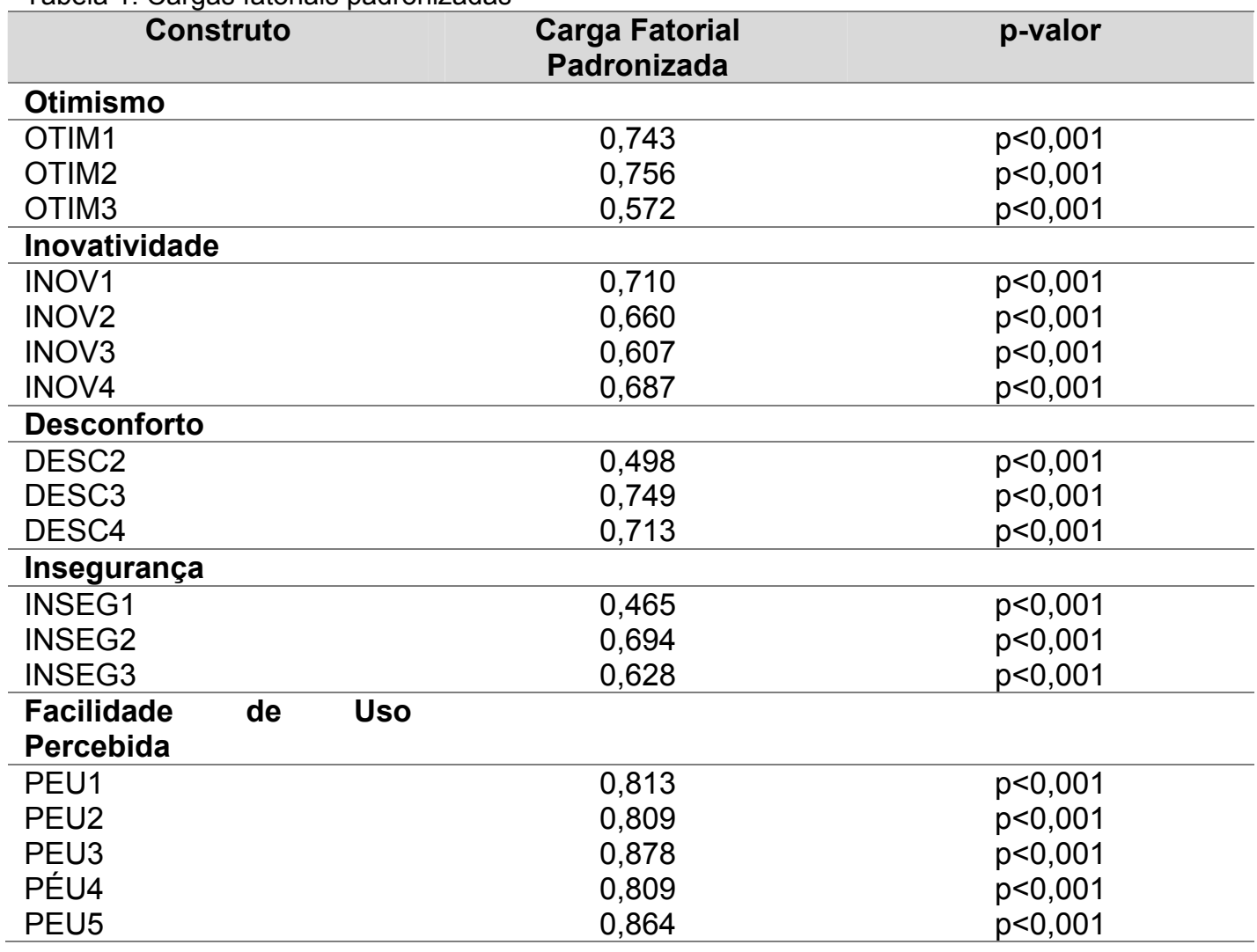


Tabela 1: Cargas Fatoriais Padronizadas (continuação)

\begin{tabular}{|c|c|c|}
\hline Construto & $\begin{array}{l}\text { Carga Fatorial } \\
\text { Padronizada }\end{array}$ & p-valor \\
\hline \multicolumn{3}{|l|}{ Utilidade Percebida } \\
\hline PU1 & 0,773 & $\mathrm{p}<0,001$ \\
\hline PU2 & 0,737 & $p<0,001$ \\
\hline PU3 & 0,783 & $p<0,001$ \\
\hline PU5 & 0,812 & $p<0,001$ \\
\hline \multicolumn{3}{|l|}{ Vantagem Relativa } \\
\hline RA1 & 0,856 & $p<0,001$ \\
\hline RA2 & 0,747 & $p<0,001$ \\
\hline RA3 & 0,886 & $p<0,001$ \\
\hline RA4 & 0,828 & $p<0,001$ \\
\hline \multicolumn{3}{|l|}{ Fruição } \\
\hline ENJ1 & 0,672 & $p<0,001$ \\
\hline ENJ2 & 0,854 & $p<0,001$ \\
\hline ENJ3 & 0,851 & $p<0,001$ \\
\hline \multicolumn{3}{|l|}{ Qualidade Percebida } \\
\hline PQ1 & 0,838 & $p<0,001$ \\
\hline$P Q 2$ & 0,900 & $p<0,001$ \\
\hline PQ3 & 0,826 & $p<0,001$ \\
\hline \multicolumn{3}{|l|}{ Risco Percebido } \\
\hline PR1 & 0,794 & $p<0,001$ \\
\hline PR2 & 0,884 & $p<0,001$ \\
\hline PR3 & 0,838 & $p<0,001$ \\
\hline PR4 & 0,782 & $p<0,001$ \\
\hline \multicolumn{3}{|l|}{ Confiança } \\
\hline TRU1 & 0,826 & $p<0,001$ \\
\hline TRU2 & 0,845 & $p<0,001$ \\
\hline TRU3 & 0,598 & $p<0,001$ \\
\hline \multicolumn{3}{|c|}{ Atitude em relação ao uso } \\
\hline ATT1 & 0,890 & $p<0,001$ \\
\hline ATT2 & 0,808 & $p<0,001$ \\
\hline ATT3 & 0,884 & $p<0,001$ \\
\hline \multicolumn{3}{|l|}{ Intenção de uso } \\
\hline INT1 & 0,923 & $p<0,001$ \\
\hline INT2 & 0,919 & $p<0,001$ \\
\hline INT3 & 0,946 & $p<0,001$ \\
\hline
\end{tabular}

Fonte: Elaborada pelo autor

Ao analisar a tabela acima, é possível perceber que todas as cargas fatoriais são significativas e apresentam a direção esperada. No entanto, as cargas fatoriais das dimensões inibidoras da Prontidão para a Tecnologia - Desconforto e Insegurança - apresentaram valores abaixo do adequado $(0,5)$. 
A análise de validade convergente também pode ser realizada por meio da Análise da Confiabilidade, da Confiabilidade Composta e da Variância Média Extraída (AVE). Neste sentido, Hair et al. (2009) indica que são aceitáveis valores superiores a 0,6 para o Alfa de Cronbach, sendo desejáveis valores superiores a 0,7. O mesmo autor indica que são desejados valores para a confiabilidade composta superiores a 0,7. Contudo, valores entre 0,6 e 0,7 podem ser aceitos, desde que algum outro indicador de validade de construto apresenta bons valores.

Por fim, são considerados adequados para a variância média extraída (AVE) valores superiores a 0,5 (HAIR et al., 2009). A Tabela a seguir apresenta os valores das referidas análises.

Tabela 2: Análise de Confiabilidade, Confiabilidade Composta e Variância Média Extraída (AVE)

\begin{tabular}{lccc}
\multicolumn{1}{c}{ Construto } & $\begin{array}{c}\text { Confiabilidade } \\
(\mathbf{\alpha})\end{array}$ & $\begin{array}{c}\text { Confiabilidade } \\
\text { Composta (CR) }\end{array}$ & $\begin{array}{c}\text { Védia Exiância } \\
\text { (AVE) }\end{array}$ \\
\hline Otimismo & 0,713 & 0,735 & 0,483 \\
Inovatividade & 0,761 & 0,784 & 0,477 \\
Desconforto & 0,687 & 0,695 & 0,439 \\
Insegurança & 0,611 & 0,626 & 0,364 \\
Facilidade de Uso Percebida & 0,919 & 0,920 & 0,698 \\
Utilidade Percebida & 0,863 & 0,859 & 0,603 \\
Vantagem Relativa & 0,897 & 0,899 & 0,692 \\
Fruição & 0,828 & 0,838 & 0,635 \\
Qualidade Percebida & 0,888 & 0,891 & 0,731 \\
Risco Percebido & 0,892 & 0,895 & 0,681 \\
Confiança & 0,783 & 0,807 & 0,558 \\
Atitude & 0,895 & 0,896 & 0,742 \\
Intenção & 0,950 & 0,950 & 0,864 \\
\hline
\end{tabular}

Fonte: Elaborada pelo autor.

Pelos resultados acima descritos é possível identificar que todos os construtos apresentam validade convergente. Contudo, as dimensões ligadas à Prontidão para a Tecnologia (Otimismo, Inovatividade, Desconforto e Insegurança) apresentaram valores de AVE inferiores ao recomendado. Apesar disso, Fornell e Larcker (1981) indicam que a AVE é uma medida mais conservadora que a confiabilidade composta, posto que construtos com valores de AVE inferiores a 0,5 podem apresentar validade convergente de acordo com valores apresentados de confiabilidade composta - e este foi o caso observado nesta pesquisa. Portanto, em função de apresentarem valores aceitáveis em outros critérios utilizados, os referidos construtos podem ser considerados como apresentando validade convergente. 
Por sua vez, a dimensão da Insegurança apresentou valores indesejáveis em praticamente todos os critérios de avaliação. No entanto, este construto foi mantido no modelo pela relevância teórica dele na composição da Prontidão para a Tecnologia.

\subsection{2}

\section{Validade discriminante}

A validade discriminante indica o nível em que um construto se diferencia dos demais construtos existentes no modelo (HAIR et al., 2009). Para a análise de validade discriminante, Fornell e Larcker (1981) sugerem que a AVE do construto seja maior que o quadrado da correlação entre o construto envolvido e os demais construtos.

O Quadro 10 a seguir exibe a matriz da Análise de Validade Discriminante, contendo o AVE de cada construto na diagonal, e os quadrados das correlações com os demais construtos no restante da matriz.

Quadro 10: Matriz da análise de validade discriminante

\begin{tabular}{|c|c|c|c|c|c|c|c|c|c|c|}
\hline & TR & PEU & PU & RA & ENJ & PQ & PR & TRU & ATT & INT \\
\hline TR & $\mathbf{0 , 2 5 0}$ & & & & & & & & & \\
\hline PEU & 0,245 & $\mathbf{0 , 6 9 8}$ & & & & & & & & \\
\hline PU & 0,195 & 0,354 & $\mathbf{0 , 6 0 3}$ & & & & & & & \\
\hline RA & 0,172 & 0,248 & 0,878 & $\mathbf{0 , 6 9 2}$ & & & & & & \\
\hline ENJ & 0,153 & 0,300 & 0,564 & 0,526 & $\mathbf{0 , 6 3 5}$ & & & & & \\
\hline PQ & 0,176 & 0,301 & 0,572 & 0,564 & 0,724 & $\mathbf{0 , 7 3 1}$ & & & & \\
\hline PR & 0,109 & $0,010^{*}$ & $0,000^{*}$ & $0,001^{*}$ & $0,000^{*}$ & $0,004^{*}$ & $\mathbf{0 , 6 8 1}$ & & & \\
\hline TRU & 0,133 & 0,229 & 0,373 & 0,365 & 0,446 & 0,593 & $0,001^{*}$ & $\mathbf{0 , 5 5 8}$ & & \\
\hline ATT & 0,135 & 0,268 & 0,576 & 0,563 & 0,645 & 0,604 & $0,003^{*}$ & 0,607 & $\mathbf{0 , 7 4 2}$ & \\
\hline INT & 0,168 & 0,161 & 0,486 & 0,444 & 0,419 & 0,430 & $0,013^{*}$ & 0,411 & 0,658 & $\mathbf{0 , 8 6 4}$ \\
\hline *valores não significativos \\
Fonte: Elaborado pelo autor.
\end{tabular}

Os resultados apresentados no Quadro 10 indicam problemas de validade discriminante entre os construtos Utilidade Percebida e Vantagem Relativa, bem como entre os construtos Fruição e Qualidade Percebida. Além disso, os construtos Fruição e Confiança apresentam problemas de validade discriminante em relação à Atitude. 
Em casos onde a validade discriminante não pode ser confirmada, as relações entre diferentes construtos podem estar comprometidas e, consequentemente, as hipóteses a serem testadas apresentarão resultados de credibilidade questionável. Farrell (2008) indica que, nestes casos, é necessário realizar uma Análise Fatorial Exploratória para evidenciar indicadores que estejam apresentando cargas fatoriais cruzadas e, se possível, excluí-las do modelo.

Contudo, se após a exclusão destes indicadores - ou diante da impossibilidade da exclusão destes - os problemas de validade discriminante ainda persistirem, Farrell Farrell (2008) recomenda a fusão dos construtos envolvidos, caso tal fusão seja teoricamente apropriada. Em último caso, o autor sugere a exclusão de um dos construtos envolvidos do modelo.

No caso desta pesquisa, a exclusão de indicadores não se mostrou suficiente para eliminar os problemas de validade discriminante. Diante disto, foi realizada uma Análise Fatorial Exploratória, que identificou que os construtos Vantagem Relativa e Utilidade Percebida se comportam como um único fator.

Este novo fator, denominado Utilidade e Vantagem Percebida (PUA), passou a apresentar sete indicadores - três da Utilidade Percebida e quatro da Vantagem Relativa - além de exibir indicadores de validade convergente satisfatórios (alfa $=0,922, \mathrm{CR}=0,924$ e AVE=0,637).

Da mesma forma, os construtos de Fruição e Qualidade Percebida foram unificados, originando o fator Apreciação da Qualidade Percebida (EPQ). Este novo fator, composto por quatro indicadores - um de Fruição e três de Qualidade Percebida - também apresentou valores satisfatórios de validade convergente (alfa $=0,893, \mathrm{CR}=0,897$ e $\mathrm{AVE}=0,685$ ).

No que diz respeito à adequação teórica necessária para a fusão entre construtos, pode-se dizer que tal aspecto foi respeitado na pesquisa. Os construtos de Vantagem Relativa e Utilidade Percebida dizem respeito ao estágio de avaliação da tecnologia em questão, e a semelhança entre eles já foi observada por Venkatesh et al. (2003), que unificou estes e outros construtos dentro do conceito de expectativa de efeito em relação à inovação tecnológica. Antes dele, Davis et al. (1989) 
também identificaram similaridades entre os dois construtos, o que justifica a união dos mesmos nesta pesquisa.

Quanto à fusão entre Fruição e Qualidade Percebida, Davis et al. (1992) e Gurtner et al. (2014) indicam que a qualidade percebida exerce influência direta e significativa sobre a fruição. Além disso, Oliver (1994) indica que ambos os conceitos podem ser considerados antecedentes da satisfação em relação ao serviço. Xu et al. (2013) apontam que a fruição pode ser influenciada pela qualidade do serviço, por mediação da satisfação quanto ao mesmo. Baker e Crompton (2000, p. 789) apresentam o conceito de satisfação quanto aos atributos, definido como "a satisfação proveniente das observações do desempenho dos atributos" do produto ou serviço. Este conceito se assemelha ao conceito de Apreciação da Qualidade Percebida aqui apresentado.

Por fim, fez-se necessária a exclusão de um dos indicadores do construto Confiança, a fim de se obter a validade discriminante do modelo. Apesar do referido construto passar a apresentar apenas dois indicadores, Hair et al. (2009) aponta que um construto sub-identificado não invalida o modelo proposto, desde que este construto apresente alguma relação significativa com outro construto, o que foi identificado na presente pesquisa.

Após a eliminação de indicadores e a fusão de construtos, a validade discriminante pôde ser comprovada, conforme exibido no Quadro 11, com os valores da AVE de cada construto na diagonal, e os quadrados das correlações com os demais construtos no restante da matriz.

Quadro 11: Matriz de validade discriminante após ajustes.

\begin{tabular}{|c|c|c|c|c|c|c|c|c|}
\hline & TR & PEU & PUA & EPQ & PR & TRU & ATT & INT \\
\hline TR & $\mathbf{0 , 2 5 0}$ & & & & & & & \\
\hline PEU & 0,245 & $\mathbf{0 , 6 9 7}$ & & & & & & \\
\hline PUA & 0,182 & 0,300 & $\mathbf{0 , 6 3 7}$ & & & & & \\
\hline EPQ & 0,174 & 0,325 & 0,608 & $\mathbf{0 , 6 8 5}$ & & & & \\
\hline PR & 0,110 & $0,010^{*}$ & $0,000^{*}$ & $0,004^{*}$ & $\mathbf{0 , 6 8 1}$ & & & \\
\hline TRU & 0,115 & 0,200 & 0,328 & 0,561 & $0,003^{*}$ & $\mathbf{0 , 7 2 6}$ & & \\
\hline ATT & 0,135 & 0,268 & 0,587 & 0,654 & $0,003^{*}$ & 0,549 & $\mathbf{0 , 7 4 2}$ & \\
\hline INT & 0,169 & 0,161 & 0,468 & 0,453 & $0,013^{* *}$ & 0,387 & 0,658 & $\mathbf{0 , 8 6 4}$ \\
\hline
\end{tabular}




\subsection{3}

\section{Validade da face e validade nomológica}

De acordo com Hair et al. (2009), entende-se por validade de face como sendo a consistência entre o conteúdo dos indicadores e a definição do construto em si. Neste sentido, a validade de face foi obtida por meio da escolha de escalas já previamente utilizadas na literatura, devidamente traduzidas e analisadas por pesquisadores da área de Administração. Além disso, o pré-teste auxiliou no processo de avaliação da validade de face.

A validade nomológica, por sua vez, verifica se as correlações entre os construtos - observada no modelo de mensuração - são consistentes com a teoria já existente (HAIR et al., 2009). Neste sentido, a análise da matriz de correlações entre os construtos pode fornecer a informação necessária à avaliação de validade nomológica.

De acordo com a literatura existente, espera-se uma relação positiva entre os construtos apresentados, à exceção do construto Risco Percebido, do qual se espera uma relação inversa entre ele e os demais construtos. A matriz de correlações é exibida no Quadro 12.

Quadro 12: Matriz de correlações entre os construtos

\begin{tabular}{|c|c|c|c|c|c|c|c|c|}
\hline & TR & PEU & PUA & EPQ & PR & TRU & ATT & INT \\
\hline TR & $\mathbf{1}$ & & & & & & & \\
\hline PEU & 0,50 & $\mathbf{1}$ & & & & & & \\
\hline PUA & 0,43 & 0,55 & $\mathbf{1}$ & & & & & \\
\hline EPQ & 0,42 & 0,57 & 0,78 & $\mathbf{1}$ & & & & \\
\hline PR & $-0,33$ & $-0,10^{* *}$ & $0,01^{* *}$ & $-0,06^{* *}$ & $\mathbf{1}$ & & & \\
\hline TRU & 0,34 & 0,45 & 0,57 & 0,75 & $-0,05^{* *}$ & $\mathbf{1}$ & & \\
\hline ATT & 0,37 & 0,52 & 0,77 & 0,81 & $-0,05^{* *}$ & 0,74 & $\mathbf{1}$ & \\
\hline INT & 0,41 & 0,40 & 0,68 & 0,67 & $-0,12^{*}$ & 0,62 & 0,81 & $\mathbf{1}$ \\
\hline *valores significativos com p<0,05. ** valores não-significativos \\
\hline
\end{tabular}

Fonte: Elaborado pelo autor.

Pelos resultados do Quadro 12, é possível identificar que todas as relações positivas entre os construtos foram confirmadas. As relações inversas entre Risco Percebido-Prontidão para a Tecnologia e Risco Percebido-Intenção também foram confirmadas. No entanto, ao contrário do esperado, não foram observadas correlações significativas entre Risco Percebido e os demais construtos. No entanto, posto que a relação deste 
com a intenção de uso foi considerada significativa - e o objetivo desta pesquisa é justamente identificar os fatores que levam ao uso de um serviço financeiro - o referido construto foi mantido no modelo.

\subsection{4}

Ajuste geral do modelo de mensuração

Em busca de verificar se o modelo de mensuração é realmente válido, faz-se necessária a verificação de alguns índices de ajuste geral. Conforme Hair et al. (2009) e lacobucci (2010), diversos indicadores são atualmente utilizados como parâmetros de qualidade de ajuste.

Nesta pesquisa, foram utilizados como indicadores a estatística quiquadrado (ajustada em função dos graus de liberdade), a raiz padronizada do resíduo médio (SRMR), o índice de ajuste comparativo (CFI), o índice de Tucker Lewis (TLI), o índice de ajuste incremental (IFI) e a raiz do erro quadrático médio de aproximação (RMSEA), que são normalmente utilizados na literatura para verificar o ajuste dos modelos de mensuração e estrutural (FERREIRA; ROCHA; SILVA, 2014; GURTNER; REINHARDT; SOYEZ, 2014; KURTZ et al., 2015; MOROSAN; DEFRANCO, 2016; PAUL; MODI; PATEL, 2016).

A Tabela 3 mostra os indicadores utilizados, valores de referência e os valores apresentados pelo modelo de mensuração. Os resultados apresentados evidenciaram que o modelo de mensuração apresenta bom ajuste geral, permitindo o avanço à análise do modelo estrutural.

Tabela 3: Indicadores de ajuste geral do modelo de mensuração.

\begin{tabular}{ccc} 
Indicadores de ajuste & Valores de referência & $\begin{array}{c}\text { Valores observados no } \\
\text { modelo de mensuração }\end{array}$ \\
\hline$\chi^{2} / \boldsymbol{d} . \boldsymbol{f}$. & $\leq 3,00$ & 1,794 \\
SRMR & $\leq 0,08$ & 0,062 \\
CFI & $\geq 0,92$ & 0,944 \\
TLI & $\geq 0,92$ & 0,938 \\
IFI & $\geq 0,90$ & 0,944 \\
RMSEA & $\leq 0,07$ & 0,044 com I.C.: $(0,41 ; 0,48)$ \\
\hline
\end{tabular}

Fonte: Elaborada pelo autor 


\section{2}

\section{Modelo estrutural}

Em função dos ajustes necessários para a obtenção de validade convergente e discriminante, alguns construtos precisaram ser combinados, de forma que o modelo conceitual de pesquisa, bem como as hipóteses de pesquisa precisaram ser adaptados, conforme pode ser observado na Figura 19.

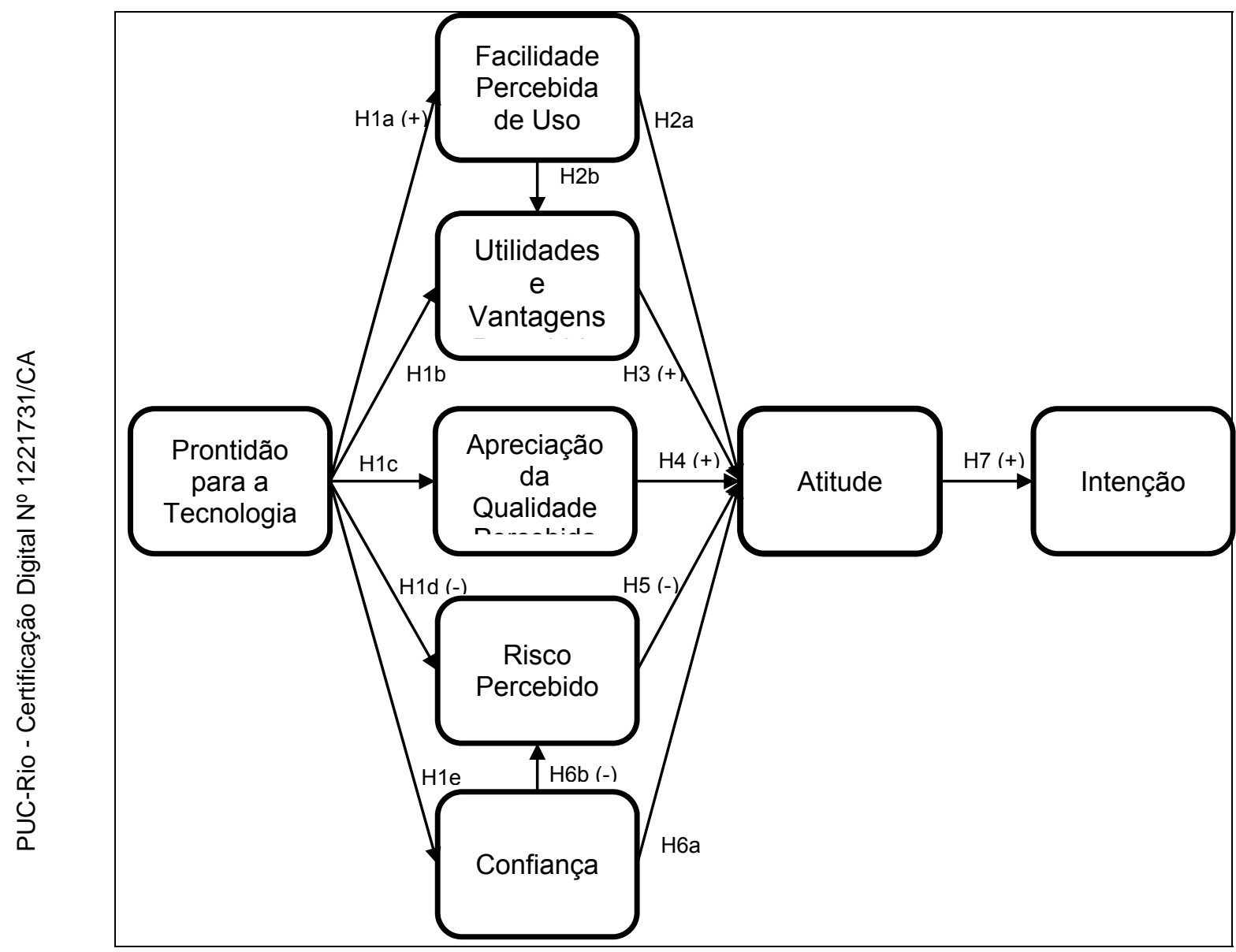

Figura 19: Modelo conceitual e hipóteses de pesquisa, após ajustes.

Fonte: Elaborada pelo autor.

A avaliação do modelo estrutural envolve a validação das relações teóricas presumidas, ou seja, o teste das hipóteses $\mathrm{H} 1$ a $\mathrm{H} 7$, que foram verificadas por meio do software AMOS 20. 


\subsection{1}

\section{Normalidade dos dados da pesquisa}

A normalidade multivariada dos dados é uma premissa para a Modelagem por Equações Estruturais (HAIR et al., 2009). No entanto, lacobucci (2010) mostra que a estimação por Máxima Verossimilhança $(\mathrm{ML})$ é considerada robusta diante da violação desta suposição. Ainda assim, a premissa de normalidade foi verificada por meio da análise univariada e multivariada da curtose, seguindo os critérios sugeridos por West et al. (1995) e Mardia (1970). A Tabela 4 mostra os resultados obtidos de curtose univariada e multivariada.

Tabela 4: Análise de normalidade dos dados da pesquisa.

\begin{tabular}{cccccc}
\hline Variável & Curtose & Variável & Curtose & Variável & Curtose \\
\hline TRI01 & 3,913 & PEU2 & 2,457 & EPQ4 & $-0,231$ \\
TRI02 & 3,095 & PEU3 & 0,752 & PR1 & $-1,189$ \\
TRI03 & 0,425 & PEU4 & 0,484 & PR2 & $-1,116$ \\
TRI05 & $-0,627$ & PEU5 & 0,661 & PR3 & $-0,877$ \\
TRI06 & $-1,012$ & PUA1 & 1,055 & PR4 & $-0,388$ \\
TRI07 & 0,085 & PUA2 & 2,022 & TRU1 & $-0,203$ \\
TRI08 & $-0,711$ & PUA3 & 0,726 & TRU2 & 0,028 \\
TRI10 & $-1,129$ & PUA4 & 0,575 & ATT1 & 0,752 \\
TRI11 & $-1,248$ & PUA5 & $-0,447$ & ATT2 & 0,117 \\
TRI12 & $-1,091$ & PUA6 & 0,744 & ATT3 & 0,238 \\
TRI13 & 3,231 & PUA7 & $-0,014$ & INT1 & $-0,14$ \\
TRI14 & 3,044 & EPQ1 & 0,749 & INT2 & 0,385 \\
TRI15 & 1,073 & EPQ2 & $-0,132$ & INT3 & $-0,117$ \\
PEU1 & 0,594 & EPQ3 & $-0,352$ & & \\
\hline
\end{tabular}

Curtose Multivariada: $352,035 \quad$ valor crítico: 59,43

Fonte: elaborada pelo autor

Como é possível identificar na Tabela 4, os valores apresentados para curtose univariada superam o valor recomendado $(3,0)$ para alguns componentes da Prontidão para a Tecnologia. Além disso, o valor da curtose multivariada apresentado é muito superior ao valor recomendado por Mardia (1970) de 3,0.

Apesar da violação de normalidade multivariada dos dados, o modelo será estimado por Máxima Verossimilhança, posto que outros métodos se mostram inadequados diante desta violação (IACOBUCCI, 2010). 


\subsection{2}

\section{Ajuste geral do modelo estrutural}

O ajuste do modelo estrutural foi realizado por meio da verificação de diversos indicadores, assim como ocorreu durante a análise do modelo de mensuração. A estatística qui-quadrado foi considerada significativa $\left(\chi^{2}=1432,34, p<0,001\right.$, com 762 graus de liberdade). No entanto, esta estatística torna-se muito sensível em pesquisas que utilizam grandes amostras de dados (KIM; FORSYTHE, 2009).

Para evitar conclusões baseadas somente neste indicador, diversos outros também foram utilizados para atestar a validade do modelo estrutural. Dentre os indicadores de ajuste absoluto, a razão entre o quiquadrado e os graus de liberdade apresentou valor inferior ao limite recomendado de 3,0 $\left(\chi^{2} /\right.$ d.f $\left.=1,88\right)$. Além disso, os indicadores SRMR raiz padronizada do resíduo médio - e RMSEA - raiz do erro quadrático de aproximação - também apresentaram valores dentro dos parâmetros recomendados $(S R M R=0,065 ; \mathrm{RMSEA}=0,047)$.

Quanto aos indicadores de ajuste incremental, o índice de ajuste comparativo - CFI - o Índice de Tucker-Lewis - TLI - e o índice de ajuste incremental - IFI - também apresentaram valores satisfatórios $(\mathrm{CFI}=0,936 ; \mathrm{TLI}=0,931$ e IFI=0,937). Estes resultados foram sintetizados na Tabela 5, que também apresenta os parâmetros de referência.

Tabela 5: Indicadores de ajuste geral do modelo estrutural.

\begin{tabular}{ccc}
\hline Indicadores de ajuste & Valores de referência & $\begin{array}{c}\text { Valores observados no } \\
\text { modelo de mensuração }\end{array}$ \\
\hline$\chi^{2} / \boldsymbol{d} . \boldsymbol{f}$. & $\leq 3,00$ & 1,880 \\
SRMR & $\leq 0,08$ & 0,065 \\
CFI & $\geq 0,92$ & 0,936 \\
TLI & $\geq 0,92$ & 0,931 \\
IFI & $\geq 0,90$ & 0,937 \\
RMSEA & $\leq 0,07$ & 0,047 com I.C.: $(0,43 ; 0,51)$ \\
\hline
\end{tabular}




\subsection{3}

\section{Resultados dos testes de hipóteses}

Uma vez verificado o ajuste adequado do modelo estrutural, a etapa seguinte consistiu em verificar se as relações existentes no modelo conceitual de pesquisa apresentaram significância estatística e direção consistente com a literatura. A Tabela 6 e a Figura 20 mostram os coeficientes de cada relação, bem como o p-valor de cada uma.

Tabela 6: Análise de significância das hipóteses do modelo conceitual.

\begin{tabular}{lcc}
\multicolumn{1}{c}{ Hipótese verificada } & Coeficiente & $\begin{array}{c}\text { p- } \\
\text { valor }\end{array}$ \\
H1a: Prontidão para a Tecnologia $\rightarrow$ Facilidade Percebida de & 0,603 & $<$ \\
Uso & 0,001 \\
\hline H1b: Prontidão para a Tecnologia $\rightarrow$ Utilidade e Vantagem & 0,746 & $<$ \\
Percebida & 0,001 \\
\hline H1c: Prontidão para a Tecnologia $\rightarrow$ Apreciação da Qualidade & 0,964 & $<$ \\
Percebida & $-0,055$ & 0,586 \\
\hline H1d: Prontidão para a Tecnologia $\rightarrow$ Risco Percebido & 0,757 & $<$ \\
\hline H1e: Prontidão para a Tecnologia $\rightarrow$ Confiança & 0,001 \\
\hline H2a: Facilidade Percebida de Uso $\rightarrow$ Atitude & 0,001 & 0,989 \\
\hline H2b: Facilidade Percebida de Uso $\rightarrow$ Utilidade e Vantagem & 0,098 & 0,067 \\
Percebida & 0,374 & $<$ \\
\hline H3: Utilidade e Vantagem Percebida $\rightarrow$ Atitude & 0,001 \\
\hline H4: Apreciação da Qualidade Percebida $\rightarrow$ Atitude & 0,279 & $<$ \\
\hline H5: Risco Percebido $\rightarrow$ Atitude & $-0,035$ & 0,001 \\
\hline H6a: Confiança $\rightarrow$ Atitude & 0,320 & $<$ \\
\hline H6b: Confiança $\rightarrow$ Risco Percebido & $-0,009$ & 0,001 \\
\hline H7: Atitude $\rightarrow$ Intenção & 0,823 & 0,931 \\
\hline
\end{tabular}

Fonte: Elaborada pelo autor. 


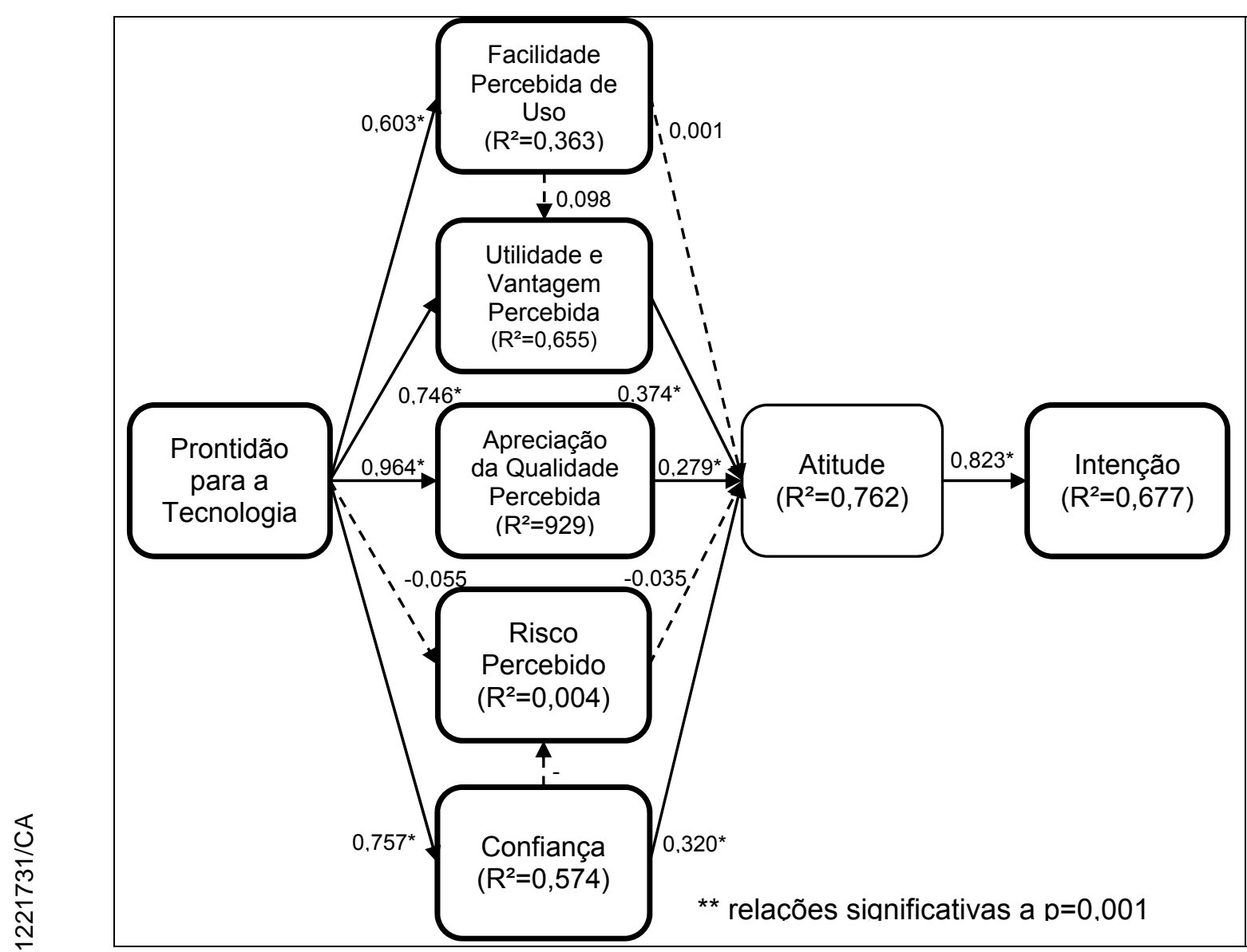

Figura 20: Modelo estrutural e coeficientes das relações verificadas.

Fonte: Elaborada pelo autor.

Os resultados indicam que as relações estabelecidas foram capazes de explicar aproximadamente $76 \%$ da atitude em relação ao uso e $68 \%$ da intenção de uso de inovações aplicadas ao setor de serviços financeiros. No entanto, os mesmos resultados indicam que as hipóteses $\mathrm{H} 1 \mathrm{~d}, \mathrm{H} 2 \mathrm{a}, \mathrm{H} 2 \mathrm{~b}, \mathrm{H} 5$ e H6b não foram consideradas significativas. As demais relações foram consideradas estatisticamente significativas e a direção destas relações foram condizentes com a literatura existente.

As hipóteses $\mathrm{H} 1 \mathrm{a}$ até $\mathrm{H} 1 \mathrm{e}$ representam a influência da Prontidão para a Tecnologia sobre os demais construtos cognitivos e afetivos referentes à adoção de tecnologias no setor de serviços financeiros. Todas estas relações foram consideradas significativas, diretas e positivas, à exceção da influência da Prontidão para a Tecnologia sobre Risco Percebido. 
A influência da Prontidão para a Tecnologia sobre estes tipos de construto já foi vista anteriormente na literatura, reforçando sua importância na literatura sobre adoção de tecnologias (DIMITRIADIS; KYREZIS, 2010; ELLIOTT; HALL; MENG, 2013; FERREIRA; ROCHA; SILVA, 2014; JIN, 2013; LILJANDER et al., 2006).

A influência da Confiança sobre a Atitude também foi considerada significativa $(0,320)$, corroborando resultados antes obtidos por Bianchi e Andrews (2012) e Arvidsson (2014), corroborando a importância deste construto na adoção de inovações que envolvam algum tipo de transação financeira.

Os resultados também indicam que o construto de Utilidade e Vantagem Percebida influencia positivamente a Atitude, resultado consistente com a literatura referente aos componentes deste construto. Além disso, a Apreciação da Qualidade Percebida também apresentou uma relação direta e positiva em relação à Atitude. No entanto, comparando os construtos que influenciaram significativamente a atitude em relação ao uso, foi possível constatar que a Apreciação da Qualidade Percebida apresentou a influência de menor magnitude $(0,279)$, ao passo que a Utilidade e Vantagem Percebida apresentaram a maior influência sobre a Atitude $(0,374)$.

No entanto, apesar de Kesharwani e Bisht (2012) e Hong e Cha (2013) evidenciarem, em suas pesquisas, a influência da Confiança sobre o Risco Percebido, a mesma não foi observada na presente pesquisa. Além disso, o construto do Risco Percebido não apresentou relação com nenhum outro construto do modelo. Bashir e Madhavaiah (2015) e Amaro e Duarte (2015), também não encontraram uma relação significativa entre Risco Percebido e Atitude, porém indicaram a existência da influência do Risco Percebido sobre a Intenção, o que poderia sugerir a investigação desta relação em um modelo alternativo. 
Da mesma semelhante, a Facilidade Percebida de Uso (PEU) não apresentou influência significativa sobre a Atitude, bem como sobre a Utilidade e Vantagem Percebida (PUA). Contudo, PEU é um construto que apresenta resultados inconstantes na literatura, muitas vezes não apresentando influência direta sobre Atitude ou Intenção (YOUSAFZAl; FOXALL; PALLISTER, 2007).

Além disso, Yousafzai et al. (2007) indicam que PEU, dentro do modelo TAM, tende a apresentar maior influência sobre atitude ou intenção em contextos mais hedônicos que utilitários. No caso do presente modelo, é possível inferir que aspectos hedônicos foram observados do construto de Apreciação da Qualidade Percebida (EPQ), de forma a tornar não significativo efeito de PEU sobre a Atitude.

\subsection{4}

\section{Análise de modelos alternativos}

A avaliação de validade do modelo estrutural se difere do modelo de mensuração por permitir a comparação entre modelos alternativos. A estimação de modelos alternativos - ou modelos rivais - é geralmente utilizada para testar a robustez do modelo originalmente proposto (DHOLAKIA; BAGOZZI; PEARO, 2004; LÓPEZ-NICOLÁS; MOLINACASTILLO; BOUWMAN, 2008). Para tanto, foram elaborados diversos modelos rivais, cujas relações e índices de ajuste foram comparados ao modelo estrutural original analisado no tópico anterior.

Para a elaboração dos modelos rivais, priorizou-se a investigação de novas relações envolvendo os construtos que não apresentaram relações significativas no modelo original. Contudo, Hair et al. (2009) ressaltam que qualquer re-especificação de modelo demanda suporte teórico adequado para tanto.

Neste sentido, o primeiro modelo alternativo apresenta diferentes relações para a Facilidade Percebida de Uso (PEU) e o Risco Percebido $(P R)$, que agora influenciam diretamente a Intenção de Uso (INT). A influência de PEU sobre INT já foi abordada diversas vezes na literatura, posto que muitas vezes sua relação com a Atitude (ATT) não é estatisticamente verificada (WU et al., 2011). Da mesma forma, a relação 
entre PR e INT já foi observada anteriormente na literatura, sempre exercendo uma influência direta e negativa sobre INT. (AMARO; DUARTE, 2015; HAN; HYUN, 2015; YANG et al., 2015). Diante disto, o Modelo Alternativo 01 , pode ser visto na Figura 21, bom como os coeficientes padronizados das relações observadas.

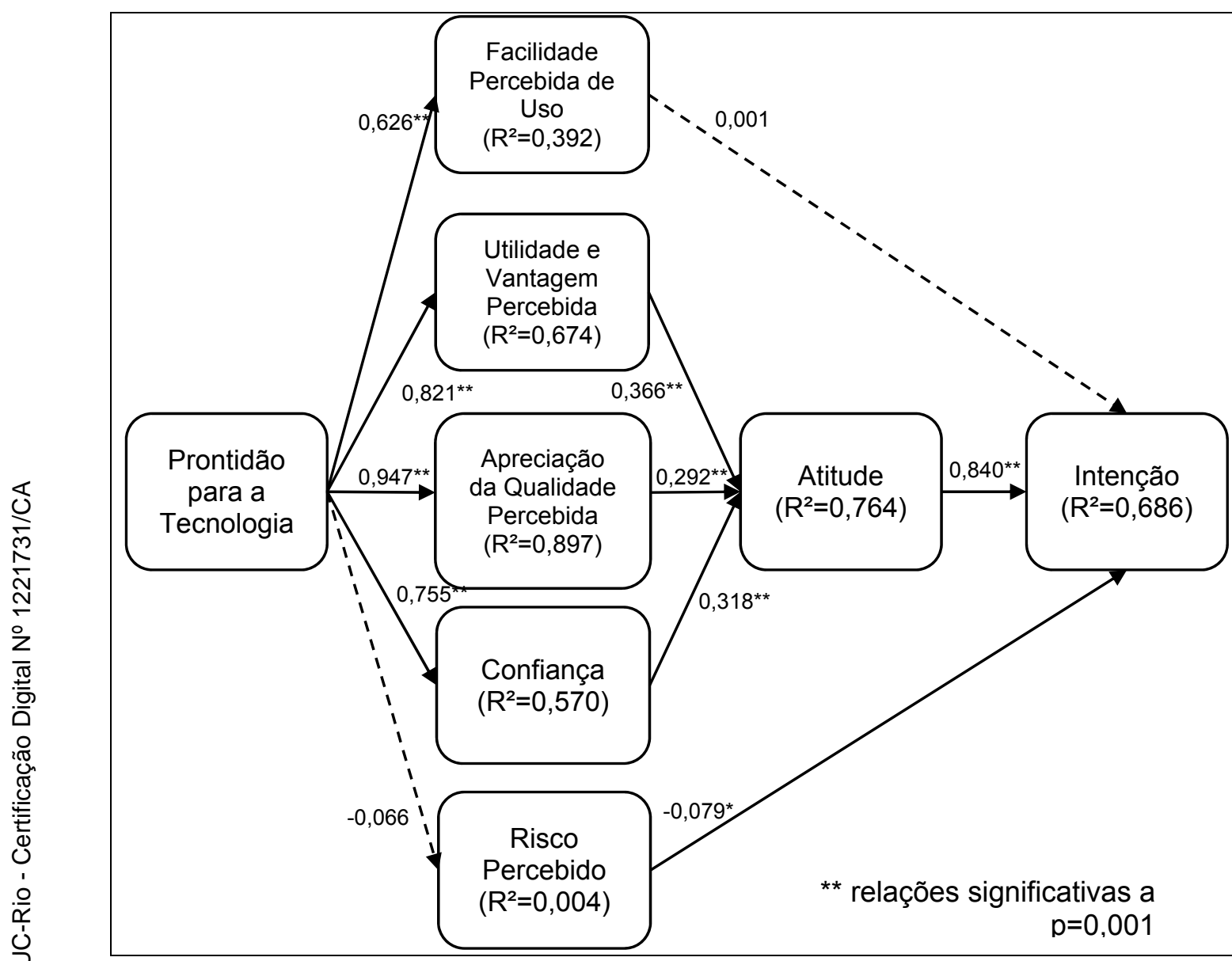

Figura 21: Modelo Alternativo 01

Fonte: Elaborada pelo autor.

O Modelo Alternativo 01 apresentou bons indicadores $\chi^{2} / d . f .=1,873 ; \quad S R M R=0,0648 ; \quad C F I=0,937 ; \quad T L I=0,932 ; \quad I F I=0,937$; $\operatorname{RMSEA}=(0,043 ; 0,050)-$ evidenciando boa qualidade de ajuste geral do modelo. Além disso, os resultados dos testes de hipóteses apontam para uma influência significativa, direta e negativa do Risco Percebido sobre a Intenção. Contudo, a magnitude desta influência foi considerada muito pequena, quando comparada à influência exercida pelos demais construtos. Por fim, não foram encontradas evidências da influência da Facilidade Percebida de Uso sobre a Intenção, resultado este também 
ocorrido algumas vezes na literatura de adoção de tecnologias (YOUSAFZAI; FOXALL; PALLISTER, 2007).

Devido à falta de evidências significativas ligando a Facilidade Percebida de Uso à Atitude ou à Intenção, este construto não foi incluído no Modelo Alternativo 02. Da mesma forma, a relação entre Prontidão para a Tecnologia e Risco Percebido também foi excluída do modelo, devido à falta de evidências estatísticas. Por fim, o Modelo Alternativo 02 apresenta uma diferente relação, entre Confiança e a Apreciação da Qualidade Percebida. Tal relação foi inspirada pelos resultados obtidos por Tsai et al. (2010), Zhou (2013) e Gao et al. (2015), que evidenciaram uma influência direta e positiva da Confiança sobre construtos referentes à fruição e satisfação. Desta forma, a Figura 22 exibe o Modelo Alternativo 02, com os coeficientes de cada relação proposta.

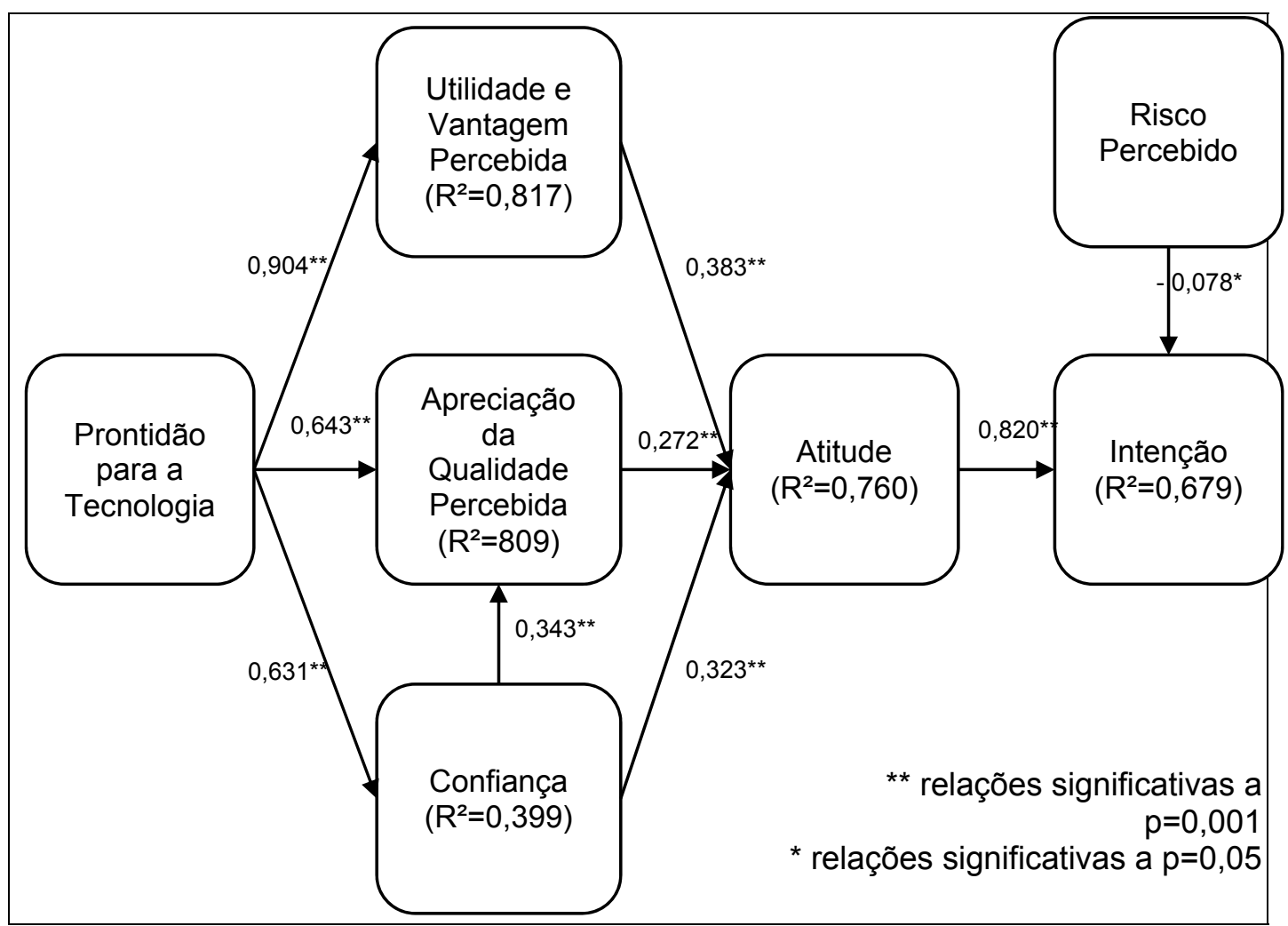

Figura 22: Modelo Alternativo 02

Fonte: Elaborada pelo autor. 
O Modelo Alternativo 02 apresentou bons indicadores de ajuste geral - $\chi^{2} /$ d.f. $=1,878 ; \quad S R M R=0,0665 ; \quad$ CFI=0,942; TLI=0,937; IFI=0,942; RMSEA $=(0,043 ; 0,051)$. Além disso, $O$ Modelo Alternativo 02 apresentou evidências significativas da influência da Confiança sobre a Apreciação da Qualidade Percebida, indicando que, quanto maior a confiança em um serviço financeiro, maior a percepção de qualidade do mesmo e a satisfação (apreciação) em relação a seu uso.

A exclusão da Facilidade Percebida de Uso tornou o modelo mais parcimonioso. Além disso, o índice de ajuste comparativo (CFI) apresentou valores melhores que os apresentados pelo Modelo Estrutural Original e pelo Modelo Alternativo 01, como é possível identificar na Tabela 7 a seguir.

Tabela 7: Comparação entre os modelos analisados, de acordo com os indicadores de ajuste geral

\begin{tabular}{cccc} 
Índices & Modelo Original & Alternativo 01 & Alternativo 02 \\
\hline$\chi^{2}$ & 1432,34 & 1430,61 & 1091,07 \\
\hline$\chi^{2} / \boldsymbol{d} . \boldsymbol{f}$. & 1,880 & 1,873 & 1,878 \\
\hline SRMR & 0,065 & 0,064 & 0,067 \\
\hline CFI & 0,936 & 0,937 & 0,942 \\
\hline TLI & 0,931 & 0,932 & 0,937 \\
\hline IFI & 0,937 & 0,937 & 0,942 \\
\hline RMSEA & 0,047 & 0,047 & 0,047 \\
\hline \% Variância da & $67,7 \%$ & $68,6 \%$ & $67,9 \%$ \\
\hline Intenção Explicada & & &
\end{tabular}

Fonte: Elaborada pelo autor

Os resultados da Tabela 7 indicam que os indicadores de ajuste geral apresentam pouca diferença entre os modelos apresentados. Diante disso, optou-se pela escolha do Modelo Alternativo 02 como sendo o modelo final da pesquisa, posto que apresentou o melhor índice CFI e por ser o mais parcimonioso. Além disso, o teste de qui-quadrado para diferença de ajuste é significativo apenas para o Modelo Alternativo 02 $\left(\Delta \chi^{2}=341,27 ; \quad \Delta\right.$ d.f. $=181 ; p$-valor $\left.<0,005\right)$, corroborando para a escolha deste modelo como o modelo final da pesquisa, como mostra a Figura 23. 


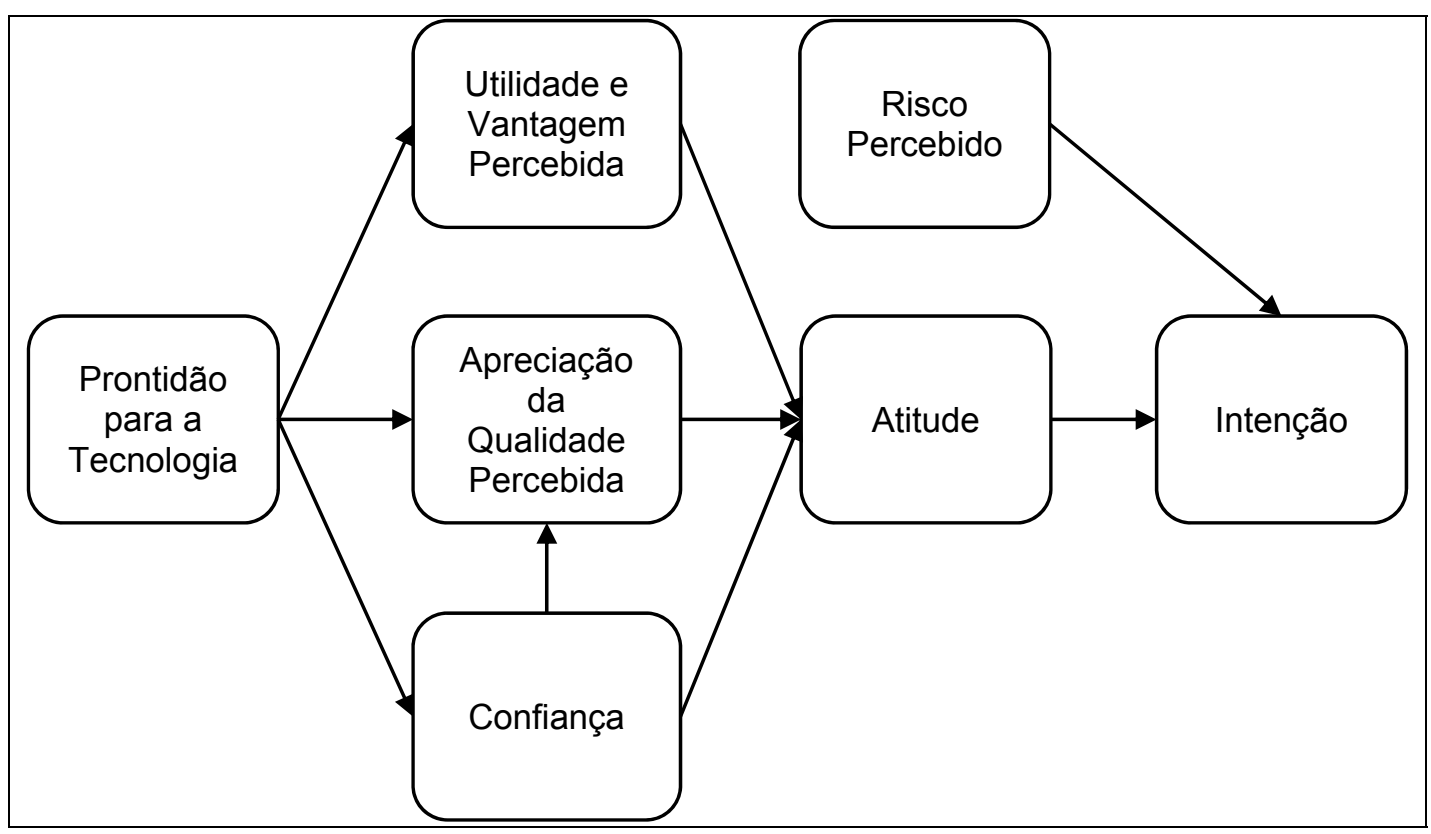

Figura 23: Modelo de Prontidão e Aceitação de Mobile Payments - Versão Final Fonte: Elaborada pelo autor.

\section{3}

Discussão dos resultados

Os resultados apresentados na seção anterior evidenciam que o modelo conceitual, originalmente proposto no tópico 2.4 , não pôde ser utilizado a fim de se investigar os fatores que influenciam a intenção de uso de inovações em serviços financeiros. Parte desta incapacidade pode ser explicada pelos problemas de validade discriminante apresentadas pelo modelo. Diante destes problemas, o modelo de pesquisa foi ajustado, com a eliminação de alguns indicadores e a combinação de alguns construtos, conforme visto no tópico 4.1.2. Este novo modelo, denominado Modelo de Prontidão e Aceitação de Mobile Payments, demandou a elaboração de novas hipóteses de pesquisa. A Tabela apresenta tanto estas novas hipóteses de pesquisa quanto as hipóteses elaboradas exclusivamente para os modelos alternativos. 
Tabela 8: Verificação das hipóteses propostas após ajustes do modelo.

\begin{tabular}{|c|c|c|}
\hline & Hipóteses inicialmente propostas & Verificadas? \\
\hline H1a: & Prontidão para a Tecnologia $\rightarrow$ Facilidade Percebida de Uso (+) & Sim \\
\hline H1b: & $\begin{array}{l}\text { Prontidão para a Tecnologia } \rightarrow \text { Utilidade e Vantagem Percebida } \\
(+)\end{array}$ & Sim \\
\hline H1c: & $\begin{array}{l}\text { Prontidão para a Tecnologia } \rightarrow \text { Apreciação da Qualidade } \\
\text { Percebida }(+)\end{array}$ & Sim \\
\hline H1d: & Prontidão para a Tecnologia $\rightarrow$ Risco Percebido (-) & Não \\
\hline H1e: & Prontidão para a Tecnologia $\rightarrow$ Confiança (+) & Sim \\
\hline H2a: & Facilidade Percebida de Uso $\rightarrow$ Atitude (+) & Não \\
\hline H2b: & $\begin{array}{l}\text { Facilidade Percebida de Uso } \rightarrow \text { Utilidade e Vantagem Percebida } \\
(+)\end{array}$ & Não \\
\hline H3: & Utilidade e Vantagem Percebida $\rightarrow$ Atitude $(+)$ & Sim \\
\hline H4: & Apreciação da Qualidade Percebida $\rightarrow$ Atitude $(+)$ & Sim \\
\hline H5: & Risco Percebido $\rightarrow$ Atitude (-) & Não \\
\hline H6a: & Confiança $\rightarrow$ Atitude $(+)$ & Sim \\
\hline H6b: & Confiança $\rightarrow$ Risco Percebido (-) & Não \\
\hline H7: & Atitude $\rightarrow$ Intenção (+) & Sim \\
\hline H8: & $\begin{array}{l}\text { Facilidade Percebida de Uso } \rightarrow \text { Intenção (somente no modelo } \\
\text { alternativo 01) }\end{array}$ & Não \\
\hline H9: & $\begin{array}{l}\text { Risco Percebido } \rightarrow \text { Intenção }(-) \text { (somente nos modelos } \\
\text { alternativos } 01 \text { e 02) }\end{array}$ & Sim \\
\hline H10: & $\begin{array}{l}\text { Confiança } \rightarrow \text { Apreciação da Qualidade Percebida (somente no } \\
\text { modelo alternativo 02) }\end{array}$ & Sim \\
\hline
\end{tabular}

O Modelo de Prontidão e Aceitação de Mobile Payments foi capaz de explicar cerca de $68 \%$ da variância da intenção de uso e $76 \%$ da atitude em relação ao uso, de forma que ele pode ser considerado um modelo com bom potencial explicativo.

Os resultados permitiram identificar que a Prontidão para a Tecnologia exerceu influência direta e positiva tanto sobre construtos cognitivos quanto sobre afetivos, de forma que quanto maior a Prontidão para a Tecnologia, maior a influência desta sobre os demais fatores que afetam a atitude e a intenção de uso. Este resultado é condizente com os resultados encontrados anteriormente na literatura (ELLIOTT; HALL; MENG, 2013; LILJANDER et al., 2006; LIN; SHIH; SHER, 2007; LIN; HSIEH, 2007; WALCZUCH; LEMMINK; STREUKENS, 2007).

Foi possível identificar que o referido construto exerceu maior influência sobre a Utilidade e Vantagem Percebida $(0,904)$ do que sobre a Apreciação da Qualidade Percebida $(0,643)$ e Confiança $(0,631)$, permitindo inferir que sua influência se fez mais presente nos aspectos cognitivos do comportamento do consumidor de serviços financeiros. 
Além disso, esta pesquisa evidenciou uma relação ainda não identificada explicitamente na literatura, que aborda a influência da Prontidão para a Tecnologia sobre a Confiança. Tal hipótese, baseada em evidências descobertas por Gefen et al. (2003) e Dimitriadis e Kyrezis (2010), confirma que a predisposição do indivíduo em relação às novas tecnologias, de forma geral, influencia a percepção que o mesmo tem quanto à credibilidade de uma inovação ligada à serviços financeiros.

Esta evidência pode orientar os prestadores de serviços financeiros a utilizar diferentes formas de promover a confiabilidade de seus serviços, de acordo com diferentes segmentos de mercado, que podem ser estratificados com base na predisposição em relação à tecnologia.

Em relação à influência sobre a Qualidade Percebida, por parte da Prontidão para a Tecnologia, o efeito direto e significativo confirma a relação suposta por Zeithaml et al. (2002), indicando que consumidores com elevada prontidão tendem a ampliar sua percepção de qualidade com relação ao serviço em questão. Além disso, também apresentam uma menor sensação de intimidação em relação à tecnologia e, por isso, apresentam maior disposição à utilização do mesmo.

A percepção de qualidade também mostrou influência significativa sobre a intenção de uso. A criação do construto de Apreciação da Qualidade Percebida indicou que tanto a percepção de qualidade quanto fatores emocionais podem influenciar positivamente a atitude em relação ao uso $(0,272)$. Este resultado é consistente com a literatura de marketing de serviços, que ressalta a importância da qualidade do serviço para o uso do mesmo (DAVIS; BAGOZZI; WARSHAW, 1992; SHIH, 2004; ZEITHAML; PARASURAMAN; MALHOTRA, 2002).

Estes resultados reforçam a importância da apreciação da experiência do serviço e da percepção de qualidade para a aceitação de inovação em serviços financeiros. Apesar de não ter sido possível analisar de forma isolada os referidos construtos - demandando pesquisas futuras para um melhor entendimento das evidências encontradas - os resultados indicam aos prestadores dos serviços financeiros a importância de se atentar não só aos aspectos utilitários dos aplicativos de pagamentos móveis, mas também para os aspectos que 
levem o potencial usuário a apreciar o processo de utilização dos mesmos. Após o início da prestação de serviços de pagamentos móveis no país, uma sugestão de pesquisa futura pode envolver a investigação de como o uso destes serviços pode ser influenciado por diferentes interfaces dos mesmos.

Outra relação importante verificada nesta pesquisa envolve aspectos ligados à Confiança. Este construto apresentou a segunda maior influência exercida sobre a Atitude $(0,323)$, além de exercer influência significativa sobre a Apreciação da Qualidade Percebida $(0,343)$. Estes resultados evidenciam, entre outras coisas, que a confiança em relação a um determinado serviço influencia diretamente na percepção do consumidor em relação à qualidade do serviço. Este resultado foi condizente com $\mathrm{o}$ encontrado por outros autores na literatura (DIMITRIADIS; KYREZIS, 2010; GEFEN; KARAHANNA; STRAUB, 2003; SUH; HAN, 2002; YU et al., 2005).

Em outras palavras, quanto mais confiável o serviço parecer aos olhos do consumidor - no caso de m-payments, isso pode significar a percepção de segurança advinda do aplicativo - maior será a percepção de qualidade por parte do consumidor, levando eventualmente a uma diferenciação do serviço em questão em relação a eventuais concorrentes. Fica clara a importância que o consumidor atribui à confiança proveniente do serviço em questão, principalmente por se tratar de serviços financeiros.

Contudo, cabe ressaltar que a magnitude desta percepção de confiança varia de acordo com o nível de prontidão para a tecnologia, como dito anteriormente. Desta forma, os prestadores de serviço não precisam apenas estarem atentos à confiabilidade promovida pelo serviço, mas também precisam promover tal sensação com estratégias diferentes de acordo com o público-alvo desejado. 
A percepção de risco, no entanto, apresentou resultados pífios nesta pesquisa. Além de não sofrer influência significativa da Prontidão para a Tecnologia, o Risco Percebido também não exerceu efeito algum sobre a Atitude. Quando investigada uma eventual relação direta entre Risco Percebido e Intenção de Uso, esta mostrou-se significativa e negativa confirmando evidências anteriores na literatura - mas de magnitude quase nula $(-0,078)$.

Apesar da elevada consistência interna deste construto, ele não se mostrou fortemente relacionado com nenhum dos demais construtos do modelo. Assim, em função de pesquisas anteriores indicarem sua importância para a decisão de aceitar ou não uma nova tecnologia, faz-se necessária a investigação de outras formas de mensuração da percepção de risco, em pesquisas futuras. Uma outra possível justificativa para os resultados apresentados pelo construto de Risco Percebido envolve a população utilizada, posto que estudantes nem sempre são os provedores dos próprios recursos financeiros, o que pode interferir na percepção de risco.

Também foi identificada a ausência de uma influência significativa da Facilidade Percebida de Uso sobre a Atitude ou a Intenção de Uso. Tal ausência pode ser justificada em função da forma pela qual os respondentes tiveram contato com o objeto de estudo. Uma vez que o serviço de m-payment ainda não foi implementado no Brasil, os respondentes tiveram acesso apenas a um vídeo explicativo sobre o mesmo. Desta forma, é possível que a ausência de contato direto com o serviço possa ter interferido na percepção de facilidade de uso dos respondentes.

Além disso, Venkatesh (1999) indica que este a Facilidade Percebida de Uso tende a apresentar melhores resultados em contextos hedônicos, o que pode ter contribuído para seu resultado inesperado nesta pesquisa, posto que serviços financeiros apresentam um contexto predominantemente utilitário. 
Por fim, os aspectos cognitivos do comportamento do consumidor aqui retratados pelo construto Utilidade e Vantagem Percebida exerceram a maior influência sobre a Atitude $(0,383)$. Este resultado é condizente com diversas pesquisas anteriores, que indicam que os fatores cognitivos são responsáveis pela maior parte da variância da atitude em relação à aceitação e uso de tecnologias (KING; HE, 2006; SCHEPERS; WETZELS, 2007; SCHIERZ; SCHILKE; WIRTZ, 2010; SHAIKH; KARJALUOTO, 2015).

Estes resultados deixam claro que o consumidor, apesar de ser influenciado por aspectos emocionais durante a decisão de utilizar ou não um novo tipo de serviço financeiro (como diversão, por exemplo), não toma suas decisões usando estes como base principal. Pelo contrário, os potenciais consumidores tomam esta decisão baseados predominantemente nos aspectos cognitivos de percepção de utilidade e na percepção de melhoria em relação a serviços utilizados atualmente.

Com base nisto, os prestadores de serviços financeiros podem organizar suas estratégias de marketing levando em conta - entre outros fatores - a promoção de conceitos ligados aos benefícios diretos do uso dos referidos serviços, bem como conceitos ligados às vantagens oferecidas em relação às demais alternativas de pagamentos existentes. Estratégias como estas já são observadas em propagandas destes serviços em outros países, que reforçam a comodidade e a segurança existente no fato desta modalidade de pagamento não envolver mais o uso de cartões de crédito (fisicamente), tampouco envolver o manuseio de seus dados financeiros por algum funcionário do estabelecimento onde ocorrer o pagamento em questão.

Por fim, é importante destacar a elevada magnitude do efeito da Atitude sobre a Intenção $(0,820)$. Este resultado contribui com a discussão existente em torno da utilização ou não deste construto em modelos de aceitação de tecnologias, ao evidenciar que a intenção de uso é fortemente influenciada pela atitude inicial em relação à utilização ou não do serviço financeiro em questão, evidenciando o poder mediador da Atitude entre os demais construtos e a Intenção. 
Contudo, cabe ressaltar que os resultados aqui apresentados não podem ser utilizados por prestadores de serviços financeiros sem uma análise aprofundada do contexto a ser aplicado. Isto se justifica em função dos dados utilizados terem sido obtidos junto a um perfil muito específico em relação à toda a população do país. Caso o público-alvo desejado seja diferente do delimitado como a população desta pesquisa, novas investigações se fazem necessárias para a confirmação das relações aqui observadas.

Ainda assim, esta pesquisa contribui para a literatura de aceitação de tecnologias, uma vez que apresenta um novo conjunto de interrelações entre construtos que influenciam diretamente e indiretamente a aceitação de tecnologias no setor de serviços financeiros. Posteriormente, sugere-se que o Modelo de Prontidão e Aceitação de Mobile Payments seja testado em diferentes populações ou diferentes categorias de serviços, a fim de ampliar a generalização dos resultados e relações aqui apresentadas. 


\section{5. \\ Conclusões}

\section{1}

\section{Considerações finais}

Este estudo teve como objetivo desenvolver e testar um modelo de aceitação de tecnologias orientado para os serviços de pagamentos móveis - mobile payments ou m-payments. Este modelo permitiu, entre outras coisas, investigar a influência da Prontidão para a Tecnologia sobre o comportamento do consumidor no que diz respeito ao uso deste tipo de serviço. Além disso, foi possível observar o impacto de construtos de elevada importância no setor de serviços financeiros - como Confiança e Risco Percebido - bem como de construtos já consolidados na literatura de aceitação de novas tecnologias - como Utilidade Percebida e Facilidade Percebida , entre outros - sobre a Atitude em relação ao uso e sobre a Intenção de uso dos serviços de m-payments.

Contudo, o modelo originalmente formulado não pode ser testado, devido a problemas de validade discriminante. Tais problemas foram solucionados após a combinação de alguns construtos, de forma que foram criados os construtos "Utilidades e Vantagens Percebidas" e "Apreciação da Qualidade Percebida".

Os resultados da pesquisa indicaram que a Prontidão para a Tecnologia exerce uma influência direta e positiva tanto sobre construtos cognitivos quanto sobre construtos afetivos - exceto Risco Percebido durante o processo de tomada de decisão quanto ao uso de tecnologias no setor de serviços de m-payments. 
Além disso, foi possível identificar que fatores cognitivos exerceram maior influência sobre a atitude em relação ao uso, quando comparados a fatores afetivos e fatores característicos do setor de serviços de $\mathrm{m}$ payments. Este resultado é consistente com a literatura de adoção de inovações que indica que, em caso de produtos/serviços de característica predominantemente utilitária - como é o caso dos serviços em questão- a decisão quanto ao uso destes é dominada pelos aspectos cognitivos do comportamento (CHILDERS et al., 2001).

Contudo, dentre os aspectos cognitivos, a Facilidade Percebida de Uso não apresentou influência significativa sobre a Atitude ou sobre a Intenção de Uso. Isto pode ser justificado pelo fato dos respondentes não terem obtido acesso direto ao serviço de m-payment, e sim assistido a um vídeo explicativo sobre o mesmo, o que pode ter interferido na percepção de facilidade de uso. Ainda assim, o modelo final da pesquisa foi capaz de explicar cerca de $76 \%$ da atitude em relação ao uso e cerca de $68 \%$ da intenção de uso de inovações no setor de serviços de m-payments.

Os resultados provenientes do teste do modelo proposto permitem inferir que este pode contribuir de forma relevante para a literatura sobre a adoção de m-payments, por diversos motivos. Em primeiro lugar, a pesquisa evidencia a existência de uma predisposição individual quanto ao uso de tecnologias em geral (Prontidão para a Tecnologia). Tal predisposição influencia não só a percepção de utilidade e das vantagens do serviço em questão, mas também influencia a percepção de qualidade do mesmo. A influência da Prontidão para a Tecnologia sobre a Qualidade Percebida é relevante para a literatura, pois evidencia que características individuais ligadas às tecnologias, de forma geral, podem interferir na percepção do indivíduo em relação à qualidade do serviço. Além disso, em termos gerenciais, este resultado pode subsidiar a formulação de diferentes estratégias de divulgação de atributos para diferentes públicos-alvo. 
Em segundo lugar, a pesquisa evidencia a influência da Prontidão para a Tecnologia sobre a Confiança em relação a um serviço financeiro. Tal influência - direta e positiva - indica que indivíduos com maior predisposição ao uso de tecnologias tendem a confiar mais nestas. Este resultado possui implicações tanto acadêmicas (ao contribuir para o estudo dos antecedentes da confiança) quanto gerenciais (ao fornecer subsídios para estratégias de marketing ligadas à segurança dos serviços de m-payments).

Contudo, no que diz respeito ao Risco Percebido, não foi observada influência significativa da Prontidão para a Tecnologia sobre o mesmo. Além disso, a percepção de risco apresentou influência mínima sobre a intenção de uso. Estes resultados, em contraste com a relevância deste construto observada na literatura de serviços financeiros, podem ter sido causados pela escala utilizada na mensuração do mesmo. Neste sentido, sugere-se para pesquisas futuras 0 teste de outras escalas de mensuração. Outra possível justificativa para os resultados apresentados pelo construto de Risco Percebido envolve a população utilizada, posto que estudantes nem sempre são os provedores dos próprios recursos financeiros, o que pode interferir na percepção de risco.

No que diz respeito à terceira e quarta questões investigadas nesta pesquisa - sobre a influência da confiança e da percepção de qualidade sobre a intenção de uso - ambos os construtos apresentaram influência positiva sobre a mesma, por intermédio da atitude em relação ao uso.

Os resultados indicaram que Confiança exerceu maior influência sobre a Atitude quando comparada à influência da Apreciação da Qualidade Percebida. Contudo, a inserção da percepção da qualidade em um construto junto a indicadores ligados a aspectos afetivos impossibilitou uma comparação adequada entre a influência da percepção de qualidade e confiança. Isto porque o contexto utilitário dos serviços de pagamentos móveis pode ter contribuído para a redução dos valores dos indicadores afetivos e, consequentemente, da influência da Apreciação da Qualidade Percebida sobre a Atitude. 
No entanto, por se tratar de serviços financeiros, já era esperada uma maior influência de aspectos ligados à confiança do que de aspectos ligados à qualidade do serviço, posto que Arvidsson (2014) indica que transações financeiras são consideradas um assunto sensível para o indivíduo, de forma que este tende a avaliar a inovação com base em aspectos ligados à confiança.

\section{2}

\section{Implicações gerenciais}

Os resultados obtidos por esta pesquisa permitem evidenciar algumas sugestões que podem ser utilizadas no meio empresarial. A prontidão para a tecnologia apresentada pelos consumidores em relação à aceitação de novos serviços pode levar as empresas a melhor orientarem a promoção de determinados atributos de seus serviços, dependendo do público alvo desejado, permitindo aprimorar as estratégias de posicionamento e segmentação de mercado.

Se o público alvo da empresa envolver clientes com reduzidos níveis de TRI, por exemplo, menor será a percepção destes clientes em relação às utilidades e vantagens fornecidas por este serviço, de forma que a empresa deverá reforçar os atributos ligados à segurança e confiabilidade de seus serviços. Desta forma, isto poderá ampliar não só a confiança, mas também a percepção de qualidade em relação ao serviço em questão, posto que esta é influenciada pela confiança percebida.

Por outro lado, se o público alvo da empresa envolver apenas indivíduos com elevada prontidão para a tecnologia, a promoção do serviço deverá apresentar foco na utilidade do mesmo e das vantagens que ele apresenta em relação aos concorrentes. Diante da elevada influência desta prontidão sobre a percepção destes atributos, imagina-se que este público alvo dará maior atenção a este tipo de informação na hora de decidir sobre a utilização ou não de um novo serviço. 
Desta forma, as empresas precisam não somente se atentar às questões ligadas à segmentação e posicionamento do mercado, mas também a questões ligadas à confiabilidade e às vantagens oferecidas pelo serviço em questão. A sensação de confiabilidade apresentou uma considerável influência sobre a percepção de qualidade e, consequentemente, sobre a sensação de fruição decorrente desta.

\section{3}

\section{Limitações da pesquisa}

Esta pesquisa apresenta limitações decorrentes dos métodos escolhidos para amostragem, coleta e tratamento dos dados. No que diz respeito aos critérios de amostragem, a seleção de respondentes por conveniência e por "bola de neve" prejudica a generalização de resultados, posto que os respondentes - que se voluntariaram para participar da pesquisa - podem não representar adequadamente a população, gerando algum tipo de viés nos resultados.

No que diz respeito à coleta de dados, a não possibilidade de utilização de um serviço específico de m-payment pode se mostrar uma limitação ao estudo, por não permitir que os respondentes tenham contato direto com os serviços. Além disso, apresentar a um potencial consumidor a experiência obtida a partir de um serviço é uma tarefa complexa, dadas as características específicas dos serviços, já mencionadas na revisão de literatura deste trabalho. Isto só seria possível por meio da realização de experimentos com elevado nível de controle do ambiente, o que inviabilizaria a realização desta pesquisa. Tal limitação pode ter prejudicado as avaliações cognitivas e afetivas em relação ao objeto de estudo, sendo talvez um dos motivos que levaram à não identificação de influência alguma da Facilidade Percebida de Uso sobre a Atitude ou sobre a Intenção. 
Outra limitação diz respeito ao instrumento de coleta de dados. O uso da survey pode levar à limitações no que diz respeito à inferência causal, pois não permitem excluir problemas ligados à endogeneidade (TUBENCHLAK et al., 2015). No que diz respeito às diversas fontes de endogeneidade, Podsakoff et al. (2003) indicam técnicas estatísticas capazes de eliminar problemas provocados pela variância comum ao método - common method variance. Dentre as possíveis técnicas de solução para tal problema, foram utilizadas a Análise de Fator Único de Harman e a Análise do Fator Comum Latente (PODSAKOFF et al., 2003). Contudo, ainda assim seria possível a ocorrência de endogeneidade, por fatores que não podem ser evitados em função desta forma de coleta de dados.

\section{4}

\section{Sugestões para pesquisas futuras}

Em função da limitação da falta de contato direto com o serviço, uma importante sugestão de pesquisa futura envolve o teste dos modelos utilizados nesta pesquisa - em uma população semelhante à utilizada nesta pesquisa - após a inserção de algum serviço de pagamento móvel de amplo acesso no país. Desta forma, seria possível a verificação das relações observadas nesta pesquisa, ampliando ainda mais a compreensão dos fatores que levam à adoção de inovações no setor de serviços financeiros - inclusive permitindo a reavaliação da influência da Facilidade Percebida de Uso sobre a Atitude e a Intenção. Além disso, a replicação deste modelo após a inserção dos serviços de m-payments no Brasil permitirá investigar questões referentes à continuação de uso de $m$ payments após a experiência com o serviço, bem como a verificação de quais fatores exercem maior influência na intenção de continuação de uso dos serviços de m-payments. 
Outra sugestão envolve os modelos aqui apresentados, que podem ser testados em outros contextos - diferentes populações e/ou diferentes tipos de serviços - a fim de verificar se as relações aqui evidenciadas também são relevantes em outros cenários. Esta sugestão pode clarificar o potencial de aplicação dos resultados desta pesquisa para o meio empresarial, que pode demandar a oferta de seus serviços em condições diferentes das observadas nesta pesquisa.

Além disso, alguns construtos não puderam ser observados de forma isolada (Utilidade Percebida, Vantagem Relativa, Fruição e Qualidade Percebida). Pesquisas futuras podem reavaliar o impacto destes construtos de forma isolada, posto que os problemas de validade discriminante podem deixar de ocorrer em outros contextos / populações / amostras.

Por fim, a investigação sobre a percepção de risco não obteve os resultados inicialmente esperados. Além da sugestão de replicação deste estudo em uma diferente população - posto que estudantes podem apresentar distorções na percepção de risco financeiro - uma outra sugestão envolve a utilização de diferentes escalas de mensuração em pesquisas futuras. 


\section{6. Referências bibliográficas}

AHN, T.; RYU, S.; HAN, I. The impact of Web quality and playfulness on user acceptance of online retailing. Information \& Management, v. 44, n. 3, p. 263-275, 2007.

AJZEN, I. From Intentions to Actions: a theory of planned behavior. In: KUHL, J.; BECKMANN, J. (Eds.). . Action-Control: from cognition to behavior. Heidelberg: Springer, 1985.

AMARO, S.; DUARTE, P. An integrative model of consumers' intentions to purchase travel online. Tourism Management, v. 46, p. 64-79, 2015.

ANDREASSEN, T. W.; STREUKENS, S. Online complaining: unterstanding the adoption process and the role of individual and situational characteristics. Managing Service Quality: An International Journal, v. 23, n. 1, p. 4-24, 2013.

ARTS, J. W. C.; FRAMBACH, R. T.; BIJMOLT, T. H. A. Generalizations on consumer innovation adoption: A meta-analysis on drivers of intention and behavior. International Journal of Research in Marketing, v. 28, n. 2, p. 134-144, 2011.

ARVIDSSON, N. Consumer attitudes on mobile payment services results from a proof of concept test. International Journal of Bank Marketing, v. 32, n. 2, p. 150-170, 2014.

ASSOCIAÇÃO NACIONAL DE TELECOMUNICAÇÕES - ANATEL. Julho de 2015 fecha com 281,45 milhões de acessos móveis. Disponível em: $<$ http://www.anatel.gov.br/institucional/index.php?option=com_content\&vie $\mathrm{w}=$ article\&id=622:julho-de-2015-fecha-com-281-45-milhoes-de-acessosmoveis-dados\&catid=48\&Itemid=433>. Acesso em: 24 set. 2015.

AYEH, J. K.; AU, N.; LAW, R. Predicting the intention to use consumergenerated media for travel planning. Tourism Management, v. 35, p. 132-143, 2013.

BAE, Y.; CHANG, H. Adoption of smart TVs: a Bayesian network approach. Industrial Management \& Data Systems, v. 112, n. 6, p. 891910, 2012.

BAGOZZI, R. P.; LEE, K.-H. Consumer Resistance to, and Acceptance of, Innovations. Advances in Consumer Research, v. 26, n. 1, p. 218-225, 1999. 
BAKER, D. A.; CROMPTON, J. L. Quality, satisfaction and behavioral intentions. Annals of Tourism Research, v. 27, n. 3, p. 785-804, 2000.

BASHIR, I.; MADHAVAIAH, C. Consumer attitude and behavioural intention towards Internet banking adoption in India. Journal of Indian Business Research, v. 7, n. 1, p. 67-102, 2015.

BIANCHI, C.; ANDREWS, L. Risk, trust, and consumer online purchasing behaviour: a Chilean perspective. International Marketing Review, v. 29, n. 3, p. 253-275, 2012.

BLACK, K. Business Statistics: For Contemporary Decision Making. 7 ed ed. Hoboken, NJ: Wiley, 2011.

BLYTHE, M.; HASSENZAHL, M. The Semantics of Fun: Differentiating Enjoyable Eeperiences. In: BLYTHE, M. A. et al. (Eds.). . Funology. Human-Computer Interaction Series. [s.I.] Springer Netherlands, 2003. p. 91-100.

BRADY, M. K.; CRONIN JR., J. J. Some New Thoughts on Conceptualizing Perceived Service Quality: A Hierarchical Approach. Journal of Marketing, v. 65, n. 3, p. 34-49, 2001.

BRUNER II, G. C.; KUMAR, A. Explaining consumer acceptance of handheld Internet devices. Journal of Business Research, v. 58, n. 5, p. 553-558, 2005.

CHANG, K.-C. et al. Integrating loss aversion into a technology acceptance model to assess the relationship between website quality and website user's behavioural intentions. Total Quality Management \& Business Excellence, v. 23, n. 7/8, p. 913-930, 2012.

CHAOUALI, W.; BEN YAHIA, I.; SOUIDEN, N. The interplay of counterconformity motivation, social influence, and trust in customers' intention to adopt Internet banking services: The case of an emerging country. Journal of Retailing and Consumer Services, v. 28, p. 209-218, 2016.

CHEN, L.; GILLENSON, M. L.; SHERRELL, D. L. Enticing online consumers: an extended technology acceptance perspective. Information \& Management, v. 39, n. 8, p. 705-719, 2002.

CHEN, L.-D.; TAN, J. Technology Adaptation in E-commerce:: Key Determinants of Virtual Stores Acceptance. European Management Journal, v. 22, n. 1, p. 74-86, fev. 2004.

CHEN, S.; CHEN, H.; CHEN, M. Determinants of satisfaction and continuance intention towards self-service technologies. Industrial Management \& Data Systems, v. 109, n. 9, p. 1248-1263, 2009.

CHILDERS, T. L. et al. Hedonic and utilitarian motivations for online retail shopping behavior. Journal of Retailing, v. 77, n. 4, p. 511-535, 2001. 
CRESPO, A. H.; BOSQUE, I. R. DEL; SANCHEZ, M. M. G. DE LOS S. The influence of perceived risk on Internet shopping behavior: a multidimensional perspective. Journal of Risk Research, v. 12, n. 2, p. 259-277, 2009.

CRONIN JR., J. J.; TAYLOR, S. A. Measuring Service Quality: A Reexamination and Extension. Journal of Marketing, v. 56, n. 3, p. 5568, 1992.

CROSNO, J. L.; CUI, A. P. A Multilevel Analysis of the Adoption of Sustainable Technology. Journal of Marketing Theory \& Practice, v. 22, n. 2, p. 209-224, 2014.

CRUZ, P. et al. Mobile banking rollout in emerging markets: Evidence from Brazil. International Journal of Bank Marketing, v. 28, n. 5, p. 342-371, 2010.

CURRAN, J. M.; MEUTER, M. L. Self-service technology adoption: comparing three technologies. Journal of Services Marketing, v. 19, n. 2, p. 103-113, 2005.

DAHLBERG, T.; GUO, J.; ONDRUS, J. A critical review of mobile payment research. Electronic Commerce Research and Applications, v. no prelo, 2015.

DAVIS, F. D. A technology acceptance model for empirically testing new end-user information systems: theory and results. Tese (Ph.D. in Management)—Cambridge: Massachusetts Institute of Technology, 1986.

DAVIS, F. D. Perceived Usefulness, Perceived Ease of Use, and User Acceptance of Information Technology. MIS Quarterly, v. 13, n. 3, p. 319340, 1989.

DAVIS, F. D.; BAGOZZI, R. P.; WARSHAW, P. R. User Acceptance of Computer Technology: A Comparison of Two Theoretical Models. Management Science, v. 35, n. 8, p. 982-1003, 1989.

DAVIS, F. D.; BAGOZZI, R. P.; WARSHAW, P. R. Extrinsic and Intrinsic Motivation to Use Computers in the Workplace. Journal of Applied Social Psychology, v. 22, n. 14, p. 1111-1132, 1992.

DHOLAKIA, U. M.; BAGOZZI, R. P.; PEARO, L. K. A social influence model of consumer participation in network- and small-group-based virtual communities. International Journal of Research in Marketing, v. 21, n. 3, p. 241-263, 2004.

DICIONÁRIO MICHAELIS. Significado de "fruição" no Dicionário Português Online: Moderno Dicionário da Língua Portuguesa Michaelis - UOL. Disponível em: $<$ http://michaelis.uol.com.br/moderno/portugues/index.php?lingua=portugu es-portugues\&palavra=frui\%E7\%E3o>. Acesso em: 24 maio. 2016. 
DIMITRIADIS, S.; KYREZIS, N. Linking trust to use intention for technology-enabled bank channels: The role of trusting intentions. Psychology \& Marketing, v. 27, n. 8, p. 799-820, 2010.

DISHAW, M. T.; STRONG, D. M. Extending the technology acceptance model with task-technology fit constructs. Information \& Management, v. 36 , n. 1, p. 9-21, 1999.

DUTOT, V. Factors influencing Near Field Communication (NFC) adoption: An extended TAM approach. The Journal of High Technology Management Research, v. 26, n. 1, p. 45-57, 2015.

ELLIOTT, K. M.; HALL, M. C.; MENG, G. Consumers' intention to use selfscanning technology: the role of technology readiness and perceptions toward self-service technology. Academy of Marketing Studies Journal, v. 17, n. 1, p. 129-143, 2013.

FARRELL, A. M. Insufficient Discriminant Validity: a comment on Bove, Pervan, Beatty, and Shiu (2009). 2008. Disponível em: $<$ https://core.ac.uk/download/files/7/115685.pdf>. Acesso em: 29 maio. 2016 .

FEATHERMAN, M. S.; MIYAZAKI, A. D.; SPROTT, D. E. Reducing online privacy risk to facilitate e-service adoption: the influence of perceived ease of use and corporate credibility. Journal of Services Marketing, v. 24, n. 3, p. 219-229, 2010.

FERREIRA, J. B. Aceitação e Prontidão do Consumidor: elaboração e teste empírico do modelo CART para adoção de produtos de tecnologia. Tese (Doutorado em Administração)—Rio de Janeiro: URRJ/COPPEAD, 2010.

FERREIRA, J. B.; ROCHA, A. DA; SILVA, J. F. DA. Impacts of technology readiness on emotions and cognition in Brazil. Journal of Business Research, v. 67, n. 5, p. 865-873, 2014.

FISHBEIN, M.; AJZEN, I. Belief, Attitude, Intention and Behavior: An Introduction to Theory and Research. Reading, MA: Addison-Wesley, 1975

FISK, R. P.; BROWN, S. W.; BITNER, M. J. Tracking the Evolution of Services Marketing Literature. Journal of Retailing, v. 69-103, n. 1, p. 61, 1993

FORNELL, C.; LARCKER, D. F. Evaluating Structural Equation Models with Unobservable Variables and Measurement Error. Journal of Marketing Research, v. 18, n. 1, p. 39-50, 1981.

GAO, L.; WAECHTER, K. A.; BAI, X. Understanding consumers' continuance intention towards mobile purchase: A theoretical framework and empirical study - A case of China. Computers in Human Behavior, v. 53, p. 249-262, dez. 2015. 
GAO, T. (TONY) et al. Consumers un-tethered: A three-market empirical study of consumers' mobile marketing acceptance. Journal of Business Research, v. 66, n. 12, p. 2536-2544, 2013.

GARRETT, J. L. et al. Adoption of Mobile Payment Technology by Consumers. Family and Consumer Sciences Research Journal, v. 42, n. 4, p. 358-368, 2014.

GEFEN, D.; KARAHANNA, E.; STRAUB, D. W. Inexperience and experience with online stores: the importance of TAM and trust. IEEE Transactions on Engineering Management, v. 50, n. 3, p. 307-321, 2003.

GOODHUE, D. L.; THOMPSON, R. L. Task-Technology Fit and Individual Performance. MIS Quarterly, v. 19, n. 2, p. 213-236, 1995.

GRABNER-KRÄUTER, S.; FAULLANT, R. Consumer acceptance of internet banking: the influence of internet trust. International Journal of Bank Marketing, v. 26, n. 7, p. 483-504, 2008.

GUPTA, R.; JAIN, K. Adoption of Mobile Telephony in Rural India: An Empirical Study. Decision Sciences, v. 45, n. 2, p. 281-307, 2014.

GURTNER, S.; REINHARDT, R.; SOYEZ, K. Designing mobile business applications for different age groups. Technological Forecasting and Social Change, v. 88, p. 177-188, 2014.

HA, S.; STOEL, L. Consumer e-shopping acceptance: Antecedents in a technology acceptance model. Journal of Business Research, v. 62, n. 5, p. 565-571, 2009.

HAIR, J. F. et al. Multivariate Data Analysis. 7 edition ed. Upper Saddle River, NJ: Prentice Hall, 2009.

HAIR, J. F. et al. Fundamentos de Pesquisa de Marketing. 3. ed. Porto Alegre: AMGH, 2014.

HAMEED, M. A.; COUNSELL, S. Establishing Relationships Between Innovation Characteristics and It Innovation Adoption in Organisations: A Meta-Analysis Approach. International Journal of Innovation Management, v. 18, n. 1, p. 1-42, 2014.

HAN, H.; HYUN, S. S. Customer retention in the medical tourism industry: Impact of quality, satisfaction, trust, and price reasonableness. Tourism Management, v. 46, p. 20-29, 2015.

HELLÉN, K.; GUMMERUS, J. Re-investigating the nature of tangibility/intangibility and its influence on consumer experiences. Journal of Service Management, v. 24, n. 2, p. 130-150, 2013. 
HESS, T. J.; MCNAB, A. L.; BASOGLU, K. A. Reliability Generalization of Perceived Ease of Use, Perceived Usefulness, and Behavioral Intentions. MIS Quarterly, v. 38, n. 1, p. 1-28, 2014.

HIRUNYAWIPADA, T.; PASWAN, A. K. Consumer innovativeness and perceived risk: implications for high technology product adoption. Journal of Consumer Marketing, v. 23, n. 4, p. 182-198, 2006.

HONG, I. B.; CHA, H. S. The mediating role of consumer trust in an online merchant in predicting purchase intention. International Journal of Information Management, v. 33, n. 6, p. 927-939, dez. 2013.

HUIJTS, N. M. A.; MOLIN, E. J. E.; VAN WEE, B. Hydrogen fuel station acceptance: A structural equation model based on the technology acceptance framework. Journal of Environmental Psychology, v. 38, p. 153-166, 2014.

IACOBUCCI, D. Structural equations modeling: Fit Indices, sample size, and advanced topics. Journal of Consumer Psychology, v. 20, n. 1, p. 90-98, 2010.

IGBARIA, M.; IIVARI, J.; MARAGAHH, H. Why do individuals use computer technology? A Finnish case study. Information \& Management, v. 29 , n. 5 , p. 227-238, 1995.

JAN, A. Services Marketing Theory Revisited: An Empirical Investigation into Financial Services Marketing. IOSR Journal of Business and Management, v. 4, n. 4, p. 36-45, 2012.

JIN, C. The perspective of a revised TRAM on social capital building: The case of Facebook usage. Information \& Management, v. 50, n. 4, p. 162-168, 2013.

JIN, D.; CHAI, K.; TAN, K. Organizational adoption of new service development tools. Managing Service Quality: An International Journal, v. 22, n. 3, p. 233-259, 2012.

KAUSHIK, A. K.; RAHMAN, Z. Innovation adoption across self-service banking technologies in India. International Journal of Bank Marketing, v. 33, n. 2, p. 96-121, 2015.

KESHARWANI, A.; BISHT, S. S. The impact of trust and perceived risk on internet banking adoption in India. International Journal of Bank Marketing, v. 30, n. 4, p. 303-322, 2012.

KHALIFA, M.; SHEN, K. N. Explaining the adoption of transactional B2C mobile commerce. Journal of Enterprise Information Management, $\mathrm{v}$. 21, n. 2, p. 110-124, 2008. 
KIM, D. J.; FERRIN, D. L.; RAO, H. R. A trust-based consumer decisionmaking model in electronic commerce: The role of trust, perceived risk, and their antecedents. Decision Support Systems, v. 44, n. 2, p. 544564, 2008.

KIM, J.; FORSYTHE, S. Adoption of sensory enabling technology for online apparel shopping. European Journal of Marketing, v. 43, n. 9/10, p. 1101-1120, 2009.

KIM, J.; FORSYTHE, S. Factors affecting adoption of product virtualization technology for online consumer electronics shopping. International Journal of Retail \& Distribution Management, v. 38, n. 3, p. 190-204, 2010.

KIM, K. K.; SHIN, H. K.; KIM, B. The role of psychological traits and social factors in using new mobile communication services. Electronic Commerce Research and Applications, v. 10, n. 4, p. 408-417, 2011.

KING, W. R.; HE, J. A meta-analysis of the technology acceptance model. Information \& Management, v. 43, n. 6, p. 740-755, 2006.

KLEIJNEN, M.; LEE, N.; WETZELS, M. An exploration of consumer resistance to innovation and its antecedents. Journal of Economic Psychology, v. 30, n. 3, p. 344-357, 2009.

KLERCK, D.; SWEENEY, J. C. The effect of knowledge types on consumer-perceived risk and adoption of genetically modified foods. Psychology and Marketing, v. 24, n. 2, p. 171-193, 2007.

KÖSTER, A.; MATT, C.; HESS, T. Carefully choose your (payment) partner: How payment provider reputation influences m-commerce transactions. Electronic Commerce Research and Applications, v. 15, p. 26-37, 2016.

KOUFARIS, M.; HAMPTON-SOSA, W. The development of initial trust in an online company by new customers. Information \& Management, v. 41 , n. 3, p. 377-397, 2004.

KULVIWAT, S. et al. Toward a unified theory of consumer acceptance technology. Psychology and Marketing, v. 24, n. 12, p. 1059-1084, 2007.

KURTZ, R. et al. Fatores de Impacto na Atitude e na Intenção de Uso do M-Learning: um teste empírico. Revista Eletrônica de Administração, v. 21, n. 1, p. 27-56, 2015.

LAM, S. Y.; CHIANG, J.; PARASURAMAN, A. The effects of the dimensions of technology readiness on technology acceptance: An empirical analysis. Journal of Interactive Marketing, v. 22, n. 4, p. 1939, 2008. 
LAROCHE, M. et al. Exploring How Intangibility Affects Perceived Risk. Journal of Service Research, v. 6, n. 4, p. 373-389, 2004.

LEE, T. The Impact of Perceptions of Interactivity on Consumer Trust and Transaction Intentions in Mobile Commerce. Journal of Electronic Commerce Research, v. 6, n. 3, p. 165-180, 2005.

LEE, Y.-K. et al. A unified perspective on the factors influencing usage intention toward mobile financial services. Journal of Business Research, v. 65, n. 11, p. 1590-1599, 2012.

LILJANDER, V. et al. Technology readiness and the evaluation and adoption of self-service technologies. Journal of Retailing and Consumer Services, v. 13, n. 3, p. 177-191, 2006.

LIN, C. S.; WU, S.; TSAI, R. J. Integrating perceived playfulness into expectation-confirmation model for web portal context. Information \& Management, v. 42, n. 5, p. 683-693, 2005.

LIN, C.-H.; SHIH, H.-Y.; SHER, P. J. Integrating technology readiness into technology acceptance: The TRAM model. Psychology and Marketing, v. 24, n. 7, p. 641-657, 2007.

LIN, J.-S. C.; HSIEH, P.-L. The influence of technology readiness on satisfaction and behavioral intentions toward self-service technologies. Computers in Human Behavior, v. 23, n. 3, p. 1597-1615, 2007.

LÓPEZ-NICOLÁS, C.; MOLINA-CASTILLO, F. J.; BOUWMAN, H. An assessment of advanced mobile services acceptance: Contributions from TAM and diffusion theory models. Information \& Management, v. 45, n. 6, p. 359-364, 2008.

LOVELOCK, C.; GUMMESSON, E. Whither Services Marketing? In Search of a New Paradigm and Fresh Perspectives. Journal of Service Research, v. 7, n. 1, p. 20-41, 2004.

LUO, X. et al. Examining multi-dimensional trust and multi-faceted risk in initial acceptance of emerging technologies: An empirical study of mobile banking services. Decision Support Systems, v. 49, n. 2, p. 222-234, 2010.

MALAQUIAS, R. F.; HWANG, Y. An empirical study on trust in mobile banking: A developing country perspective. Computers in Human Behavior, v. 54, p. 453-461, 2016.

MALHOTRA, N. Pesquisa De Marketing. Uma Orientação Aplicada. 6 ed. ed. Porto Alegre: Bookman, 2011.

MARDIA, K. V. Measures of Multivariate Skewness and Kurtosis with Applications. Biometrika, v. 57, n. 3, p. 519-530, 1970. 
MEHRABIAN, A.; RUSSELL, J. A. The Basic Emotional Impact of Environments. Perceptual and Motor Skills, v. 38, n. 1, p. 283-301, 1974.

MEUTER, M. L. et al. Choosing Among Alternative Service Delivery Modes: An Investigation of Customer Trial of Self-Service Technologies. Journal of Marketing, v. 69, n. 2, p. 61-83, 2005.

MICK, D. G.; FOURNIER, S. Paradoxes of Technology: Consumer Cognizance, Emotions, and Coping Strategies. Journal of Consumer Research, v. 25, n. 2, p. 123-143, 1998.

MOORE, G. C.; BENBASAT, I. Development of an Instrument to Measure the Perceptions of Adopting an Information Technology Innovation. Information Systems Research, v. 2, n. 3, p. 192-222, 1991.

MORAES, A. C. S. et al. Compras via Celular: a intenção de uso pelo consumidor. Revista Pretexto, v. 15, n. 1, p. 86-105, 2014.

MOROSAN, C.; DEFRANCO, A. It's about time: Revisiting UTAUT2 to examine consumers' intentions to use NFC mobile payments in hotels. International Journal of Hospitality Management, v. 53, p. 17-29, 2016.

$\mathrm{OH}, \mathrm{S}$. H. et al. Consumer adoption of virtual stores in Korea: Focusing on the role of trust and playfulness. Psychology and Marketing, v. 26, n. 7, p. 652-668, 2009.

OLIVEIRA, T. et al. Extending the understanding of mobile banking adoption: When UTAUT meets TTF and ITM. International Journal of Information Management, v. 34, n. 5, p. 689-703, 2014.

OLIVER, R. L. Conceptual Issues in the Structural Analysis of Consumption Emotion, Satisfaction, and Quality: Evidence in a Service Setting. Advances in Consumer Research, v. 21, n. 1, p. 16-22, 1994.

PAI, F.-Y.; HUANG, K.-I. Applying the Technology Acceptance Model to the introduction of healthcare information systems. Technological Forecasting and Social Change, v. 78, n. 4, p. 650-660, 2011.

PARASURAMAN, A. Technology Readiness Index (TRI) A Multiple-Item Scale to Measure Readiness to Embrace New Technologies. Journal of Service Research, v. 2, n. 4, p. 307-320, 2000.

PARASURAMAN, A.; COLBY, C. L. Techno-Ready Marketing. New York: The Free Press, 2001.

PARASURAMAN, A.; COLBY, C. L. An Updated and Streamlined Technology Readiness Index: TRI 2.0. Journal of Service Research, $p$. 01-17, 2014. 
PARASURAMAN, A.; ZEITHAML, V. A.; BERRY, L. L. A Conceptual Model of Service Quality and Its Implications for Future Research. Journal of Marketing, v. 49, n. 4, p. 41-50, 1985.

PARASURAMAN, A.; ZEITHAML, V. A.; BERRY, L. L. SERVQUAL: A Multiple-Item Scale for Measuring Consumer Perceptions of Service Quality. Journal of Retailing, v. 64, n. 1, p. 12-40, 1988.

PARASURAMAN, A.; ZEITHAML, V. A.; BERRY, L. L. Alternative Scales for Measuring Service Quality: A Comparative Assessment Based on Psychometric and Diagnostic Criteria. Journal of Retailing, v. 70, n. 3, p. 201-230, 1994.

PAUL, J.; MODI, A.; PATEL, J. Predicting green product consumption using theory of planned behavior and reasoned action. Journal of Retailing and Consumer Services, v. 29, p. 123-134, 2016.

PAVLOU, P. A. Consumer Acceptance of Electronic Commerce: Integrating Trust and Risk with the Technology Acceptance Model. International Journal of Electronic Commerce, v. 7, n. 3, p. 101-134, 2003.

PLEASURE. Oxford Learner's Dictionary Online. Disponível em: <http://www.oxfordlearnersdictionaries.com>. Acesso em: 7 out. 2015.

PODSAKOFF, P. M. et al. Common method biases in behavioral research: A critical review of the literature and recommended remedies. Journal of Applied Psychology, v. 88, n. 5, p. 879, 2003.

POPIELARZ, D. T. An Exploration of Perceived Risk and Willingness to Try New Products. Journal of Marketing Research, v. 4, n. 4, p. 368372, 1967.

PÜSCHEL, J.; AFONSO MAZZON, J.; MAURO C. HERNANDEZ, J. Mobile banking: proposition of an integrated adoption intention framework. International Journal of Bank Marketing, v. 28, n. 5, p. 389-409, 2010.

RAM, S.; SHETH, J. N. Consumer Resistance to Innovations: The Marketing Problem and its solutions. Journal of Consumer Marketing, $v$. 6, n. 2, p. 5-14, 1989.

REMENYI, D. et al. Doing Research in Business and Management: An Introduction to Process and Method. London: SAGE, 1998.

ROGERS, E. M. New Product Adoption and Diffusion. Journal of Consumer Research, v. 2, n. 4, p. 290-301, 1976.

ROGERS, E. M. Diffusion of Innovations. 5. ed. New York: Free Press, 2003.

ROSELIUS, R. Consumer Rankings of Risk Reduction Methods. Journal of Marketing, v. 35, n. 1, p. 56-61, 1971. 
RUST, R. T.; CHUNG, T. S. Marketing Models of Service and Relationships. Marketing Science, v. 25, n. 6, p. 560-580, 2006.

RUST, R. T.; HUANG, M.-H. The Service Revolution and the Transformation of Marketing Science. Marketing Science, v. 33, n. 2, p. 206-221, 2014.

SCHEMBRI, S.; SANDBERG, J. The experiential meaning of service quality. Marketing Theory, v. 11, n. 2, p. 165-186, 2011.

SCHEPERS, J.; WETZELS, M. A meta-analysis of the technology acceptance model: Investigating subjective norm and moderation effects. Information \& Management, v. 44, n. 1, p. 90-103, 2007.

SCHIERZ, P. G.; SCHILKE, O.; WIRTZ, B. W. Understanding consumer acceptance of mobile payment services: An empirical analysis. Electronic Commerce Research and Applications, v. 9, n. 3, p. 209-216, 2010.

SCHUMPETER, J. A. Teoria do Desenvolvimento Econômico. São Paulo: Nova Cultural, 1997.

SHAIKH, A. A.; KARJALUOTO, H. Mobile banking adoption: A literature review. Telematics and Informatics, v. 32, n. 1, p. 129-142, 2015.

SHIH, H.-P. An empirical study on predicting user acceptance of eshopping on the Web. Information \& Management, v. 41, n. 3, p. 351368, 2004.

SHOSTACK, G. L. Breaking Free from Product Marketing. Journal of Marketing, v. 41, n. 2, p. 73-80, 1977.

SLADE, E. L.; WILLIAMS, M. D.; DWIVEDI, Y. K. Mobile payment adoption: Classification and review of the extant literature. Marketing Review, v. 13, n. 2, p. 167-190, 2013.

SLOVIC, P.; PETERS, E. Risk Perception and Affect. Current Directions in Psychological Science, v. 15, n. 6, p. 322-325, 2006.

SNYDER, $\mathrm{H}$. et al. Identifying categories of service innovation: A review and synthesis of the literature. Journal of Business Research, no prelo 2016.

SOSCIA, I.; ARBORE, A.; HOFACKER, C. F. The impact of trial on technology adoption: the case of mobile TV. Journal of Research in Interactive Marketing, v. 5, n. 2/3, p. 226-238, 2011.

STAYKOVA, K. S.; DAMSGAARD, J. The race to dominate the mobile payments platform: Entry and expansion strategies. Electronic Commerce Research and Applications, v. 14, n. 5, p. 319-330, 2015. 
SUH, B.; HAN, I. Effect of trust on customer acceptance of Internet banking. Electronic Commerce Research and Applications, v. 1, n. 34, p. 247-263, 2002.

SWILLEY, E. Technology rejection: the case of the wallet phone. Journal of Consumer Marketing, v. 27, n. 4, p. 304-312, 2010.

TSAI, C.-H. et al. The effect of reducing risk and improving personal motivation on the adoption of knowledge repository system. Technological Forecasting and Social Change, v. 77, n. 6, p. 840-856, 2010.

TUBENCHLAK, D. B. et al. Motivações da Comunicação Boca a Boca Eletrônica Positiva entre Consumidores no Facebook. Motivations for Positive Electronic Word-of-mouth between Consumers on Facebook., v. 19, n. 1, p. 107-126, 2015.

VENKATESH, V. Creation of Favorable User Perceptions: Exploring the Role of Intrinsic Motivation. MIS Quarterly, v. 23, n. 2, p. 239-260, 1999.

VENKATESH, V. Determinants of Perceived Ease of Use: Integrating Control, Intrinsic Motivation, and Emotion into the Technology Acceptance Model. Information Systems Research, v. 11, n. 4, p. 342-365, 2000.

VENKATESH, V. et al. User Acceptance of Information Technology: Toward a Unified View. MIS Quarterly, v. 27, n. 3, p. 425-478, 2003.

VENKATESH, V.; L. THONG, J. Y.; XU, X. Consumer Acceptance and Use of Information Technology: Extending the Unified Theory of Acceptance and Use of Technology. MIS Quarterly, v. 36, n. 1, p. 157178, 2012.

VENKATESH, V.; SPEIER, C. Computer Technology Training in the Workplace: A Longitudinal Investigation of the Effect of Mood. Organizational Behavior and Human Decision Processes, v. 79, n. 1, p. 1-28, 1999.

WALCZUCH, R.; LEMMINK, J.; STREUKENS, S. The effect of service employees' technology readiness on technology acceptance. Information \& Management, v. 44, n. 2, p. 206-215, 2007.

WEST, S. G.; FINCH, J. F.; CURRAN, P. J. Structural Equation Models With Non-Normal Variables: problems and remedies. In: HOYLE, R. (Ed.). . Structural Equation Modelling: concepts, issues and applications. Newbury Park: Sage, 1995. p. 56-75.

WU, J.-H.; WANG, S.-C. What drives mobile commerce?: An empirical evaluation of the revised technology acceptance model. Information \& Management, v. 42, n. 5, p. 719-729, 2005. 
WU, K. et al. A meta-analysis of the impact of trust on technology acceptance model: Investigation of moderating influence of subject and context type. International Journal of Information Management, v. 31, n. 6, p. 572-581, 2011.

XIN, H.; TECHATASSANASOONTORN, A. A.; TAN, F. B. Antecedents of Consumer Trust in Mobile Payment Adoption. Journal of Computer Information Systems, v. 55, n. 4, p. 1-10, 2015.

XU, J. (DAVID); BENBASAT, I.; CENFETELLI, R. T. Integrating Service Quality with System and Information Quality: An Empirical Test in the EService Context. MIS Quarterly, v. 37, n. 3, p. 777-A9, 2013.

YANG, S. et al. Mobile payment services adoption across time: An empirical study of the effects of behavioral beliefs, social influences, and personal traits. Computers in Human Behavior, v. 28, n. 1, p. 129-142, 2012.

YANG, Y. et al. Understanding perceived risks in mobile payment acceptance. Industrial Management \& Data Systems, v. 115, n. 2, p. 253-269, 2015.

YOUSAFZAI, S. Y.; FOXALL, G. R.; PALLISTER, J. G. Technology acceptance: a meta-analysis of the TAM: Part 1. Journal of Modelling in Management, v. 2, n. 3, p. 251-280, 2007.

YOUSAFZAI, S.; YANI-DE-SORIANO, M. Understanding customerspecific factors underpinning internet banking adoption. International Journal of Bank Marketing, v. 30, n. 1, p. 60-81, 2012.

$\mathrm{YU}$, J. et al. Extending the TAM for a t-commerce. Information \& Management, v. 42, n. 7, p. 965-976, 2005.

ZEITHAML, V. A.; PARASURAMAN, A.; BERRY, L. L. Problems and Strategies in Services Marketing. Journal of Marketing, v. 49, n. 2, p. 3346, 1985.

ZEITHAML, V. A.; PARASURAMAN, A.; MALHOTRA, A. Service quality delivery through web sites: A critical review of extant knowledge. Journal of the Academy of Marketing Science, v. 30, n. 4, p. 362-375, 2002.

ZHAO, L. et al. Assessing the effects of service quality and justice on customer satisfaction and the continuance intention of mobile value-added services: An empirical test of a multidimensional model. Decision Support Systems, v. 52, n. 3, p. 645-656, 2012.

ZHOU, T. Understanding users' initial trust in mobile banking: An elaboration likelihood perspective. Computers in Human Behavior, v. 28, n. 4, p. 1518-1525, 2012. 
ZHOU, T. An empirical examination of continuance intention of mobile payment services. Decision Support Systems, v. 54, n. 2, p. 1085-1091, 2013.

ZHOU, T. Understanding the determinants of mobile payment continuance usage. Industrial Management \& Data Systems, v. 114, n. 6, p. 936948, 2014. 


\title{
Apêndice
}

\section{Questionário a ser utilizado na pesquisa}

\section{FAVOR RESPONDER A TODAS AS PERGUNTAS DESTE QUESTIONÁRIO COM A MÁXIMA ATENÇÃO POSSÍVEL. AGRADECEMOS DESDE JÁ A SUA COLABORAÇÃO}

\begin{abstract}
Em relação aos serviços de mobile payment e sua experiência com esse serviço, por favor responda:
\end{abstract}

I. Indique seu grau de concordância em cada uma das afirmativas a seguir, referentes à sua relação com a tecnologia.

\section{Novas tecnologias contribuem para uma melhor} qualidade de vida.

2 A tecnologia me dá mais liberdade de movimento.

3 A tecnologia permite que as pessoas tenham mais controle sobre seu dia-a-dia.

4 A tecnologia me torna mais produtivo no âmbito pessoal.

5 Outras pessoas me pedem conselhos sobre as novas tecnologias.

6 Em geral, estou entre os primeiros do meu grupo de amigos em adquirir uma nova tecnologia logo que ela surge.

7 Normalmente, consigo entender os novos produtos e serviços de alta tecnologia sem a ajuda de outros.

9 Estou atualizado com os últimos desenvolvimentos tecnológicos das minhas áreas de interesse.

10 Quando utilizo o suporte técnico de um fornecedor de produtos ou serviços de alta tecnologia, às vezes me sinto como se alguém que sabe mais do que eu estivesse tirando vantagem de mim.

11 Os serviços de suporte técnico (por telefone ou internet) não ajudam, porque não explicam as coisas em termos compreensíveis.

12 Às vezes, penso que os sistemas de tecnologia não são projetados para serem usados por pessoas comuns.

13 Não existe manual de produto ou serviço de alta tecnologia que seja escrito em uma linguagem simples.

14 As pessoas estão muito dependentes da tecnologia para a realização de tarefas.

15 A tecnologia em excesso distrai as pessoas até um certo ponto em que se torna nociva.

16 A tecnologia diminui a qualidade de relacionamentos por meio da redução da interação pessoal.

17 Não me sinto seguro em fazer negócios com uma empresa que só pode ser acessada pela internet. 
II. Por favor, indique seu nível de concordância em relação a sua expectativa de experiência com serviços de mobile payments (m-payments).

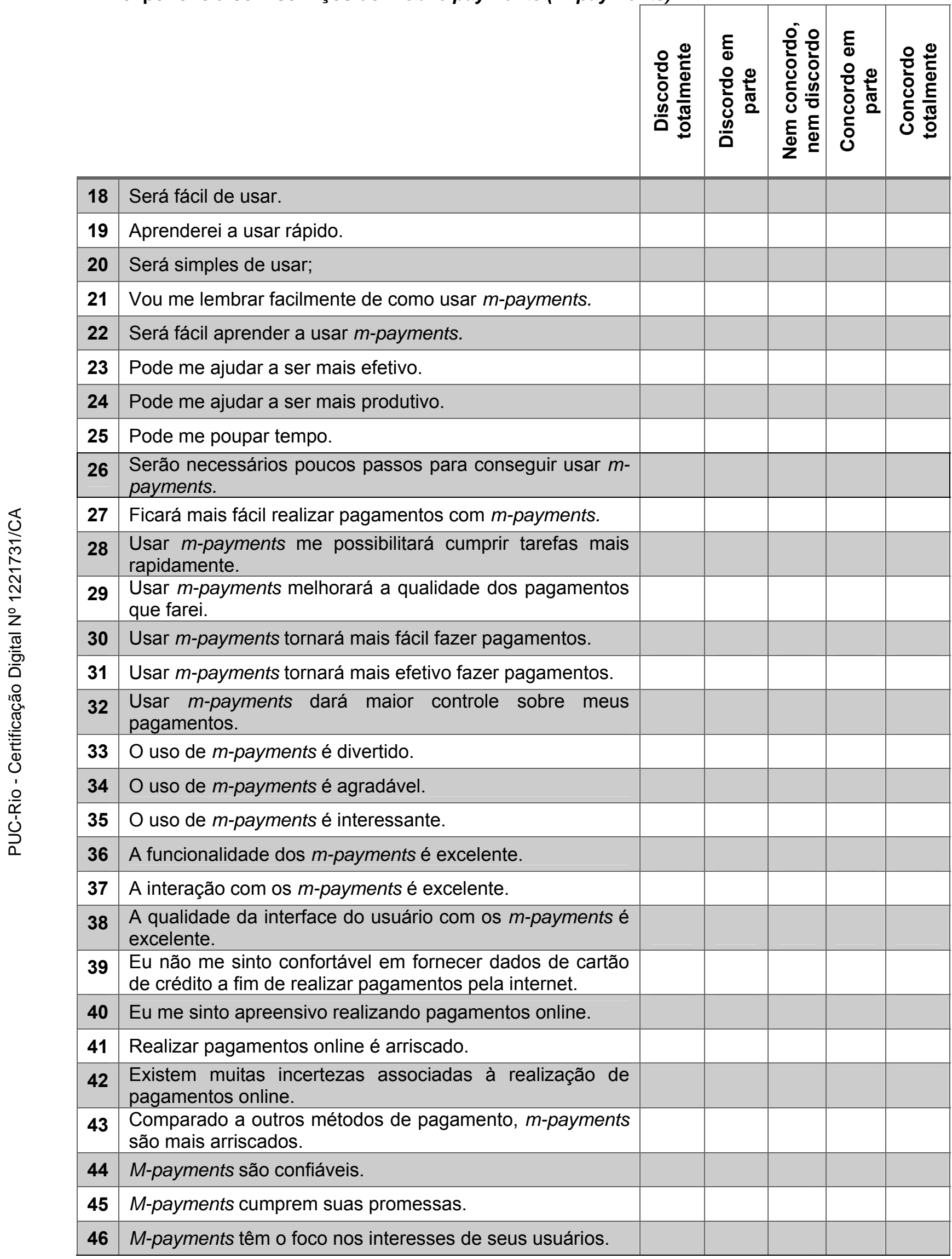


II. Por favor, indique seu nível de concordância em relação a sua expectativa de experiência com serviços de mobile payments (m-payments). (continuação)

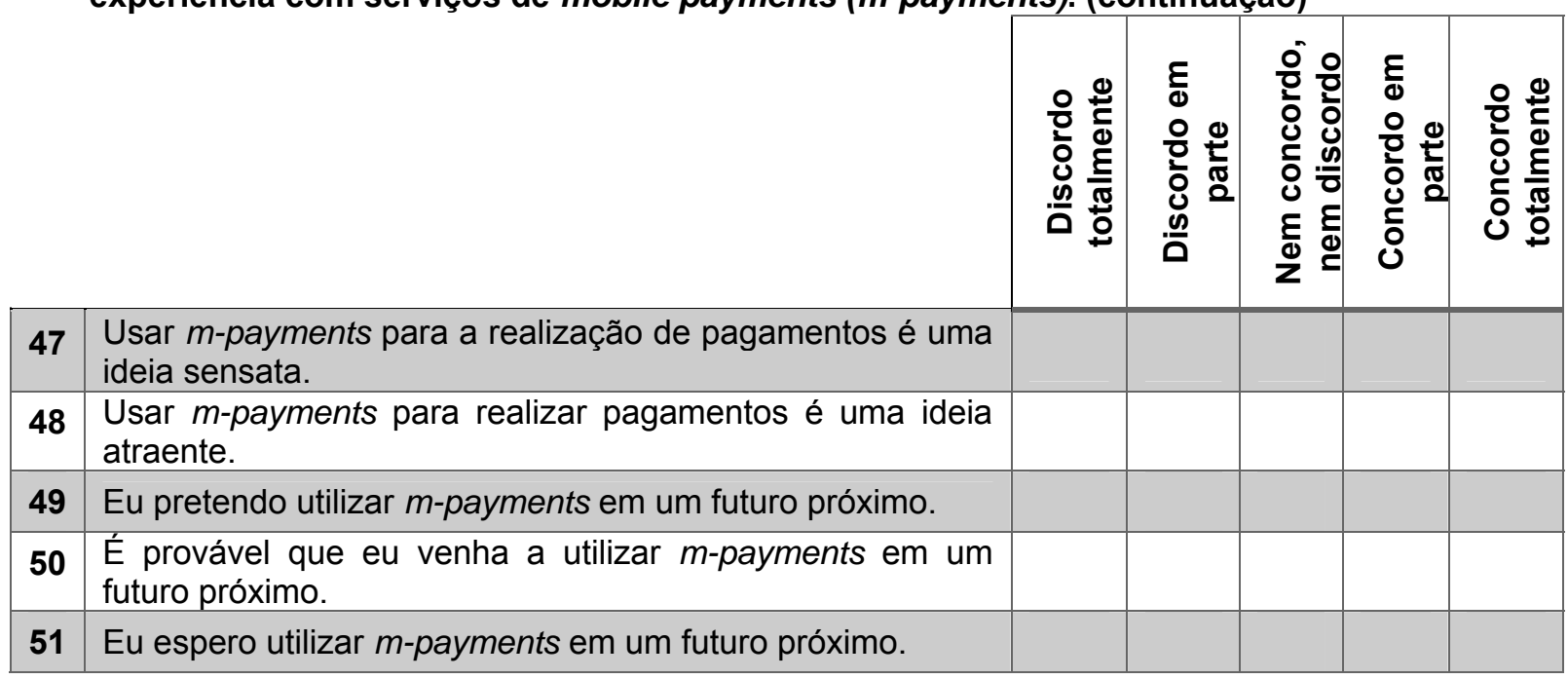

52. Em que estado você reside?
Minas Gerais
Rio de Janeiro
Outro

53. Qual seu nível de escolaridade?
Superior Incompleto
Superior Completo
Pós-Graduação Lato Sensu Incompleta
Pós-Graduação Lato Sensu

Completa

Mestrado Incompleto

Mestrado Completo

Doutorado Incompleto

Doutorado Completo

\section{Muito obrigado por sua participação!}

